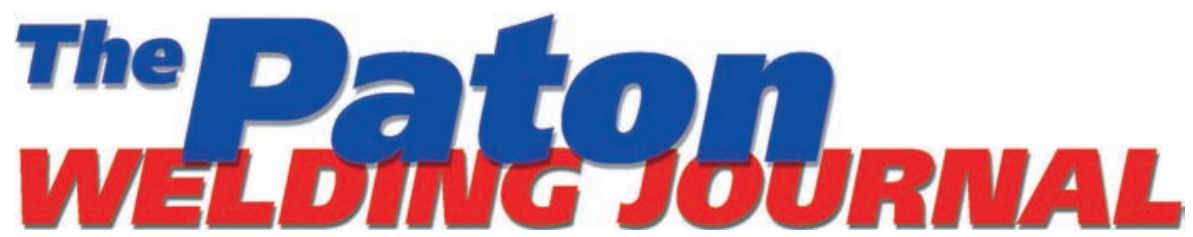

April 2017
No. 4

Published since 2000
EDITORIAL BOARD

Editor-in-Chief B.E. Paton

Scientists of PWI, Kiev S.I. Kuchuk-Yatsenko (vice-chief ed.), V.N. Lipodaev (vice-chief ed.)

Yu.S. Borisov, G.M. Grigorenko A.T. Zelnichenko, V.V. Knysh,

I.V. Krivtsun, Yu.N. Lankin, L.M. Lobanov, V.D. Poznyakov, I.A. Ryabtsev, K.A. Yushchenko

Scientists of Ukrainian Universities V.V. Dmitrik, NTU «KhPI», Kharkov V.V. Kvasnitsky, NTUU «KPI», Kiev V.D. Kuznetsov, NTUU «KPI», Kiev

\section{Foreign Scientists} N.P. Alyoshin

N.E. Bauman MSTU, Moscow, Russia Guan Qiao

Beijing Aeronautical Institute, China A.S. Zubchenko

DB «Gidropress», Podolsk, Russia M. Zinigrad

Ariel University, Israel V.I. Lysak

Volgograd STU, Russia

Ya. Pilarczyk

Welding Institute, Gliwice, Poland U. Reisgen

Welding and Joining Institute, Aachen, Germany G.A. Turichin

St. Petersburg SPU, Russia

Founders

E.O. Paton Electric Welding Institute, NASU International Association «Welding» Publisher

International Association «Welding» Translators

A.A. Fomin, O.S. Kurochko, I.N. Kutianova Editor

N.G. Khomenko

Electron galley

D.I. Sereda, T.Yu. Snegiryova Address

E.O. Paton Electric Welding Institute, International Association «Welding» 11 Kazimir Malevich Str. (former Bozhenko Str.), 03680, Kiev, Ukraine

Tel.: (38044) 20060 16, 2008277

Fax: (38044) 20082 77, 2008145

E-mail: journal@paton.kiev.ua

www.patonpublishinghouse.com

State Registration Certificate

KV 4790 of 09.01.2001

ISSN 0957-798X

Subscriptions

$\$ 348,12$ issues per year

air postage and packaging included.

Back issues available.

All rights reserved.

This publication and each of the articles contained herein are protected by copyright.

Permission to reproduce material contained in this journal must be obtained in writing from the Publisher.

\section{CONTENTS}

Ukrainian-Chinese scientific and technical cooperation 2

\section{SCIENTIFIC AND TECHNICAL}

Kuchuk-Yatsenko S.I., Kazymov B.I. and Zagadarchuk V.F. Influence of metal structure of pipes on mechanical properties of flash-butt welded joints

Yushchenko K.A., Mats A.V., Neklyudov I.M., Sokolenko V.I. and

Chernyak N.A. Effect of alternating magnetic field on magnetic

properties, structure and stressed state of vessel steel welded joints

Knysh V.V., Solovej S.A., Kirian V.I., Nyrkova L.I. and Osadchuk S.A.

Application of high-frequency peening to improve the performance

of butt welded joints in the atmosphere of temperate climate

Poklyatsky A.G., Motrunich S.I. and Klochkov I.N. Physico-mechanical

properties of thin-sheet aluminum alloy D16 butt joints produced

by friction stir welding

Borisov Yu.S., Borisova A.L., Astakhov E.A., Tsymbalista T.V.,

Burlachenko A.N., Vasilkovskaya M.A. and Kildy A.I. Detonation

coatings of intermetallic powders of $\mathrm{Fe}-\mathrm{Al}$ system produced using

mechanical alloying

\section{INDUSTRIAL}

Korzhik V.N., Pashchin N.A., Mikhoduj O.L., Grinyuk A.A., Babich A.A. and Khaskin V.Yu. Comparative evaluation of methods of arc and hybrid plasma-arc welding of aluminum alloy 1561 using consumable electrode

Nesterenkov V.M., Kravchuk L.A., Arkhangelsky Yu.A. and Orsa Yu.V. Formation of welded joints of magnesium alloys in pulse multipass electron beam welding

Falchenko Yu.V., Petrushinets L.V. and Fedorchuk V.E. Influence of temperature of heating in vacuum on behaviour of oxide film on the surface of $\gamma$-TiAl intermetallic alloy

Stupnitsky T.R., Student M.M., Pokhmursky V.I. and Tymus M.B.

Development of electric arc spray coatings for reconditioning rods of hydraulic cylinders of mining equipment, using flux-cored wires

Shelyagin V.D., Khaskin V.Yu., Bernatsky A.V. and Siora A.V. Laser welding of thin-wall filter elements of steel 08Kh18N10T 


\section{UKRAINIAN-CHINESE SCIENTIFIC AND TECHNICAL COOPERATION}

At the beginning of January this year 25 years passed since the establishment of diplomatic relations between Ukraine and People's Republic of China. One of the priority directions of bilateral relations is the cooperation in the field of science and technology. The example of this is the old and fruitful cooperation of the Ukrainian welders and Chinese colleagues.

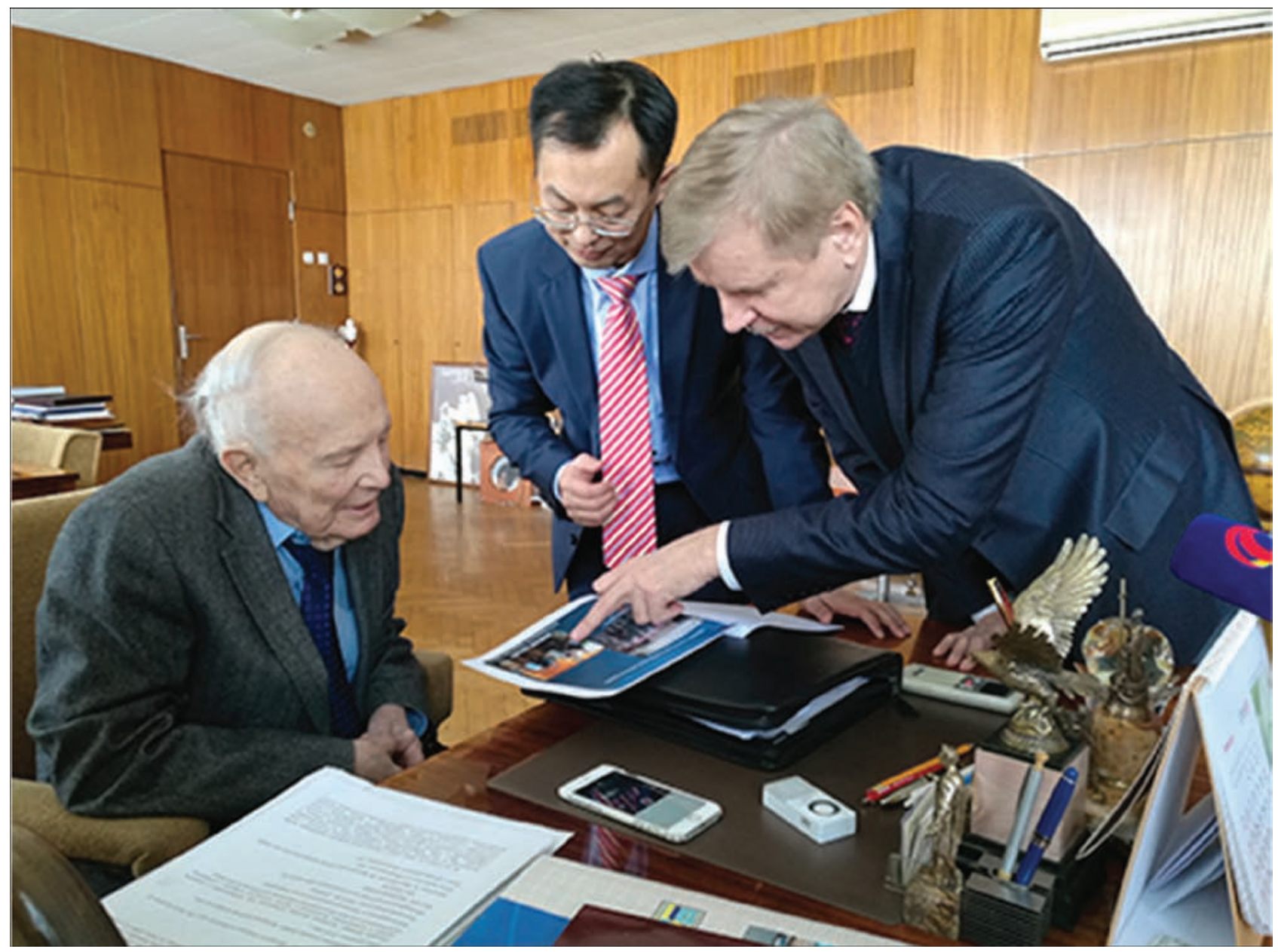

During meeting at the PWI on February 16, 2017 (from left to right: Academician Paton B.E., Mr. Zhang Wei, Dr. Korzhik V.N.)

«Over 25 years, passed since the establishment of diplomatic relations between Ukraine and People’s Republic of China, the significant results were achieved in the field of scientific and technical cooperation between our countries, and the cooperation in the field of electric welding and materials science can be considered in general as a striking example of the mutually beneficial bilateral scientific cooperation» noted Paton B.E., Academician, the President of the National Academy of Sciences of Ukraine, during the visit of Mr. Zhang Wei, the first Secretary of Embassy of PR China in Ukraine to the E.O. Paton Electric Welding Institute of the NAS of Ukraine. The reporting about this meeting and interview with Academician Paton B.E., Director of the Institute, were published in «Renmin Ribao», one of central Chinese newspapers.

Cooperation of Ukraine with China in the sphere of electric welding technologies has an old history (for example, in Harbin the «Paton» installation for electroslag welding has been already operated a half of century), but after the signing the Intergovernmental Agreement and establishment of the Commission on cooperation between the Government of Ukraine and Government of People's Republic of China in 2011 the spectrum of directions was greatly widened. At the same 2011 the E.O. Paton Chinese-Ukrainian Institute of Welding was officially opened by the initiative of the National Academy of Sciences of Ukraine, Ministry of Science 
and Technology of PR China and State Department on management of foreign specialists of PR China in the Guangdong province.

As Paton B.E. noted, over the years of existence of the joint E.O. Paton Chinese-Ukrainian Institute of Welding, founded on the base of the scientific and technical platform, the new innovation form of the international cooperation in the sphere of high technologies, the both countries received the unique and very useful experience. He mentioned that the results, obtained for 5 years, were sufficiently successful and «meeting not only the interests of Guangdong province and the National Academy of Sciences of Ukraine, but China and Ukraine as a whole».

Realization of this Chinese-Ukrainian project has joined effectively the technological capabilities of Ukraine with market requirements of China, and also actively promoted the embodiment of Chinese efforts into life for the technological breaks in many key branches of economy. The E.O. Paton Chinese-Ukrainian Institute of Welding managed not only to concentrate the most progressive knowledge and equipment in the field of electric welding and materials science, but also to direct efforts for the creation of innovations in the interests of several different industry branches. These are the technologies and equipment for flash-butt welding of pipelines and stop valves, which open the opportunities in the construction of reinforced concrete bridges, viaducts and motor roads. These are also methods of joining the aluminium alloys, used in construction of special-purpose ships, in aviation and cosmonautics. In addition, these are technologies of restoration of parts by using the high-velocity plasma spraying for the textile industry, polygraphy, etc. Important results were obtained also in the fulfillment of large scientific projects in the field of oceanographic engineering, as well as in manufacture of equipment for nuclear power stations and application of welding technologies in medicine. Owing to the effective cooperation the welding technologies, used in China, were greatly improved and optimized to the advanced world level.

Dr. Korzhik Vladimir N., the co-director of the E.O. Paton Chinese-Ukrainian Institute of Welding from the Ukrainian side, who is working in this project from the very beginning, informed that during these years the Institute fulfilled more than 300 research programs of the governmental and regional level, services for spreading and technical support of technologies were given to more than 100 enterprises. More than 300 scientific papers and monographs were published from the results of the carried out works, 56 patents were received.

During recent years the cooperation is actively progressing with such powerful Chinese industrial concerns, as China Aerospace Science and Technology Corporation (CASC), Aviation Industry Corporation of China (AVIC), China State Shipbuilding Corporation (CSSC), Anshan Iron and Steel Group Metallurgical Company, Dongfang Electric Machinery Corporation.

Furthermore, during all years of its activity the E.O. Paton Chinese-Ukrainian Institute of Welding paid a lot of attention to the development of fundamental research investigations and supported the academic exchange between our countries in every way. Among the events, organized by the Institute, it is possible to mention the seminar on welding technologies in oceanographic engineering, seminar on key technologies of Arctic shipbuilding, etc.

The Institute activity was marked by 15 awards of Guangdong province, prizes of profiled Ministries and Establishments. For the great contribution to the process of modernization of China and development of scientific and technical cooperation between China and Ukraine the Academician Paton B.E. in 2012 and Dr. Korzhik V.N. in 2014 were awarded the higher and most authorized governmental award for foreign specialists: order of Friendship of People's Republic of China.

At the end of the meeting the academician Paton B.E. noted that the Ukrainian scientists appreciate highly the strategy «Chinese production-2025» developed by the Chinese government. In his opinion this strategy will promote the soonest transformation of China into a global industrially developed state, and the development of welding technologies, as the fundamentals for manufacturing specialized equipment, will receive a new powerful impetus for the further development. In particular, he expressed a hope for the extension of cooperation in the field of welding of live tissues in the interests of a clinic medicine.

From the Russian version of newspaper «Renmin Ribao» 


\title{
INFLUENCE OF METAL STRUCTURE OF PIPES ON MECHANICAL PROPERTIES OF FLASH-BUTT WELDED JOINTS
}

\author{
S.I. KUCHUK-YATSENKO, B.I. KAZYMOV and V.F. ZAGADARCHUK \\ E.O. Paton Electric Welding Institute, NASU \\ 11 Kazimir Malevich Str., 03680, Kiev, Ukraine. E-mail: office@paton.kiev.ua
}

\begin{abstract}
Technology of flash-butt welding occupies a sufficient place in different industries, including welding of different purpose pipes. At a high quality of joints the discrepancies in values of properties are observed in a number of cases. The paper considers the causes of such discrepancies and their relationship with the initial structure of metal of pipes. It was revealed that the formation of areas with a structural heterogeneity in joints is predetermined by the structure and volume of segregation bands of nonmetallic inclusions in steel and is not related to the technological parameters of welding. In welding of advanced pipe steels, produced by a controllable rolling, the required mechanical properties of the joints are provided. 10 Ref., 1 Table, 8 Figures.
\end{abstract}

Keywords: pipelines, flash-butt welding, quality of joints, nondestructive testing, standards, mechanical tests, bending tests, delaminations, cracks, nonmetallic inclusions, segregation bands, structural heterogeneity, rejection criteria

Flash-butt welding (FBW) is successfully applied in different industries, including welding of different purpose pipes. The technologies and equipment for this welding method, developed at the E.O. Paton Electric Welding Institute of the NAS of Ukraine, have found a wide application in the construction of different pipelines. The welding process is fully automatic. At the same time, the parameters are controlled, providing a high stability of joints quality. In addition, a nondestructive testing of welded joints is performed applying the modern ultrasonic testing systems (UST). While performing welding operations, mechanical tests of reference batches of specimens, cut out from welded circumferential joints, are periodically carried out. The tests are conducted according to the methods approved by regulatory documents provided by departmental and state standards. The departmental standards take into account the specific conditions of works in construction and maintenance of pipeline systems, the state ones cover broader fields of application of technologies and welding consumables.

In the recent decade a harmonization of departmental and state standards with international standards is carried out. During construction of land pipelines, the international standard API 1104 [1] is widely applied.

At the E.O. Paton Electric Welding Institute of the NAS of Ukraine a large experience in applying FBW technology in construction of land pipelines has been gained, including, in particular, the results of compre- hensive mechanical tests of joints of circumferential welds of different steels, as well as nondestructive testing (UST, X-ray inspection) and in-process control of welding parameters [2].

The study of these data shows that the joints of pipes made by FBW are characterized by high and stable values as compared to the other methods applied for welding pipes in field conditions, that is confirmed by the publications of organizations applying FBW technology and equipment [3]. An analysis of the available data also shows that in welding of some batches of pipes a discrepancy between the results of mechanical tests and other types of testing is observed. In the absence of any defects, the discrepancies in values below the admissible limits were observed from the results of nondestructive and in-process control during tests of separate specimens for bending, which resulted in need for repeated tests.

The aim of the investigations was to determine the causes of arising such discrepancies and their influence on the structure and chemical composition of pipe steel.

For investigations the circumferential joints of pipes with a $1420 \mathrm{~mm}$ diameter of steel of strength class X60 with a $19 \mathrm{~mm}$ wall thickness and those of steel of strength class X70 with a $16 \mathrm{~mm}$ wall thickness were taken. Welding was performed in the machine K700 using the optimum modes adopted for the mentioned wall thicknesses of pipes in accordance with VSN 006-89 [4]. In total 18 butts of pipes, made 
Mechanical properties of circumferential pipe butts (quantity of joints - 9)

\begin{tabular}{|c|c|c|c|c|c|}
\hline \multirow{2}{*}{ Evaluation method } & \multirow{2}{*}{ Strength class } & \multirow{2}{*}{ Tensile strength, MPa } & \multirow{2}{*}{ Fracture location } & \multicolumn{2}{|c|}{ Bend tests } \\
\hline & & & & Bending angle, deg & Weld quality \\
\hline \multirow{4}{*}{$\begin{array}{l}\text { Tests in accordance with } \\
\text { GOST 6996-66 }\end{array}$} & \multirow{2}{*}{ X60 } & $\underline{541-563}$ & \multirow{2}{*}{ Along base metal and weld } & $>70$ (7 butts) & Norm \\
\hline & & 555 & & $<70$ (2 butts) & Rejection \\
\hline & \multirow{2}{*}{$\mathrm{X} 70$} & 599-619 & \multirow{2}{*}{ Along base metal } & $>70$ (8 butts $)$ & Norm \\
\hline & & 612 & & $<70$ (1 butt) & Rejection \\
\hline \multirow{2}{*}{$\begin{array}{c}\text { Tests in accordance with } \\
\text { API } 1104\end{array}$} & $\mathrm{X} 60$ & $\frac{547-569}{559}$ & \multirow{2}{*}{ Along base metal } & 180 & Norm \\
\hline & $\mathrm{X} 70$ & $\frac{589-611}{602}$ & & 180 & Same \\
\hline
\end{tabular}

of steel of each strength class, were investigated. The mechanical tests of welded joints of specimens of each steel were carried out in accordance with the international standard API 1104 [1], as well as with the interstate standard GOST 6996-66 [5].

In each batch, a half of the specimens were tested according to the standard API 1104, and the second one - according to GOST 6996-66. The results of mechanical tests of welded joints are shown in Table. The mechanical properties of the pipe metal had the following values of the standard tensile strength: the pipes of strength class X60-540 MPa, the pipes of strength class X70 - 588 MPa. Here the chemical composition of the metal of two batches of pipes is presented. Steel of strength class X60, wt.\%: 0.18 C; $0.42 \mathrm{Si}, 1.50 \mathrm{Mn} ; 0.018 \mathrm{~S} ; 0.014 \mathrm{P} ; 0,04 \mathrm{Ni} ; 0.02 \mathrm{Cr}$; $0.04 \mathrm{Cu}$. Steel of strength class X70, wt. \%: $0.07 \mathrm{C}$; $0.31 \mathrm{Si} ; 1.53 \mathrm{Mn} ; 0.004 \mathrm{~S} ; 0.017 \mathrm{P} ; 0.27 \mathrm{Ni} ; 0.002 \mathrm{Cr}$.

The metallographic examinations were carried out in the light microscope «Neophot-32», the analyses of chemical composition of fractures surface of joints were made in the Auger microprobe JAMP 9500F of JEOL Company (Japan).

Figure 1 shows macrosections of joints of steels of strength class X60 and X70. With the same width of heat-affected zone (HAZ), the macrostructure of joints is different, which is determined by the structure of base metal of pipes. In both batches the structure of base metal has banding. The pipes metal of steels of strength class X60 (Figure 2,a) has, as compared to the pipe metal of strength class X70, a higher point of banding 5 according to GOST 5640. The banding of steel of strength class X70 (Figure 2, b) corresponds to the point 2. By the content of nonmetallic inclusions the steels are differed more significantly. In steel of strength class X60, the content of nonmetallic inclusions in the bands of rolled metal is higher and estimated by the point 4 in accordance with GOST 1778. The chains of nonmetallic inclusions form the continuous lines (Figure 2,c). In steel of strength class X70 these are the separate small inclusions having not higher than 3 points (Figure 2, d). According to the chemical composition, the inclusions in both steels represent sulfides, oxides and silicates. According to the chemical composition of metal (Table), the sulfur content in pipe steel of strength class X60 is 3 times higher than in steel of strength class X70. This gives grounds to assume that in the segregation bands of strength class X60 the manganese sulfides prevail. The structure of metal along the line of joints and of the regions adjacent to it is coarse-grained (Figure 3, a). The forming structure of joint line represents a polyhedral ferrite. In the region of coarse grains, the microstructure represents a lamellar ferrite with an ordered second phase. The size of the primary austenite grains reaches No.2 and No.3 in accordance with GOST 5639-82 for joints of pipes of strength class X60 (Figure 3,a) and No.3 and No.4 for joints of pipes of strength class X70 (Figure 3, $b$ ).

In the pipes metal of strength class X70 there are no stitch nonmetallic inclusions (Figure 2,d). This can be explained by a more advanced technology for production of such steels by the method of a controllable rolling.

The table shows the results of mechanical tests of welded joints made in accordance with the require-

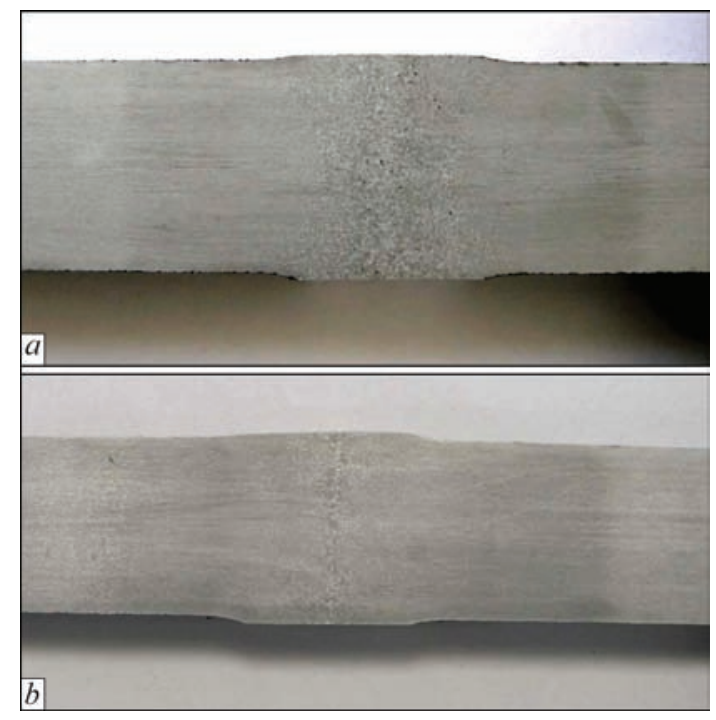

Figure 1. Macrostructure of circumferential joints of pipes made of steel of strength class X60 (a) and X70 (b) 


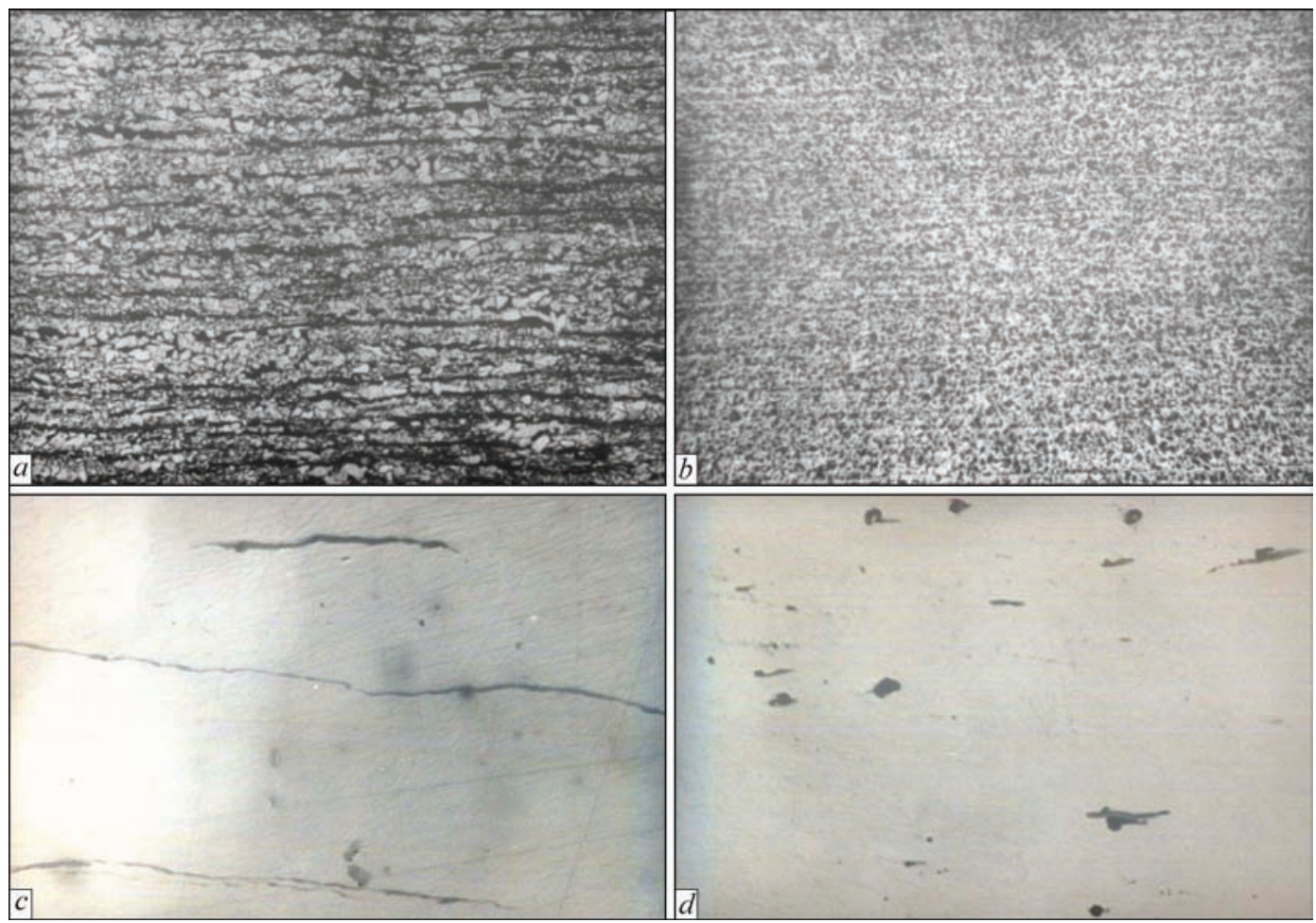

Figure 2. Microstructure $(\times 100)$ of pipes base metal of steels of strength class X60 (a) and X70 (b); $c$ - chains of nonmetallic inclusions in steel of class X60 $(\times 500)$; $d$ - separate small nonmetallic inclusions in steel of class X70 $(\times 500)$

ments of API 1104 and the interstate standard GOST 6996-66. The main difference between GOST 699666 and API 1104 is more severe testing of welded joints specimens on bending. The comparison of test results shows that in tensile tests the tensile strength of joints of pipes is at the level corresponding to the values of base metal of the mentioned steels. The results of bending tests of welded joints of all batches of specimens according to method of API 1104 also correspond to the requirements of this standard. During bending tests of batches of specimens according to the methods of GOST 6996-66 the separate discrepancies in values below the admissible level were observed. This is connected with arising of crack-like openings

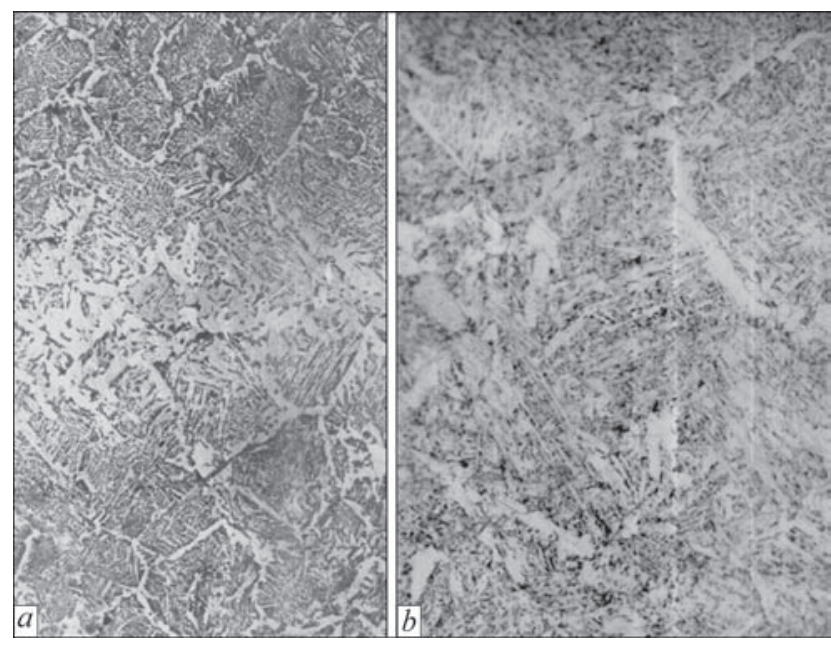

Figure 3. Microstructure of joint metal of steels of strength class $\mathrm{X} 60(a, \times 100)$ and $\mathrm{X} 70(b, \times 200)$
(Figure $4, a$ ) and delaminations of outer layers of specimens (Figure 4, b), subjected to tension during bending. In most cases, the crack and subsequent delamination began in the places where segregation bands escaped to the surface and the fracture of specimen occurred after reduction in the cross-sectional area of the specimen, if its bending is continued. The origination of initial crack occurred on separate sections of the surface, subjected to tension, depending on the width of segregation band, escaping to the surface of the specimen after its treatment and removal of the weld reinforcement, i.e. flash.

As is seen from Figure 5, $a[6]$, the bending angle of fibers and segregation interlayers has a maximum
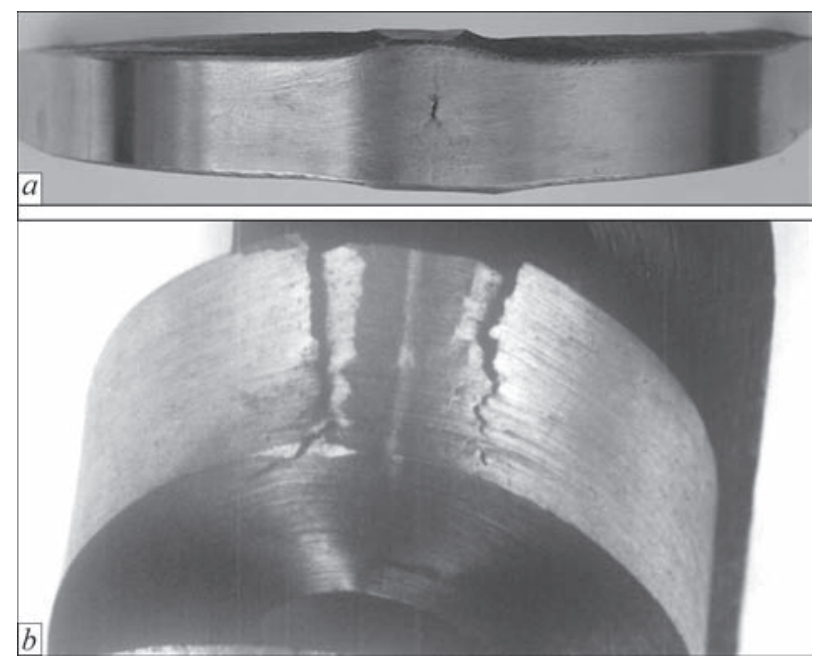

Figure 4. Defects of joints of pipes produced by FBW: crack-like opening $(a)$; delamination of outer layer $(b)$ 


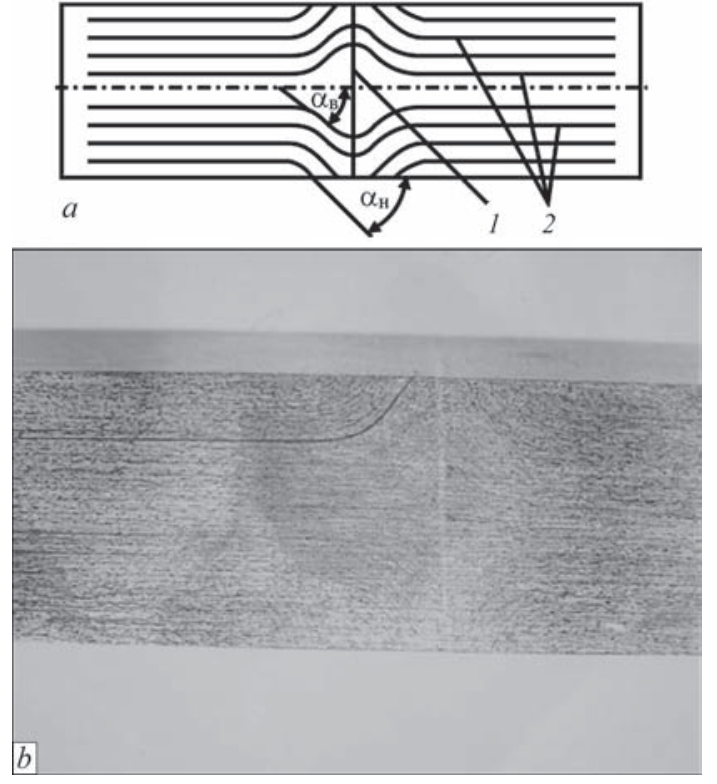

Figure 5. Scheme of welded joint (a) and location of escape of segregation band to the surface of pipe wall $(b): 1$ - joint line; 2 - bands of rolled metal; $\alpha_{\mathrm{H}}$ is the angle of bending the bands of rolled metal near the surface; $\alpha_{\mathrm{s}}$ is the angle of bending the bands of rolled metal in the middle of the joint

value at the weld center and decreases as the fibers moved away from the center to the sheet surface. At the same time, the maximum compression deformation of heated near-contact layers of metal is observed in the weld center, and as the bands move away from the center, they undergo compression with bending, the outer layers experience tensile stresses acting on segregation interlayers and reducing their density. In most cases, the tears and cracks in the zone of tension of surface layers occur at the places where segregation layers escape to the surface of welded specimens at the distance of $2-3 \mathrm{~mm}$ from the weld center (Figure $5, b)$. This is predetermined by the increase in the thickness of segregations as a result of «opening» of the segregation layer during its deformation, as well as by the lower mechanical properties of sections with nonmetallic inclusions.

As the carried out investigations show, the anisotropy of mechanical properties is characteristic for base metal of pipes made of steel of strength class X60 with a diameter of $1420 \mathrm{~mm}$ produced in the 1990s. During the rupture tests of specimens, cut out along the rolled metal and in the direction perpendicular to the rolled surface, the ratio $\sigma_{\mathrm{r} . \mathrm{s}} / \sigma_{\mathrm{t}}$ in certain cases was $K=\sigma_{\mathrm{r} . \mathrm{s}} / \sigma_{\mathrm{t}}=0.8$, where $\sigma_{\mathrm{t}}$ is the strength of pipe metal along the rolled surface, $\sigma_{\mathrm{r} . \mathrm{s}}$ is the strength of pipe metal across the rolled surface. The low $K C V$ values of impact toughness of base metal of these pipes, tested across the thickness of the wall with a notch located in the direction of rolling, were also observed. At a room temperature, the minimum $K C V$ values were

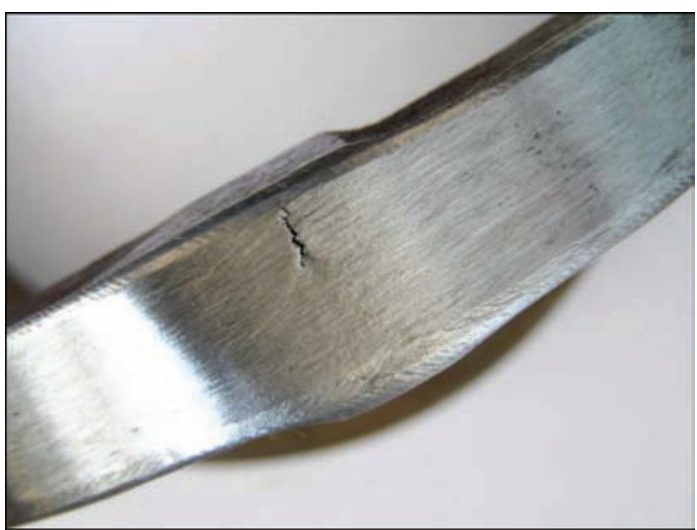

Figure 6. Appearance of specimen with a crack along the welding line

$32.3 \mathrm{~J} / \mathrm{cm}^{2}$, and at the temperature of minus $20{ }^{\circ} \mathrm{C}$ they decreased to $14.5 \mathrm{~J} / \mathrm{cm}^{2}$.

In some specimens of welded joints, during bending tests the cracks of small length along the welding line were observed (Figure 6). At the same time the bending angle of the specimens was $180^{\circ}$ and the state of weld as to the presence of cracks and their admissible size corresponded to the requirements of API 1104. At the same time, such specimens did not meet the requirements of GOST 6996-66. During visual inspection of such specimens, after bringing them to a complete fracture by additional bending, the areas on the fracture surface were found, where on the background of crystalline fracture the areas were present differed from the rest of the fracture surface by an undeveloped relief and the dark coloring (Figure 7). Such defects in practice of flash-butt welding were defined as «dead spots» (DS) [7]. The degree of influence of DS on the values of bending tests is determined by their area and location on the joint plane. If DS is located in the area subjected to tension, then the values of tests can decrease even at a small area

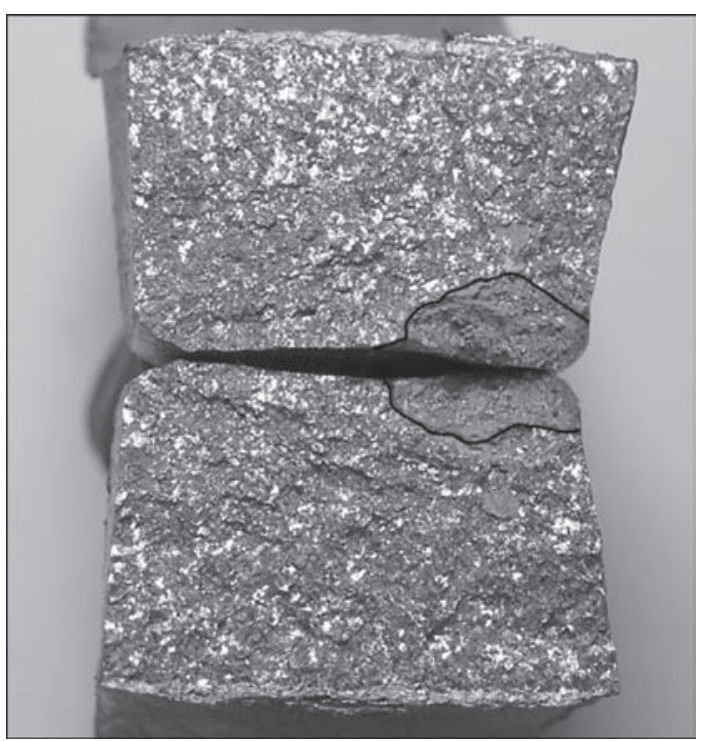

Figure 7. DS at the fracture surface 


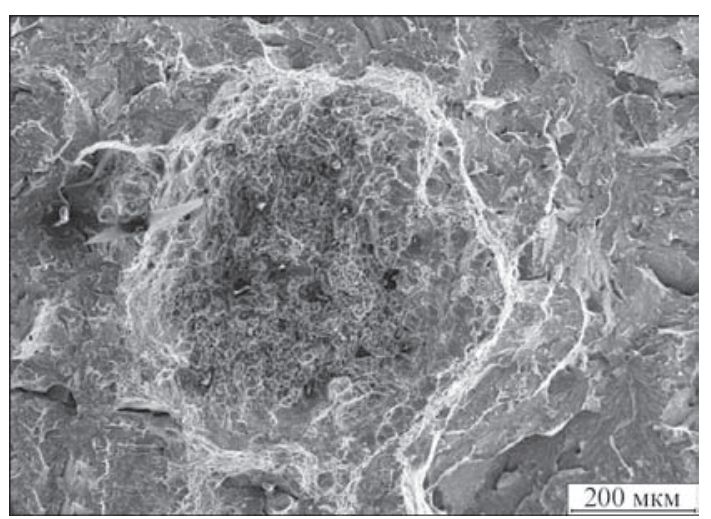

Figure 8. Microstructure of fracture surface of the joint in DS region

of DS (16-20 $\left.\mathrm{mm}^{2}\right)$. In tensile tests, the presence of DS with the area of $30-50 \mathrm{~mm}^{2}$ does not influence the test results. When the microstructure of DS was examined in a scanning electron microscope, it was revealed that it bears a pit character (Figure 8). In the pits the numerous small nonmetallic inclusions were observed. As to their composition, these inclusions do not differ from nonmetallic inclusions on the base of $\mathrm{Mn}, \mathrm{Si}, \mathrm{S}$, and $\mathrm{Fe}$, included in the composition of pipe steel of strength class X60. These data allow making a conclusion that DS formation is influenced by nonmetallic inclusions, which are contained in the base metal of pipes. Considering different probabilities of getting them into welded joint from segregation bands, it can be assumed that the region of segregation band during its deformation can be located along the joint plane. This assumption is acceptable if we admit that the bending angle of segregation bands under deformation is close to $90^{\circ}$. The similar formation of structure during the process of deformation of rolled products was considered in the work [8] as-applied to friction welding of pipes. It was shown that decrease in ductile properties is predetermined by orientation of segregation bands parallel to the welding plane. As can be seen from the scheme of a welded joint (Figure $5, a$ ) made by FBW, the bending angle even in the weld center does not exceed $30^{\circ}$. Therefore, during deformation an insignificant part of the «material» of segregation band can get to the joint and its influence on weld formation will not be significant.

More probable is the formation of DS from the melt of a liquid metal, constantly renewed at the ends of parts during flashing [9]. In the work [10], performed at the E.O. Paton Electric Welding Institute of the NAS of Ukraine, it was shown that the cavity in the ends, simulating nonmetallic inclusions in the metal and filled with the «material» of segregation band, i.e. nonmetallic inclusions, leads to the formation of joints with a defect of the DS type on this surface area.
The similar phenomenon is possible if segregation band has a sufficiently large volume. Its «material», interacting with the melt, which is formed at the ends of the welded parts in the process of flashing before upsetting, enriches it in separate areas and creating the conditions for DS formation in such a way.

At small sizes of DS of up to $15 \mathrm{~mm}^{2}$, a significant influence on the values of mechanical properties of welded joints during tests for bending and tension is not observed. At a larger area of DS, the values of bending tests are reduced. It should be noted that in the tests of joints of steel of strength class X70, the DS occurred extremely rare, and their dimensions did not exceed $15 \mathrm{~mm}^{2}$. In welded joints of steel of strength class X60, the probability of DS arising is significantly higher, their area reached $30 \mathrm{~mm}^{2}$. This confirms the relationship between the appearance of MP and the content of nonmetallic inclusions in steel. In the base metal of X60 class steel, the largest segregation bands are observed, which contain Mn sulfides, forming brittle interlayers in the metal. The content of sulfur in this steel is almost 3 times higher than its level in the steel of strength class X70.

From the comparison of mechanical tests values of welded joints specimens of steels of strength class X60 and X70 for bending in accordance with the standards API 1104 and GOST 6996-66 it is seen that all discrepancies below the normative values belong to the specimens tests of steel of strength class X60 in accordance with GOST 6996-66. This is predetermined by the accepted scheme of cutting specimens out of a welded joint. During tests in accordance with GOST 6996-66, the tension in bending belongs to the fibers adjacent to the outer or inner surface of the pipe, the degree of their elongation at the same bending radius increases with increase in thickness of specimen. In the tests according to API 1104, the thickness of bent specimen remains constant, and the width is proportional to the thickness of pipe wall. All the fibers, regardless the varied bending angle of the welded joint specimen, are subjected to the same tension. Therefore, the results of tests according to the API 1104 standard more objectively reflect the ductile properties of the metal at different regions both in the joint plane as well as in the weld as a whole. The given data confirm the rationality of the application of API 1104 standard in evaluation of the level of mechanical properties of the joints produced by FBW regardless of the wall thickness of pipes.

During evaluation of the joints quality from the results of mechanical bending tests, it is necessary to take into account the peculiarities of steel structure of pipes being welded, the presence of a large number of segregation inclusions, especially sulfides in the base 
metal, which can cause delaminations in specimens during tests.

The appearance of separate cracks and delaminations in specimens during bending tests and reduction in values below the required level can not be the grounds for negative conclusion throughout the whole reference batch. The repeated tests make it possible to reveal whether crack (or delamination) is single on the surface of a specimen or it is found on specimens cut out in other joint sections.

The presence of separate cracks, as is given in the considered case, is not a rejection feature, even if the bending angle was lower than the normative requirements. The appearance of cracks along the entire width of the specimen or on the specimen(s) adjacent to it (them) indicates the need for adjustment of FBW modes. During bending tests of welded butts specimens of steel pipes of strength class X60 and X70 with a thickness of more than $10 \mathrm{~mm}$, the presence of DS in the fractures with up to $15 \mathrm{~mm}^{2}$ area should not to be considered as a rejection feature and grounds for adjustment of the welding mode parameters.

The carried out investigations allow making the following generalizations: during FBW of pipes in the welded joint zone the regions with structural heterogeneity are formed which can become the sources for development of delaminations and cracks during bending test of specimens; the formation of such areas is determined by the structure and volume of segregation bands of nonmetallic inclusions in steel and is not related to technological parameters of welding; in welding of advanced pipe steels of strength class $\mathrm{X} 70-\mathrm{X} 80$, characterizing by higher requirements to purity, the presence of regions of structural heterogeneity in welds practically does not influence the results of mechanical tests; during bend testing of large batches of specimens the fracture-like openings in the weld center were observed in some of them, which was caused by the formation of structural heterogeneity in these areas, characterized as «dead spots». It was revealed that their chemical composition is close to the composition of nonmetallic inclusions of segregation bands of base metal. The probability of «dead spots» arising is higher in welding of steels, characterized by an increased content of nonmetallic inclusions. If their area does not exceed $15 \mathrm{~mm}^{2}$, they do not influence the results of mechanical tests of the investigated batches of specimens of steels of strength class X60 and X70; the comparison of test results of welded joints of FBW pipes of different steels shows that the test procedure, as described in API 1104 standard, allows a more objective evaluation of the properties of joints of pipes having a different composition of steels and wall thickness.

1. (1999) API Standard 1104: Welding of pipelines and related facilities ASME boiler and pressure vessel. $19 \mathrm{ed}$.

2. Kuchuk-Yatsenko, S.I. (1992) Flash-butt welding. Kiev: Naukova Dumka.

3. Mazur, I.I., Serafin, O.M., Karpenko, M.P. (1988) Resistance welding of pipelines: Ways of improvement. Stroitelstvo Truboprovodov, 4, 8-11.

4. VSN 006-89: Departmental building specifications. Construction of main and industrial pipelines. Welding: 1989-07-01, Minneftegazstroj.

5. GOST 6996-66: Welded joints. Methods of determination of mechanical properties. Moscow: Standart.

6. Kuchuk-Yatsenko, S.I. et al. (1980) Plasticity of pipe steel joints in resistance butt welding. Avtomatich. Svarka, 2, 1-8.

7. Kuchuk-Yatsenko, S.I., Shvets, Yu.V., Shvets, V.I. (2014) Influence of non-metallic inclusions in pipe steels of strength class X65-X80 on values of impact toughness of flash-butt welded joints. The Paton Welding J., 12, 2-7.

8. Dunkerton, S.B. (1986) Toughness properties of friction welds in steels. Research Suppl. to the Welding J., 8, 193-s-202-s.

9. Kuchuk-Yatsenko, S.I., Shvets, V.I., Didkovsky, A.V. et al. (2013) Defects of joints of high-strength rails produced using flash-butt welding. The Paton Welding J., 9, 2-8.

10. Kuchuk-Yatsenko, S.I. et al. (1984) Formation of dead spot in resistance butt welded joints. Avtomatich. Svarka, 11, 23-26. 


\title{
EFFECT OF ALTERNATING MAGNETIC FIELD ON MAGNETIC PROPERTIES, STRUCTURE AND STRESSED STATE OF VESSEL STEEL WELDED JOINTS
}

\author{
K.A. YUSHCHENKO ${ }^{1}$, A.V. MATS $^{2}$, I.M. NEKLYUDOV ${ }^{2}$, V.I. SOKOLENKO² ${ }^{2}$ and N.A. CHERNYAK ${ }^{2}$ \\ ${ }^{1}$ E.O. Paton Electric Welding Institute, NASU \\ 11 Kazimir Malevich Str., 03680, Kiev, Ukraine. E-mail: office@paton.kiev.ua \\ ${ }^{2}$ National Science Center Kharkov Institute of Physics and Technology \\ 1 Akademicheskaya Str., 61108, Kharkov, Ukraine. E-mail: vsokol@kipt.kharkov.ua
}

\begin{abstract}
Earlier investigations showed that treatment of welded joints of reactor vessel steel 15Kh2NMFA with alternating magnetic field of commercial frequency significantly improves a complex of mechanical properties under conditions of uniaxial tension that is accompanied by decrease of a level of thermal stresses in a weld zone. Aim of the present work is study of the effect of magnetic treatment on magnetic characteristics, structure, level and distribution of residual stresses in the welded joint. Changes of stress-strain state in different areas of the welded joint were evaluated on data of X-ray diffraction and electron-microscopic examinations. It is shown that effect of alternating magnetic field results in decrease of a level of microstresses in a transition layer and balancing of spectrum of these stresses in all area of heat affect. Correlation of changes of initial magnetic susceptibility and microstresses in the transition layer and formation of expressed magnetic texture in the weld central part is noted. The mechanisms of changes of magnetic properties and structure at magnetic treatment of welded joint, which are related with activation of plastic microdisplacements and defect redistribution, were considered. Given method of magnetic treatment can be observed as magnetic tempering, providing rise of homogeneity of stress-strain state of welded joints. This promotes increase of their resistance to nucleation and propagation of cracks. 10 Ref., 1 Table, 3 Figures.
\end{abstract}

Ke yw ords : welded joint, vessel steel, magnetic treatment, structure, internal stresses

Performance of welded joints in the structure elements can result in development of spatially-inhomogeneous stressed state with formation of zones of local stress concentration. They introduce start of plastic deformation at very small external loads and as a result provoke degradation of service characteristics, in particular, under conditions of static, cyclic and impact loading. Known methods for decreasing the level of residual stresses and development of more uniform their distribution in order to prevent appearance of micro- and macrodiscontinuities stipulate special heat treatment, ultrasonic, pulse or vibration treatment [1].

Earlier it was shown that treatment of welded specimens of steel 15Kh2NMFA in stressed-strain state with alternating magnetic field significantly improves mechanical properties under conditions of uniaxial tension, increase impact toughness, decrease temperature of ductile-brittle transition and level of first-kind stresses in welding zone and in heat-affected zone [2]. Welded joint of vessel steel as a result of magnetic treatment can be characterized with correlated change of magnetic properties, structure and stress fields due to interaction of magnetic and lattice subsystems, that is typical for magnetic-ordered materials [3].

In this connection, aim of the present work lies in study of impact of magnetic effect on structure, magnetic characteristics, level and distribution of microstresses in welded joints of steel 15Kh2NMFA.

Materials and investigation procedures. A plate of $12 \times 50 \times 150 \mathrm{~mm}^{3}$ with a groove of $8 \mathrm{~mm}$ depth and $10 \mathrm{~mm}$ width was made of solid billet of vessel steel $15 \mathrm{Kh} 2 \mathrm{NMFA}$. It was used for making a weld with argon-arc non-consumable electrode welding. Welding rate made $6 \mathrm{~m} / \mathrm{h}$ and number of passes equaled 13 . Edges of the plate were fixed in the grips for prevention of shape change in weld cooling. A Table shows composition of steel and filler wire.

Specimens, structural state of which corresponded to different areas of welded joint from central weld part to metal at around $18 \mathrm{~mm}$ distance from it, were made from welded joint using spark cutting. Figure 1 shows a scheme of welded joint «tailoring».

Magnetic treatment of the specimens was carried out employing alternating magnetic field of $50 \mathrm{~Hz}$ frequency. The specimens were located in a magnetic field direction and were cooled by flowing water 
Composition of steel and filler wire, wt.\%

\begin{tabular}{|c|c|c|c|c|c|c|c|c|c|c|}
\hline Material & $\mathrm{C}$ & $\mathrm{Si}$ & $\mathrm{Mn}$ & $\mathrm{S}$ & $\mathrm{P}$ & $\mathrm{Cr}$ & $\mathrm{Cu}$ & $\mathrm{Ni}$ & $\mathrm{Mo}$ & $\mathrm{V}$ \\
\hline 15Kh2NMFA & $0.13-0.18$ & $0.17-0.37$ & $0.3-0.6$ & $0.012-0.013$ & $<0.035$ & $1.8-2.3$ & 0.07 & $1.0-1.5$ & $0.5-0.7$ & $0.1-0.12$ \\
\hline $\begin{array}{c}\text { Sv-08G2S } \\
(d=1.2 \mathrm{~mm})\end{array}$ & 0.09 & 0.89 & 1.89 & 0.023 & 0.024 & 0.032 & 0.052 & 0.028 & - & - \\
\hline
\end{tabular}

in order to eliminate additional heating by Foucault currents. Applied mode of magnetic field influence corresponds to mode for treatment of wrought vessel steel providing maximum effect of microhardness change [4].

Measurements of magnetic characteristics were carried out in closed magnetic circuit on a permeameter scheme. Measured values of initial magnetic susceptibility $\chi$ in the specimens were used for plotting its distribution on welded joint section. Values of microstresses $\sigma_{I I}$ and dimensions $D$ of coherent-scattering regions (CSR) were determined on reflection curves, taken using difractometer DRON-4.1. Imaging of difractograms of reference (reflected Armco-iron) and investigated specimens were carried out point by point under constant conditions. Reflections (110) and (220) in filtered $K_{\alpha}$-radiation of iron anode were taken for analysis. Area of region being radiated, located close to the weld, did not exceed $4 \mathrm{~mm}^{2}$. Electron microscope examinations of fine structure were carried out for the same regions using EMV-100BR microscope.

Results and discussion. Figure 2 presents distribution of normalized quantities $\chi / \chi_{\min }$ of initial magnetic susceptibility of welded joint. It can be seen that

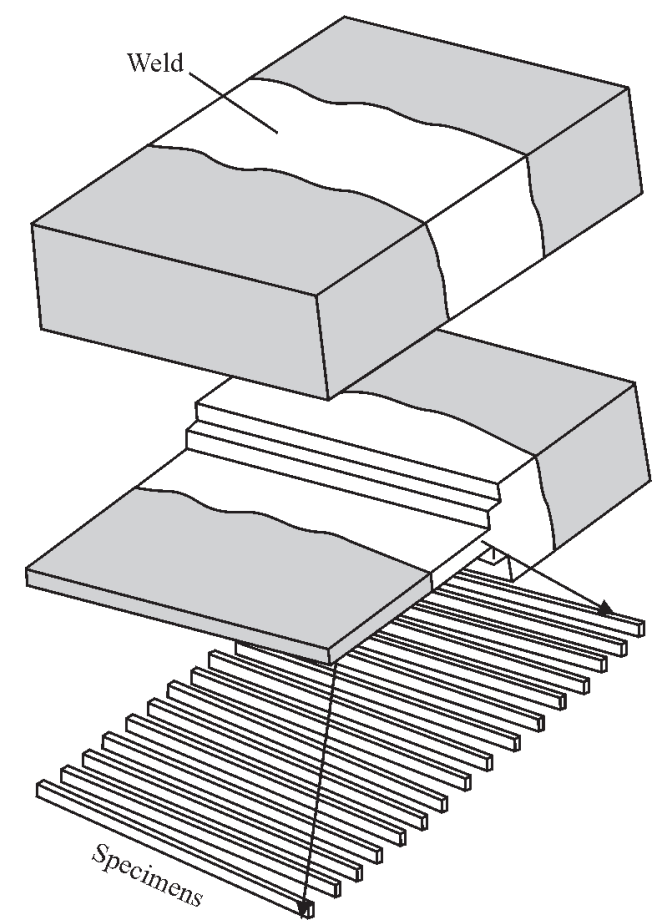

Figure 1. Scheme of manufacture of specimens from welded joint $\chi / \chi_{\text {min }}$ dependence in the initial state reaches the minimum value in HAZ close to the transition layer, at that $\chi / \chi_{\min }$ rises approximately 2 times for material close to weld center and at around $5.5 \mathrm{~mm}$ distance from the transition layer to plate edge. Significant change of distribution nature took place as a result of magnetic treatment. Thus, $40 \%$ rise of $\chi / \chi_{\min }$ is observed close to weld-steel boundary, whereas for areas distant from the transition layer there is approximately $50 \%$ decrease of this value in the weld center.

Let's consider possible reasons of different variations of the initial magnetic susceptibility for different sections of the welded joint. In scopes of existing concepts [5], the initial magnetic susceptibility is determined by reversible small displacements of domain boundaries in the area of weak magnetic fields and depends on distribution of internal stresses, relationships of concentration of different magnetic phases and magnetization orientation in a crystal. Approximately 2 times growth of $\chi / \chi_{\min }$ is observed that corresponds to decrease to the same level of an average amplitude of internal stresses $\sigma_{i}$ due to relationship $\chi \sim\left(\sigma_{i} \lambda_{s}\right)^{-1}$, where $\lambda_{s}$ is the magnetostriction constant [5].

The results of $\mathrm{X}$-ray examinations of the relative changes of a lattice period allow making a conclusion on the average value of elastic deformations, and, respectively, microstresses in microvolumes, related with dislocation hardening nature. It was found that $\sigma_{I I}$ and $D$ values in the weld at up to $2 \mathrm{~mm}$ distance from the transition layer reduced after magnetic treat-

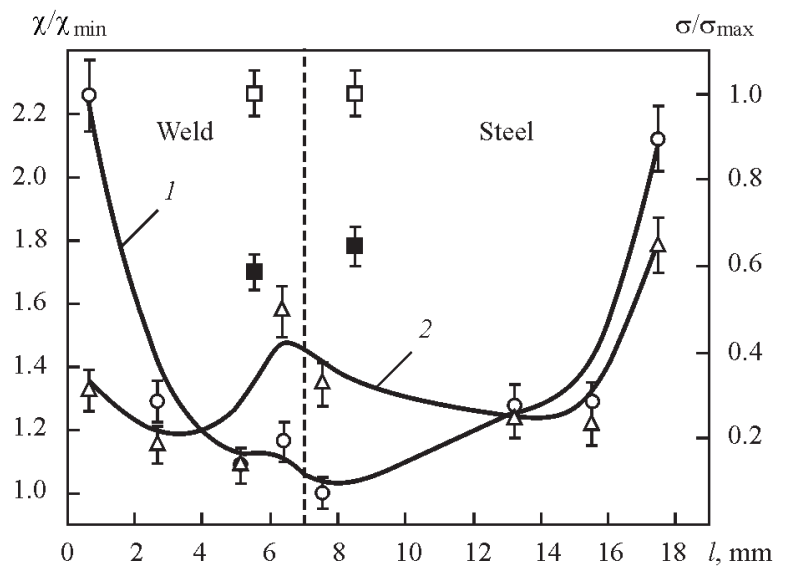

Figure 2. Distribution of given values of initial magnetic susceptibility and microstresses $(\square, \square)$ in welded joint: before magnetic treatment $(1, \square)$ and after magnetic treatment $(2, \boldsymbol{\square}) \cdot \chi_{\min } \cdot \sigma_{\max }$ are the minimum and maximum values of susceptibility and microstresses, dashed line - weld boundary 


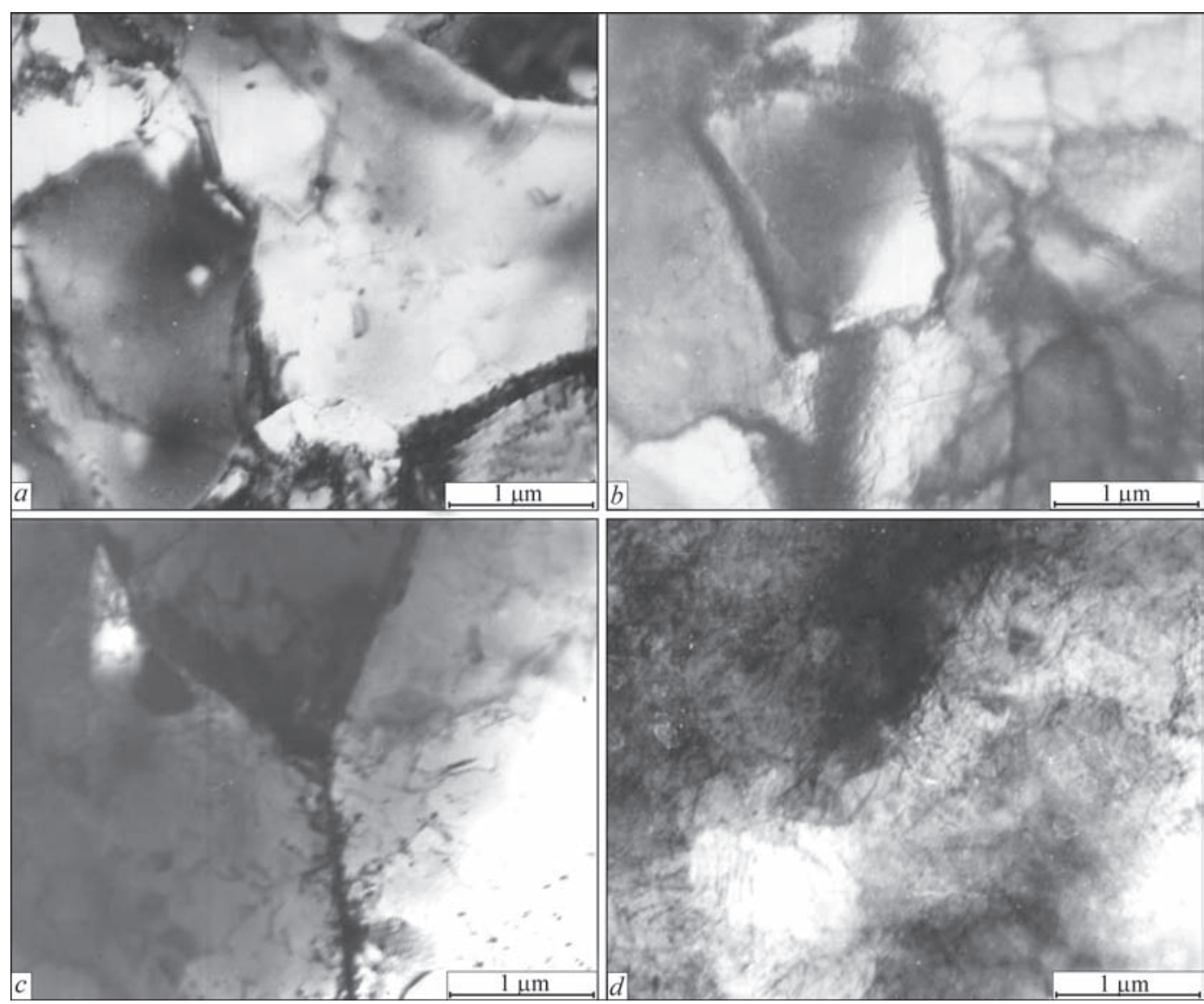

Figure 3. Microstructure of welded joint of steel 15Kh2NMFA before magnetic treatment $(a, b)$ and after $(c, d): a-$ steel; $b-$ weld ment from 650 to $380 \mathrm{MPa}$ and 0.13 to $0.083 \mu \mathrm{m}$, respectively. At the same distance from the transition layer in steel, the second kind stresses make $310 \mathrm{MPa}$, and CSR dimensions do not exceed upper limit of proper determination of $D$ (around $2.5 \mu \mathrm{m}$ ). Magnetic treatment resulted in blocks' division $(D=0.25 \mu \mathrm{m})$ and drop of stresses to $200 \mathrm{MPa}$. Thus, microstress changes observed as a result of magnetic treatment in $\mathrm{HAZ}$ at qualitative level correspond to the changes of initial magnetic susceptibility.

In the center of welded joint the level of internal stresses in the coarse grains solidified from the melt will be significantly lower and their change at magnetic treatment can not explain dramatic decrease of magnetic susceptibility. It is the most possible case for appearance of the expressed magnetic texture. Fine elongated contours of the areas close to weld boundary from the electron-microscopy images (Figure 3, $a$, b) are classified as areas of elastic bending deformations of thermal origin lattice. Density of such formations in the weld makes $4 \cdot 10^{8} \mathrm{~cm}^{-2}$ that indicates high level of inhomogeneity of stressed state.

The result of magnetic treatment is generation of the dislocations in the places of peak elastic stresses and slaking of dislocation walls with formation of chaotic dislocation assembly, similar to tempering structure (Figure 3, $c, d$ ). The same phenomenon is observed in work [6] where microstresses reduced due to vibration treatment and dislocation density rose in a near weld zone of welded steel structure.

Let's study some probable mechanisms of change of dislocation mobility and displacement of spot defects in course of magnetic treatment, making mutually complementary contributions in formation of stress fields. Magneto-elastic stresses inside the domain boundary of steel became close to values of iron $\sigma_{m} \approx$ $\approx 3 \mathrm{MPa}$, such a condition corresponds to dislocation movement, which is not fixed by impurity atoms, under effect of elastic deformations inside the domain boundary [7]. Magneto-stimulated depinning (tear) of area of dislocation line with the impurity atoms precedes an elementary act of microplastic deformation. Concentration of impurities in the weld (3-4 wt.\%) eliminates the possibility of realization of deformation controlling mechanism, related with overcoming by dislocations of the obstacles in form of the impurity atoms or their accumulations. It is known fact that there is a possibility of appearance of double dislocation kinks at application of external alternating stresses with amplitude below the Peierls stress [8]. It is naturally to assume that microdeformation of material will be controlled by movement of geometry kinks at 
dislocation edge components. Kink movement along the dislocation under effect of magneto-elastic waves in combination with internal stresses will provoke transverse movement of a dislocation line.

Evaluation of magnetic input in free energy using experimental data $(B \approx 0.1, \mathrm{~T}, \mathrm{H} \approx 40 \mathrm{kA} / \mathrm{m})$ showed that its value is close to magnetic anisotropy due to stable displacement of the pairs of interstitial atoms and vacancies [9]. Directed ordering of the spot defects is apparently the most probable mechanism of induction of magnetic anisotropy [10], which is mainly responsible for significant change of $\chi$ value directly in the weld zone.

Effects of mutual influence and self-consistence appear in the process of magnetic treatment in behavior of dislocations and spot defects in HAZ. Superposition of dynamic mechanisms stipulates development of relaxation processes, dissipation of accumulated internal energy, that results in irreversible rebuilding of dislocation structure and setting more uniform stress distribution.
1. Makhnenko, V.I., Grigoryants, A.G., Kazimirov, A.A. (1981) Welding in USSR. Vol. 2: Theoretical principles of welding, strength and design. Moscow: Nauka.

2. Neklyudov, I.M. et al. (2011) Effect of magnetic treatment on mechanical characteristics and thermal stresses of vessel plate welded joints. Fizika i Khimiya Obrabotki Materialov, 1, 84-88.

3. Mitsek, A.I., Pushkar, V.N. (1978) Real crystals with magnetic order. Kiev: Naukova Dumka.

4. Pat. 94178. Method of magnetic treatment of products from magnetic-ordered metallic alloys. Publ. 11.04.2011.

5. Vonsovsky, S.V. (1971) Magnetism. Moscow: Nauka.

6. Noskova, N.I. et al. (1986) Relaxation of residual stresses of metals in field of elastic oscillations. Problemy Prochnosti, 9, 67-72.

7. Mishin, D.D. (1981) Magnetic materials. Moscow: Vysshaya Shkola.

8. Arsenold, R.J. (1972) Microplasticity of bcc metals and solid solutions. Mechanisms of double conversions: Mikroplasticity, Moscow: Metallurgiya.

9. Bernshtejn, M.L. (1968) Thermomagnetic treatment of steel. Moscow: Metallurgiya.

10. Lesnik, A.G. (1976) Induced magnetic anisotropy. Kiev: Naukova Dumka. 


\title{
APPLICATION OF HIGH-FREQUENCY PEENING TO IMPROVE THE PERFORMANCE OF BUTT WELDED JOINTS IN THE ATMOSPHERE OF TEMPERATE CLIMATE
}

\author{
V.V. KNYSH, S.A. SOLOVEJ, V.I. KIRIAN, L.I. NYRKOVA and S.A. OSADCHUK \\ E.O. Paton Electric Welding Institute, NASU \\ 11 Kazimir Malevich Str., 03680, Kiev, Ukraine. E-mail: office@paton.kiev.ua
}

\begin{abstract}
The paper presents the results of investigations of the effectiveness of application of high-frequency mechanical peening (HFMP) to improve fatigue resistance characteristics of butt welded joints in metal structures operating in an atmosphere of temperate climate. Metallographic studies showed that HFMP treatment of fusion zone in butt welded joint of $15 \mathrm{KhSND}$ steel before exposure to high humidity conditions promoted an improvement of corrosion resistance of this zone: reduction of corrosion pit depth and of extent of HAZ damage from $100 \%$ practically to 0 . Fatigue testing of welded joints in the initial and HFMP strengthened states was performed before and after exposure to high humidity and temperature. It is found that HFMP strengthening of butt welded joints of $15 \mathrm{KhSND}$ steel before exposure allows increasing fatigue strength at $2 \cdot 10^{6}$ cycles by $39 \%$ and cyclic fatigue life up to 9 times. 16 Ref., 2 Tables, 5 Figures.
\end{abstract}

Keywords : butt welded joint, fatigue, high-frequency mechanical peening, high humidity

Welded metal structures in long-term service (bridges, bridge crossings, main pipelines, etc.) are expensive constructions, of which high safety requirements are made. As shown by statistics, $70-80 \%$ of failures of welded metal structures are associated with damage of welded joints, despite the fact that their volume is equal to just about $1.0-1.5 \%$ of total volume of the structure [1]. Fatigue is one of the most common types of fractures of welded metal structures, including bridge structures. Climatic factors of external environment essentially lower fatigue resistance of welded joints through involvement of the corrosive medium into the fracture process, resulting in corrosion damage (pitting, caverns, etc.), which are the geometrical stress raisers. Various methods are used for protection from corrosion-fatigue damage, including surface plastic deformation (SPD) of metal [1-4].

High-frequency mechanical peening (HFMP), known in foreign publications as ultrasonic impact treatment [5-8], takes up an important place among SPD methods. High effectiveness of application of this technology to improve the corrosion and fatigue resistance of welded joints was established at direct testing in corrosive solutions [9-12]. During such testing performance, the time of contact of samples with corrosive medium is from 10 up to $200 \mathrm{~h}$. In recent years there have been publications devoted to investigation of long-term influence of corrosive media on the state of metal layer, plastically deformed by HFMP technology, and, accordingly, on the change of the level of induced residual compressive stresses and fatigue resistance characteristics [13-15].
Considering the location of climatic region of Ukraine, it is of interest to evaluate the long-term influence of temperate climate atmosphere on lowering of cyclic life of welded joints in the initial and HFMP strengthened states. As requirements of corrosion resistance (metal loss rate, corrosion defect size, etc.) at the impact of high humidity and temperature are made of metal structures, operating in temperate climatic conditions, the characteristic damage can be obtained by conducting accelerated corrosion testing in G4 moisture chamber.

The objective of this work is evaluation of the effectiveness of HFMP technology application to improve the fatigue resistance characteristics of butt welded joints at the stage of fabrication of metal structures, long-term operation of which will proceed in the atmosphere of temperate climate.

Material and investigation procedure. Investigations were conducted on samples of butt welded joints of structural low-alloyed steel $15 \mathrm{KhSND}$, which is widely applied for fabrication of elements of metal structures for long-term operation (for instance, in span structures of railway and car bridges), has higher strength, and good weldability, is stable in atmospheric conditions and operable in the temperature range from $-70^{\circ} \mathrm{C}$ up to $45^{\circ} \mathrm{C}$. Chemical composition of the studied steel, wt.\% was as follows: $0.142 \mathrm{C} ; 0.466 \mathrm{Si}$; $0.63 \mathrm{Mn} ; 0.020 \mathrm{~S} ; 0.013 \mathrm{P} ; 0.31 \mathrm{Ni} ; 0.66 \mathrm{Cr} ; 0.34 \mathrm{Cu}$.

Blanks for samples of butt welded joints of $600 \times 175 \mathrm{~mm}$ size were cut out of hot-rolled plates $12 \mathrm{~mm}$ thick of category 12 in the rolling direction. Butt welded joints were produced by automatic sin- 
gle-arc square butt welding of plates from two sides (0 to $1.0 \mathrm{~mm}$ gap in the butt), using OP 192 flux (Oerlikon Company) and Sv-08G1NMA wire of $4 \mathrm{~mm}$ diameter. Reverse polarity welding was performed with power supply from electric rectifier VSZh-1600. Modes of making the first weld were as follows: $U=55 \mathrm{~V}$; $I=650-700 \mathrm{~A} ; v=26.7 \mathrm{~m} / \mathrm{h}$; for second weld (on the opposite side): $U=57 \mathrm{~V} ; I=760-780 \mathrm{~A}, v=26.7 \mathrm{~m} / \mathrm{h}$. The second weld was made after complete cooling of the first one. Eight samples of $350 \times 70 \mathrm{~mm}$ size were cut out of each $600 \times 350 \mathrm{~mm}$ welded plate (Figure 1).

Fatigue testing was conducted in servohydraulic machine URS-20 at alternating tension with cycle asymmetry $R_{\sigma}=0$ and $5 \mathrm{~Hz}$ frequency. The criterion of testing completion was total fracture of the samples or exceeding the test base of $2 \cdot 10^{6}$ stress alternation cycles.

Four series of samples of butt welded joints were tested:

- samples in as-welded (unstrengthened) state (first series);

- samples strengthened by HFMP technology (second series);

- samples in unstrengthened state after exposure to high humidity for $1200 \mathrm{~h}$ (third series);

- HFMP strengthened samples after exposure to high humidity for $1200 \mathrm{~h}$ (fourth series).

Strengthening of welded joints by HFMP technology was conducted with USTREAT-1.0 unit, in which manual compact impact tool with peizoceramic transducer is connected to ultrasonic generator with $500 \mathrm{~W}$ output power. A narrow zone of weld metal transition to the HAZ (fusion line) was subjected to surface plastic deformation. A single-row four-striker attachment with $3 \mathrm{~mm}$ striker diameter was used as strengthening device. The speed of HFMP performance at treatment of butt welded joints was $2 \mathrm{~mm} / \mathrm{s}$, amplitude of vibrations of manual impact tool end face was $25 \mu \mathrm{m}$.

Corrosion testing of samples of series 3 and 4 was conducted under the conditions, simulating temperate climate atmosphere (in moisture chamber at the temperature of $40{ }^{\circ} \mathrm{C}$ and air humidity of $98 \%$ ), for $1200 \mathrm{~h}$ that is equivalent to 12 years of operation (substantiation of testing duration and conditions are given in the procedure [16]).

After corrosion testing the method of optical microscopy was used to study the change of the condition of surface layer of near-weld zone of butt welded joints in unstrengthened and HFMP strengthened states. Metallographic sections were studied in Neophot-32 microscope, digital image of the structure was obtained with digital camera Olympus C5050. Microhardness was measured with microhardness meter M-400 of LECO Company at $50 \mathrm{~g}(0.49 \mathrm{~N})$ load.

Investigation results. Metallographic investigations established the following. Grain size, HAZ extent and
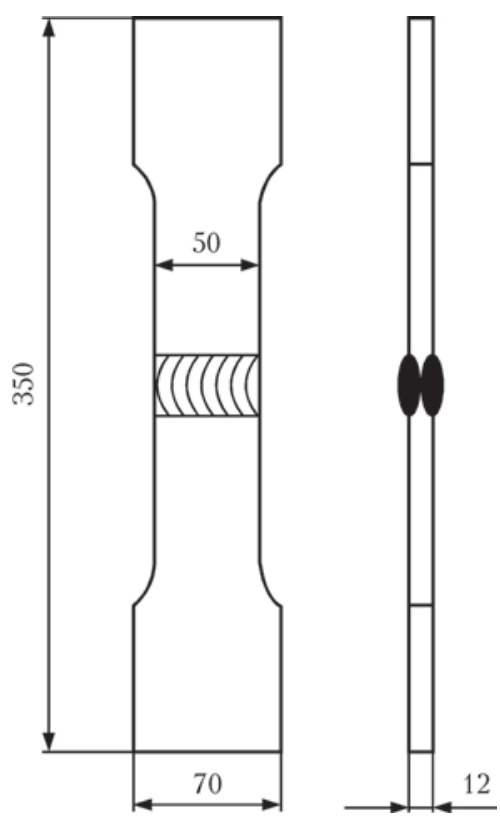

Figure 1. Shape and geometrical dimensions of samples of butt welded joint

microstructure of the first and second welds are practically the same. Directly near the welded joint surface coarse-grained zone (CGZ) of about $0.8 \mathrm{~mm}$ length contains No.5 (less often, No.4 and No.6) grains; grain size in fine-grained zone (FGZ) of about $1.3 \mathrm{~mm}$ length is Nos 7-10 (Figure 2, a). At about $2 \mathrm{~mm}$ distance from the surface CGZ size increases to $2 \mathrm{~mm}$, and grain size - up to Nos 3-4. CGZ metal structure in deeper-lying layers from rolled stock surface is ferritic with densely distributed precipitates of MAC-phase (with ordered platelike precipitates of upper bainite type with about $108 \mu \mathrm{m}$ length of individual plates). Chaotically distributed quite large particles of grain type are found. Grain boundaries are outlined by relatively wide, up to $5-8 \mu \mathrm{m}$, interlayers of intergranular polygonal ferrite. In CGZ surface layers ferrite grains were also observed, which had densely distributed MAC-phase of the type of upper and lower bainite with polygonal ferrite precipitates in the form of wider interlayers or stringers of individual grains located along their boundaries. Microhardness of metal of HAZ surface layers of the first and second welds in the initial state is equal to HV0.49-168-223 (Table 1).

After HFMP, grooves of practically the same size shifted towards the HAZ or into weld metal, formed in the zone of weld fusion with base metal in surface layers of weld and HAZ metal. Depth of plastically deformed metal layer under the groove was equal to about 260 $325 \mu \mathrm{m}$ (Figure 2,c). Intensive deformation (elongation) of grains was observed both in coarser ferrite grains with MAC-phase precipitates and in HAZ ferrite grains free from precipitates, and in cast bainite-ferrite grains of the weld. Deformed grains are located at an angle to metal surface around the groove perimeter, grain form coefficient is equal to $K_{\mathrm{f}}=8-20\left(K_{\mathrm{f}}=a / b\right.$, where $a$ and $b$ are elongated grain length and width, respectively). Micro- 

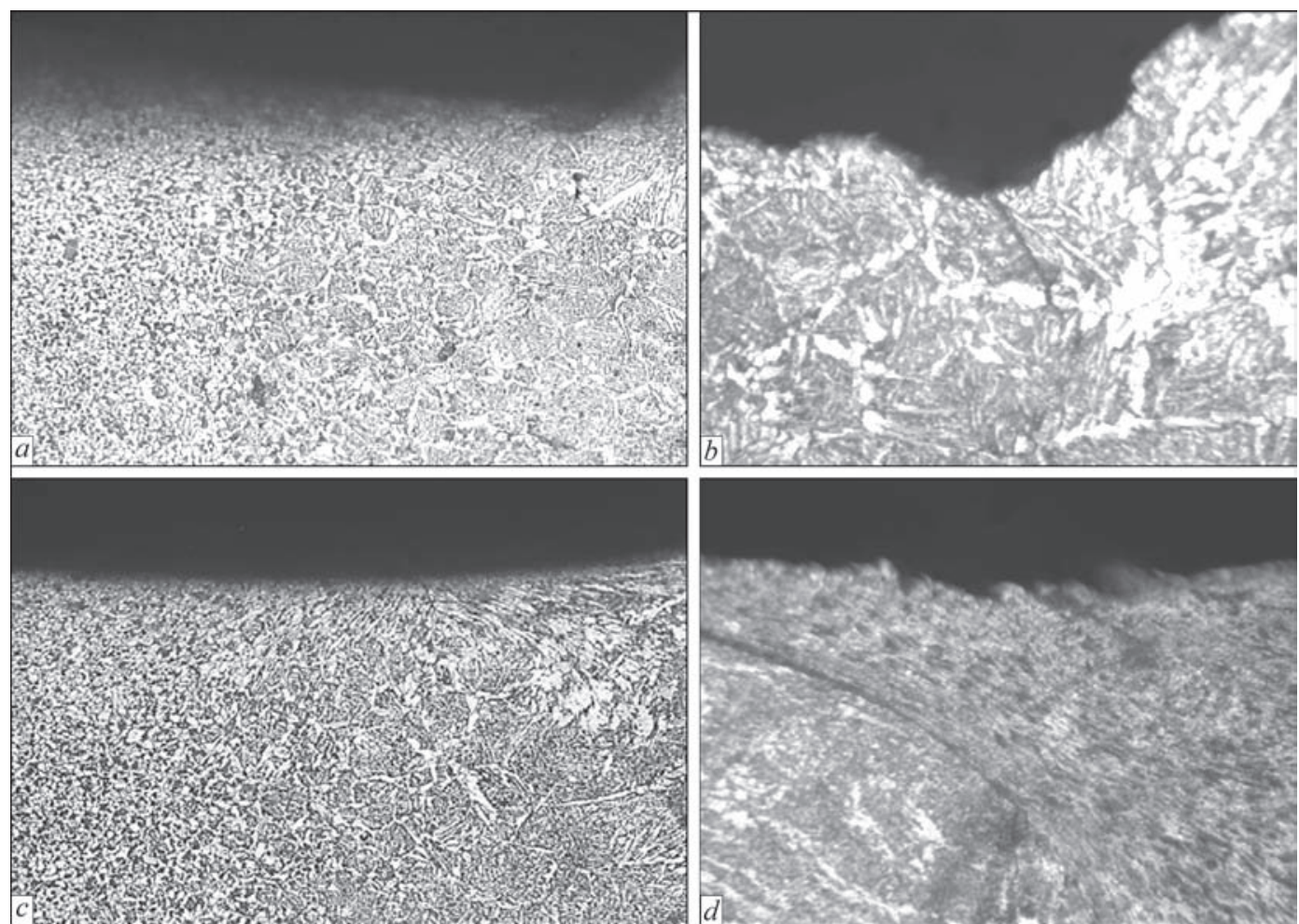

Figure 2. Microstructure of surface layer of HAZ metal, unstrengthened $(a, b)$ and strengthened by HFMP technology ( $c$, $d)$, in butt welded joint in the initial state $(a, b)$ and after corrosion testing at high humidity for $1200 \mathrm{~h}(b, d) ; a, c-\mathrm{x} 156 ; b, d-\times 400$

hardness of plastically deformed metal of HAZ surface layers is equal to HV0.49-177-232 (Table 1) that is by 8-10 \% higher than microhardness of HAZ metal surface layer in the initial condition.

After exposure under the conditions of high humidity, a non-uniform layer of corrosion products formed on the surface of both strengthened and unstrengthened samples (Figure 3). As fatigue cracks usually form along the fusion line, corrosion damage in the zone of weld metal transition to base metal was studied. In keeping with GOST 9.908 corrosion is identified as continuous non-uniform. The main types of corrosion in surface layers of HAZ metal are corrosion spots and pits of different dimensions. In unstrengthened welded joints the depth of corrosion pits in surface layers of HAZ metal varied from $0.026 \mathrm{~mm}$ to $0.130 \mu \mathrm{m}$, total projection of damage area was equal to about $100 \%$ (Table 2). In addition to corrosion pits, local corrosion damage in the form of intercrystalline cracks is found in the fusion zone (Figure 2,b). After HFMP treatment of the fusion line, a reduction of the depth of corrosion pits in the HAZ region practical- ly to zero was noted (Table 2); intercrystalline cracks coming to the surface along the line of weld fusion with base metal were revealed (Figure 2, $d$ ).

Thus, treatment of fusion line by HFMP technology promoted an increase of corrosion resistance of this zone (by corrosion defect size). More precise determination of the origin of intercrystalline cracks in welded joints before and after strengthening requires further studies.

Mechanical testing of two samples of butt welded joints of $25 \times 12 \mathrm{~mm}$ cross-section for static shorttime tension was performed. Samples failed at a distance from the weld and HAZ through base metal (Figure 4), obtained values of mechanical properties of welded joints correspond to values for base metal $\left(\sigma_{\mathrm{y}}=400 \mathrm{MPa}, \sigma_{\mathrm{t}}=565 \mathrm{MPa}, \delta_{5}=27 \%\right)$.

Results of fatigue testing of samples of butt welded joint of $15 \mathrm{KhSND}$ steel of all the series are given in Figure 5.

Large scatter of experimental data of samples of welded joints in the initial state (Figure 5, curve 1) is, apparently related to the technology of sample

Table 1. Microhardness distribution from the surface in-depth of HAZ metal in butt welded joints of 15KhSND steel before and after treatment of fusion line by HFMP technology

\begin{tabular}{|c|c|c|c|}
\hline \multicolumn{2}{|c|}{ Sample characteristic, weld number } & $l, \mathrm{~mm}$ & Microhardness HV0.49 \\
\hline \multirow{2}{*}{ In the initial state } & First weld & \multirow{2}{*}{1.73} & $192 ; 201 ; 210 ; 192 ; 168 ; 182 ; 192 ; 185 ; 181$ \\
\hline & Second weld & & $216 ; 223 ; 210 ; 210 ; 198 ; 192 ; 192 ; 197 ; 182$ \\
\hline \multirow{2}{*}{ After HFMP } & First weld & \multirow{2}{*}{1.80} & $210 ; 210 ; 210 ; 210 ; 221 ; 208 ; 181 ; 183 ; 177$ \\
\hline & Second weld & & $232 ; 232 ; 236 ; 232 ; 210 ; 203 ; 183 ; 192 ; 192$ \\
\hline
\end{tabular}



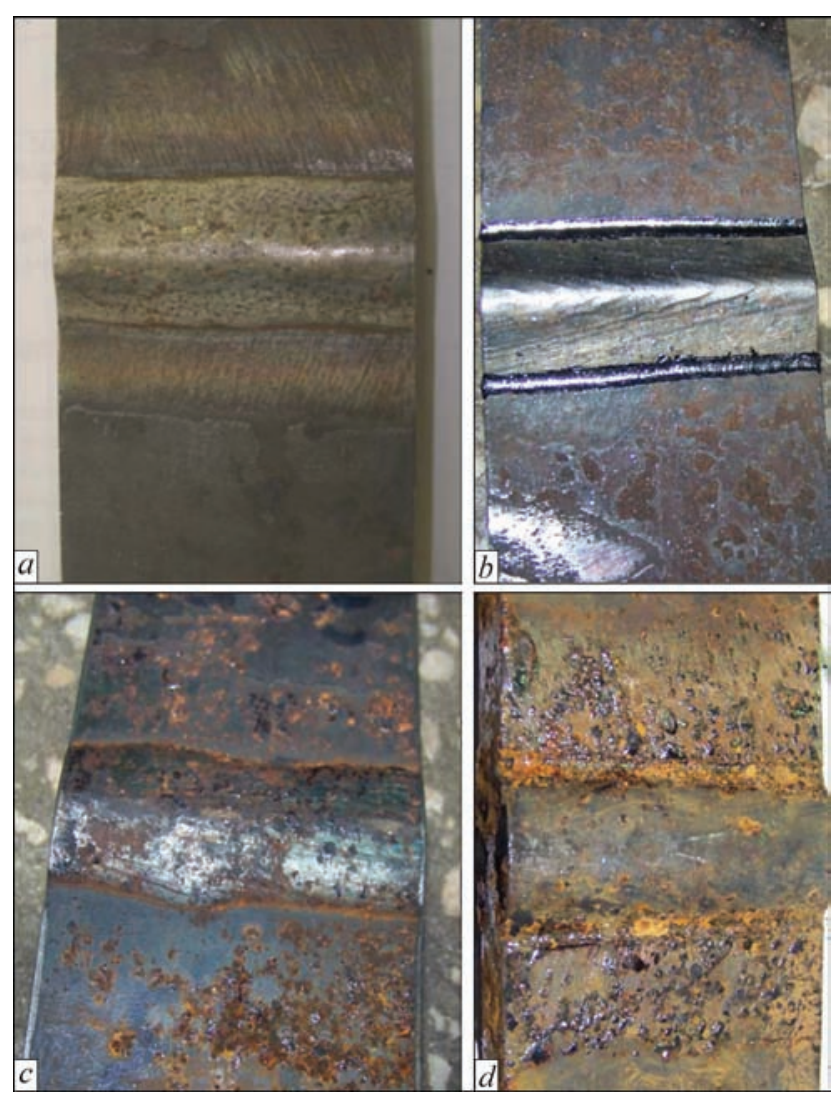

Figure 3. Appearance of samples of butt welded joints from $15 \mathrm{KhSND}$ steel in the initial $(a, c)$ and HFMP strengthened $(b$, $d)$ states before $(a, b)$ and after $(c, d)$ corrosion testing at high humidity for $1200 \mathrm{~h}$

preparation: as welded joint samples were produced by cutting $600 \times 350 \mathrm{~mm}$ plate into blanks for samples of $350 \times 70 \mathrm{~mm}$ size, the level of residual stresses in the samples could be different, depending on their position in the plate (edge, middle). Strengthening of welded joints by HFMP technology promoted a significant reduction of experimental data scatter (Figure 5, curve 2). Cyclic fatigue life of as-strengthened samples (second series) increased more than 40 times, and

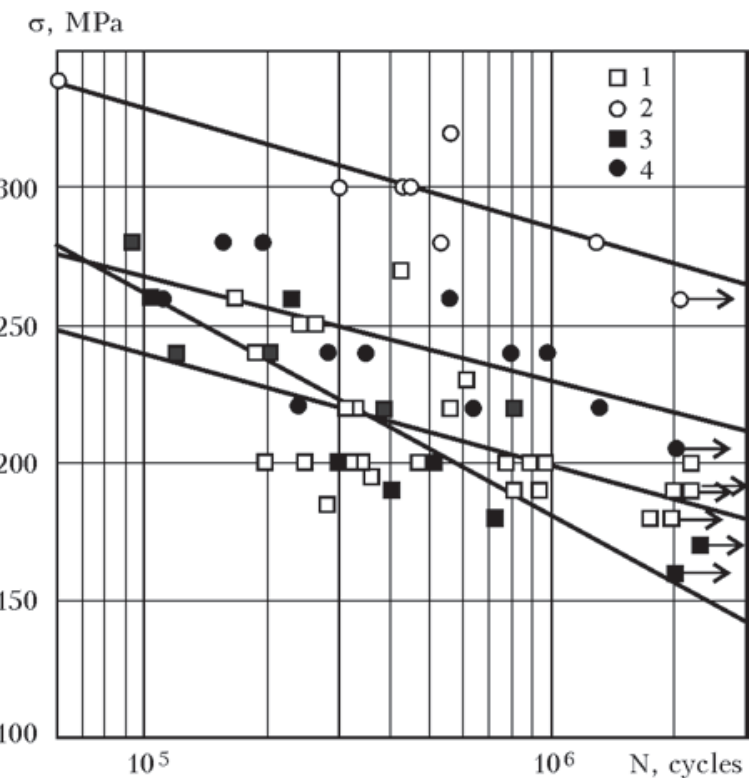

Figure 5. Fatigue curves of butt welded joints of 15KhSND steel: 1, 2 - in the initial state and after HFMP strengthening in air, respectively; 3, 4 - in the initial state and after HFMP strengthening after corrosion testing at high humidity for $1200 \mathrm{~h}$

fatigue strength at $2 \cdot 10^{6}$ cycles increased by approximately $46 \%$ (from 187 to $273 \mathrm{MPa}$ ). Three strengthened samples failed through base metal at $15-20 \mathrm{~mm}$ distance from the weld; and three samples failed along the fusion line. Obtained results (Figure 5, curves 1, 2) confirm that application of HFMP technology as the method of SPD of metal of the joints near the areas of fatigue damage localization essentially improves fatigue resistance characteristics of butt welded joints in air (without corrosion damage).

Soaking of unstrengthened samples of butt welded joints under the conditions of increased humidity for $1200 \mathrm{~h}$ (third series) led to lowering of fatigue strength at $2 \cdot 10^{6}$ cycles by approximately $16 \%$ (from 187 to $157 \mathrm{MPa}$ ) and reduction of cyclic fatigue life in the range of $4 \cdot 10^{5}-2 \cdot 10^{6}$ cycles by 2.5 times (Figure 5 ,

Table 2. Dimensions of corrosion damage of surface layer of metal of weld and HAZ of butt welded joints of 15KhSND steel after exposure under the conditions of high humidity for $1200 \mathrm{~h}$

\begin{tabular}{|c|c|c|c|c|}
\hline \multirow{2}{*}{ Sample characteristic } & \multicolumn{3}{|c|}{ Dimensions of corrosion damage of surface layers } \\
\cline { 2 - 5 } & \multicolumn{2}{|c|}{ Weld metal } & \multicolumn{2}{c|}{ HAZ metal } \\
\cline { 2 - 5 } & Depth, mm & Degree of damage, $\%$ & Depth, mm & Degree of damage, \% \\
\hline In the initial state & $0.039-0.104$ & 19 & $0.026-0.130$ & 100 \\
\hline After HFMP treatment & $0.039-0.091$ & 6.3 & Within measurement error \\
\hline
\end{tabular}

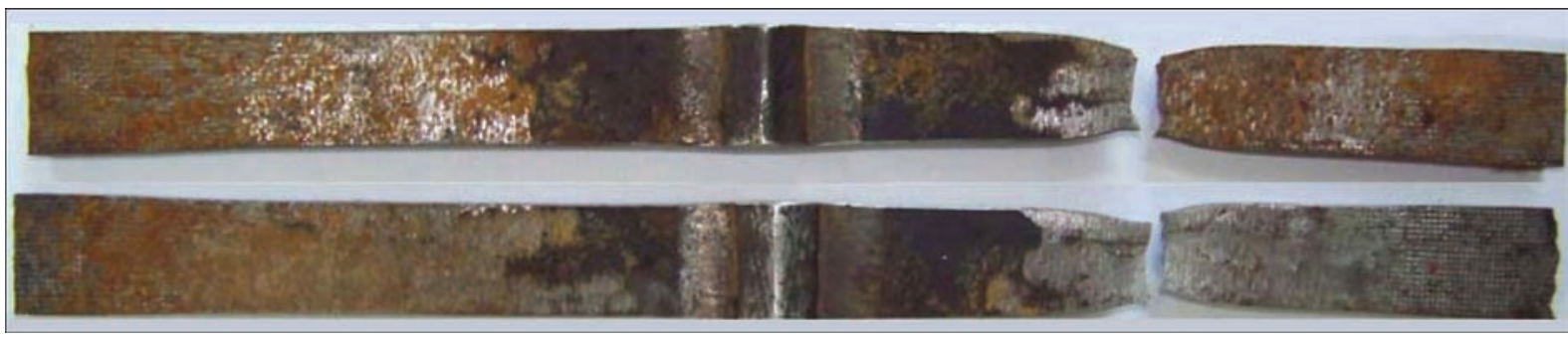

Figure 4. Appearance of welded joint samples after testing for static tension 
curve 3). Corrosive effect resulted in lowering of fatigue strength of HFMP strengthened joints by approximately $20 \%$ (from 273 to $219 \mathrm{MPa}$ ) (Figure 5, curve 4). However, obtained experimental data point to the rationality of HFMP strengthening of butt welded joints at the stage of fabrication in metal structures, which will be exposed to alternating loading and high humidity, as HFMP leads to $39 \%$ increase of fatigue strength at $2 \cdot 10^{6}$ cycles (from 157 to $219 \mathrm{MPa}$ ) in such joints, and up to 9 times increase of their cyclic fatigue life.

Failure of HFMP strengthened welded joints tested after exposure to high humidity proceeded both through the HAZ and through base metal at 15-60 mm distance from the weld. It should be noted that fatigue strength of HFMP strengthened joints even after soaking in the moisture chamber for $1200 \mathrm{~h}$ is $17 \%$ higher than fatigue limit of unstrengthened joints tested in air.

Thus, experimentally obtained results are indicative of high effectiveness of application of HFMP technology to improve fatigue resistance characteristics of welded joints of metal structures, operating under the conditions of simultaneous impact of alternating loading and temperate climate atmosphere (Figure 5, curves 3, 4).

It should be noted that additional protection of HFMP strengthened surface layer of metal from direct impact of atmospheric conditions (for instance, due to application of paint and varnish coatings), will, possibly, allow achieving maximum fatigue resistance characteristics of such joints (Figure 5, curve 2).

\section{Conclusions}

1. Metallographic studies showed that HFMP of fusion line of butt welded joints results in intensive deformation (elongation) of grains of weld and HAZ metal. Here, the depth of prastically deformed layer of metal under the groove with considerable changes of grain form (grain form factor $K_{\mathrm{f}}=8-20$ ) is equal to approximately $260-325 \mu \mathrm{m}$. It is found that HFMP strengthening of welded joints before exposure to high humidity conditions promotes an improvement of their corrosion resistance: reduction of the depth of corrosion pits and degree of HAZ metal damage from $100 \%$ to practically 0 .

2. It was confirmed that HFMP strengthening of the fusion line essentially improves fatigue resistance characteristics of welded joints of $15 \mathrm{KhSND}$ steel in air: cyclic fatigue life increases by more than 40 times, and fatigue strength at $2 \cdot 10^{6}$ cycles increases by $46 \%$.

3 . High effectiveness of HFMP technology application to improve fatigue resistance characteristics of welded joints of metal structures operating at simultaneous action of alternating loading and temperate climate atmosphere was established. HFMP strengthening of butt welded joints of $15 \mathrm{KhSND}$ steel before exposure to high humidity for $1200 \mathrm{~h}$ leads to increase of cyclic fatigue life up to 9 times, depending on the levels of applied stresses and $39 \%$ increase of fatigue strength at $2 \cdot 10^{6}$ cycles.

1. Tkachev, V.N. et al. (1971) Methods of improvement of service life of machine parts. Moscow: Mashinostroenie.

2. Pokhmursky, V.I., Khoma, M.S. (2008) Corrosion fatigue of metals and alloys. Lviv: SPOLOM.

3. Kolomijtsev, E.V. (2012) Corrosion-fatigue strength of 12Kh18N10T steel T-joints and methods of its improvement. The Paton Welding J., 12, 36-38.

4. Hashemi, B., Rezaee Yazdi,M., Azar, V. (2011) The wear and corrosion resistance of shot peened-nitride $316 \mathrm{~L}$ austenitic stainless steel. Materials \& Design, 32, 3287-3292.

5. Harati, E. et al. (2016) Effect of high frequency mechanical impact treatment on fatigue strength of welded $1300 \mathrm{MPa}$ yield strength steel. Int. J. of Fatigue, 92, 96-106.

6. Panin, V.E., Kablov, E.N., Pleshanov, V.S. (2006) Effect of ultrasonic impact treatment on structure and fatigue resistance of welded joints of high-strength steel VKS-12. Fizicheskaya Mezomekhanika, 2, 85-96.

7. Feng, Y. et al. (2016) Influence of surface topography and needle size on surface quality of steel plates treated by ultrasonic peening. Vacuum, 132, 22-30.

8. Yang, X., Ling, X., Zhou, J. (2014) Optimization of the fatigue resistance of AISI304 stainless steel by ultrasonic impact treatment. Int. J. of Fatigue, 61(4), 28-38.

9. Daavari, M., Sadough Vanini, S.A. (2015) Corrosion fatigue enhancement of welded steel pipes by ultrasonic impact treatment. Materials Letters, 139, 462-466.

10. Kolomijtsev, E.V., Serenko, A.N. (1990) Influence of ultrasonic and laser treatment on fatigue resistance of butt welded joints in air and corrosive environment. Avtomatich. Svarka, 11, 13-15.

11. Gao, W. et al. (2015) Enhancement of the fatigue strength of underwater wet welds by grinding and ultrasonic impact treatment. J. Materials Proc. Technology, 223, 305-312.

12. Knysh, V.V., Valteris, I.I., Kuzmenko, A.Z. et al. (2008) Corrosion fatigue resistance of welded joints strengthened by high-frequency mechanical peening. The Paton Welding J., 4, 2-4.

13. Ahmad, B., Fitzpatrick, M.E. (2015) Effect of ultrasonic peening and accelerated corrosion exposure on residual stress distribution in welded marine steel. Metallurg. and Mater. Transact. A, 46, 1214-1226.

14. Knysh, V.V., Solovej, S.A., Nyrkova, L.I. et al. (2016) Influence of corrosion damage on cyclic fatigue life of tee welded joints treated by high-frequency mechanical peening. The $\mathrm{Pa}$ ton Welding J., 9, 42-46.

15. Fan, Y., Zhao, X., Liu, Y. (2016) Research on fatigue behavior of the flash welded joint enhanced by ultrasonic peening treatment. Materials \& Design, 94, 515-522.

16. Kyryan, V.I., Rybakov, A.O. (2016) To establish the mechanisms of improvement of corrosion and fatigue resistance of pipeline and bridge structure welded joints by high-frequency peening: Final report on R\&D, PWI, Vol. 2.

Received 21.02.2017 


\title{
PHYSICO-MECHANICAL PROPERTIES OF THIN-SHEET ALUMINUM ALLOY D16 BUTT JOINTS PRODUCED BY FRICTION STIR WELDING
}

\author{
A.G. POKLYATSKY, S.I. MOTRUNICH and I.N. KLOCHKOV
}

E.O. Paton Electric Welding Institute, NASU

11 Kazimir Malevich Str., 03680, Kiev, Ukraine. E-mail: office@paton.kiev.ua

\begin{abstract}
A complex of investigations was carried out to study the strength characteristics of welded butt joints of structural aluminum alloy D16 of $2 \mathrm{~mm}$ thickness, produced by friction stir welding. It was shown that the use of friction stir welding provides the formation of a permanent joint with a minimum level of stress concentration in the transition zones from the weld to the base material and allows avoiding the formation of defects in the welds such as pores, macroinclusions of oxide film and hot cracks caused by melting and crystallization of metal in fusion welding. As a result of intensive plastic deformation in the weld metal, a homogeneous disoriented structure with a grain size of 3-4 $\mu \mathrm{m}$ and with dispersed phase precipitations of not more than $1 \mu \mathrm{m}$ is formed, and in the regions adjacent to it the elongation and distortion of grains in the direction of movement of the plasticized metal occurs in the zone of thermomechanical action. Due to this, the hardness of metal in the joint zone, the tensile strength under uniaxial tension and the fatigue strength under cyclic loads are increased. 11 Ref., 6 Figures.
\end{abstract}

Ke y w o rds : friction stir welding, aluminum alloy D16, hardness, tensile strength, fatigue resistance

Aluminum alloys are the basic structural material in aerospace engineering and widely used in manufacture of different types of transport, providing strength, long life and weight efficiency of structures. The most widespread aluminum alloys include the alloy D16 of the $\mathrm{Al}-\mathrm{Cu}-\mathrm{Mg}$ system, which has a good combination of endurance characteristics, fracture toughness and resistance to growth of a fatigue crack. However, due to the increased tendency to formation of crystallization cracks, it refers to the alloys which are not weldable by the fusion methods [1-3].

It is possible to avoid melting of metal in the zone of a permanent joint formation by using the new method of friction stir welding (FSW) developed in 1991 at the British Institute [4]. The weld formation occurs in a solid phase as a result of heating due to friction of a small volume of metal until the plastic state, stirring it across the entire thickness of edges being welded and deformation in a closed space. Due to this, the FSW process has significant advantages over the fusion welding. First of all, these are a lack of defects in welded joints in the form of pores, macroinclusions of oxide film and hot cracks, formation of a fine-crystalline structure of welds, a decrease in the level of softening of the materials to be joined, and an increase in mechanical properties of joints [5-9].

The aim of this work is to determine the mechanical properties and characteristics of fatigue resistance

(C) A.G. POKLYATSKY, S.I. MOTRUNICH and I.N. KLOCHKOV, 2017 of thin-sheet aluminum alloy D16 butt joints, produced by FSW.

Methods of investigations. For investigations the sheets of structural aluminum alloy D16 of $2 \mathrm{~mm}$ thick were applied. FSW of butt joints of sheets with $2 \mathrm{~mm}$ thick was carried out at $10 \mathrm{~m} / \mathrm{h}$ speed in the laboratory installation developed at the E.O. Paton Electric Welding Institute. The speed of rotation of a special tool [10] with a conical tip and a collar of $12 \mathrm{~mm}$ diameter was $1420 \mathrm{rpm}$. For comparison, the same joints were produced by argon-arc welding with a non-consumable electrode (AAWNE) at a speed of $20 \mathrm{~m} / \mathrm{h}$ at $165 \mathrm{~A}$ current using the installation MW450 («Fronius», Austria). As a filler, a strip of base material was used to avoid changes in the chemical composition of weld metal. In this case, the width of welds produced by AAWNE was $6.5 \mathrm{~mm}$ in average and that of welds made by FSW was $3.5 \mathrm{~mm}$ (at the width of zone of thermomechanical action from the facial side of the weld was about $12 \mathrm{~mm}$ ).

From the produced welded joints the sections for investigations of structure and specimens with the width of test part of $15 \mathrm{~mm}$ to determine the tensile strength at the uniaxial tension in accordance with GOST 6996-66 were manufactured. Mechanical tests of specimens were carried out in the universal servo-hydraulic complex MTS 318.25. The cyclic tests were performed at axial loads along the sinusoidal cycle with an asymmetry coefficient of $R_{\sigma}=0.1$ and the frequency of $15 \mathrm{~Hz}$ until a complete fracture of spec- 


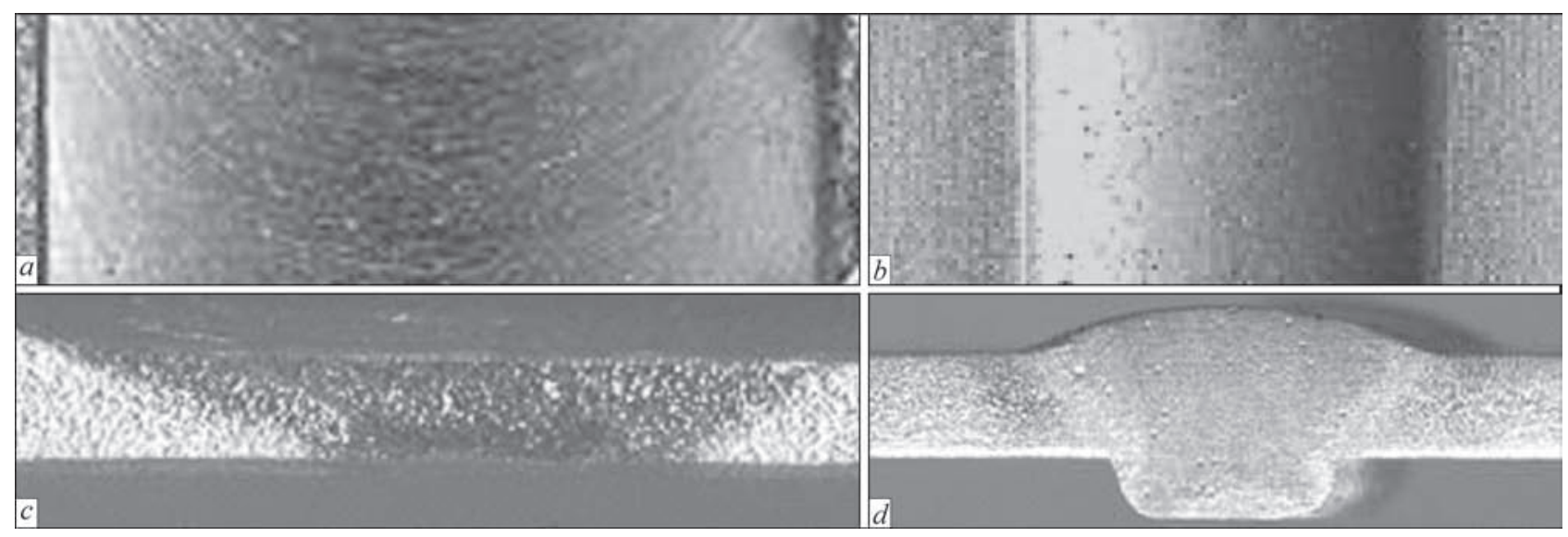

Figure 1. Appearance of facial surface $(a, b)$ and cross sections $(c, d)$ of welds of alloy D16 of 2 mm thickness, produced using FSW $(a, c)$ and AAWNE $(b, d)$

imens. The experimental data of fatigue tests were processed by the methods of linear regression analysis generally accepted for this kind of investigations. Based on the results of the carried out tests, for each series of specimens a corresponding fatigue curve on the basis of the established limits of endurance, i.e. the regression line in the coordinates $2 \sigma_{\mathrm{a}}-\lg N$, was plotted. The metal hardness was measured on the facial surface of the cleaned joints. The softening degree of metal in the welding zone was evaluated in the ROCKWELL device at the load $P=600 \mathrm{~N}$. The structural features of welded joints were evaluated using an optical electron microscope MIM-8.

Results of investigations and their discussion. As a result of the carried out investigations it was revealed that the shape and dimensions of the weld in FSW are favorably different from those produced by fusion welding due to formation of a weld on the backing without the forming groove and the formation of a permanent joint without using a filler wire (Figure 1). The absence of reinforcement and through penetrations on it allows avoiding high levels of stress concentration in the places of transition from weld to the base material, which negatively affect the service and life characteristics of welded joints.

In addition, the formation of permanent joints in a solid phase without melting the base material prevents the arising of typical defects during welding aluminum alloys by fusion. Thus, the absence of a molten metal, in which the solubility of hydrogen sharply ris-

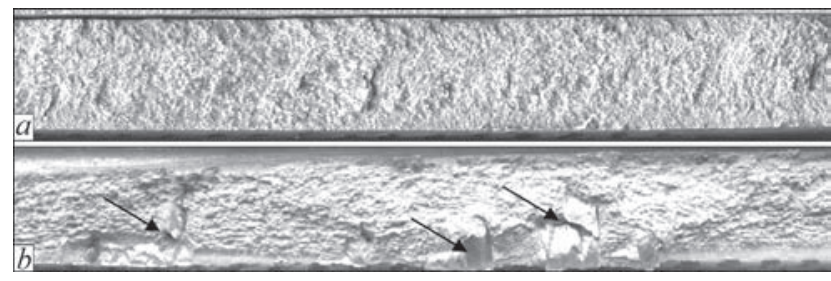

Figure 2. Longitudinal fractures of welds of alloy D16 of $2 \mathrm{~mm}$ thickness, produced using FSW ( $a$ ) and AAWNE (b) with macroinclusions of oxide film (indicated with arrows)

es, allows avoiding additional saturation of welding zone by it due to migration of this gas from the adjacent layers of metal and the formation of pores. And the deformation and intensive stirring of plasticized metal throughout the whole thickness of welded edges in the process of welding contributes to crushing of oxide films located on them. The absence of molten metal in the zone of formation of a permanent joint allows avoiding its oxidation in the process of welding. Therefore, in the welds, produced by FSW, there are no defects in the form of macroinclusions of oxide film, arising by different reasons [11] in AAWNE of aluminum alloys (Figure 2).

The most dangerous and unacceptable defects for structures of critical purpose are the hot cracks formed in the process of crystallization of molten metal in the place of accumulation of low-melting eutectic inclusions. The carried out investigations showed that in AAWNE of the Coldcroft specimens of alloy D16, the formation of hot cracks occurs in the central part of a weld (Figure 3). As in the FSW the weld is formed in a solid phase and the processes of melting and crystallization of metal are absent, then the formation of such defects can be completely avoided.

The peculiarities of welds formation in FSW also favorably affect the degree of metal weakening in the zone of permanent joints formation. Thus, the measurements of metal hardness in the zone of a permanent joint formation showed that in welding of alloy D16 by FSW, the hardness of weld metal is practically at the level of the base material (Figure 4). In the zone of thermomechanical action, the hardness of the metal gradually decreases while moving away from the weld, reaching the minimum value (HRB 97-98) near the boundary of the heat-affected zone. Whereas in AAWNE using the strips of the base material D16 as a filler, the minimum metal hardness in the central part of the weld is only HRB 89-90. At the same time, in 


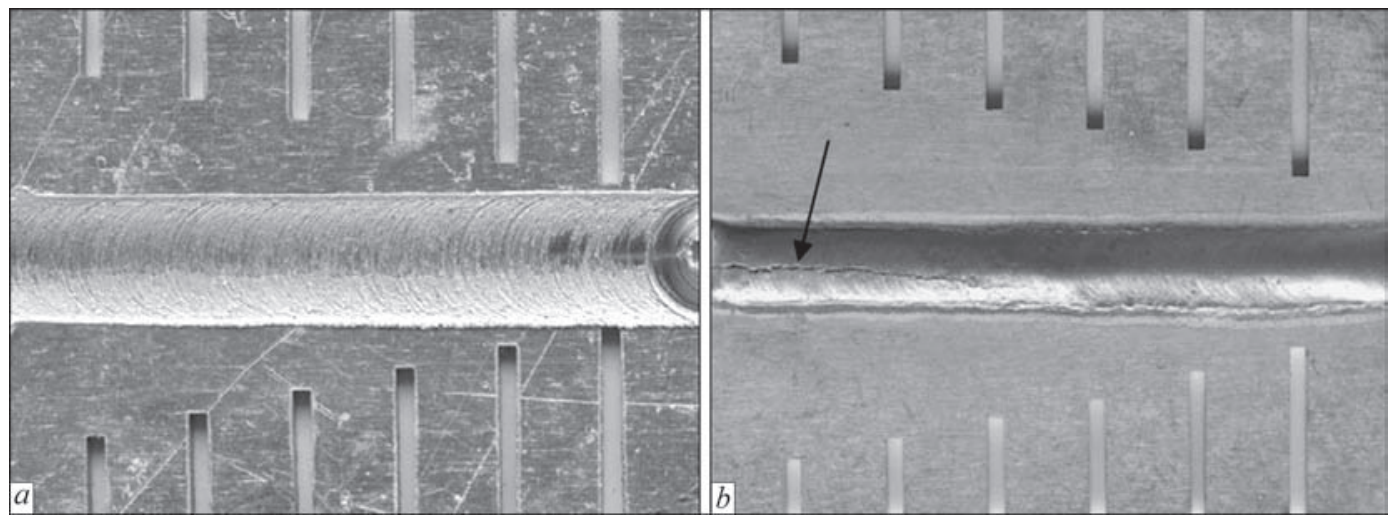

Figure 3. Coldcroft specimens of alloy D16 of $2 \mathrm{~mm}$ thickness, produced using FSW (a) and AAWNE (b) with crystallization crack (indicated with arrow)

the fusion zone of the weld with the base material the hardness of metal is at the level of HRB 92-94.

Therefore, at uniaxial static tension, the specimens of welded joints produced by FSW have the highest (425 MPa) tensile strength and are fractured near the interface of the thermomechanical action zone abutting to the heat-affected zone, where the metal has a minimum hardness. The minimum (295 MPa) tensile strength is observed in the specimens with removed reinforcements and through penetrations of welds produced by AAWNE. They are fractured along the weld, representing a cast metal with the lowest hardness. The specimens with weld reinforcement have a tensile strength at the level of $330 \mathrm{MPa}$ and are fractured in zone of weld fusion with the base material, where the maximum level of stress concentration occurs (Figure 5, $a-c$ ).

At cyclic loads in specimens of welded joints produced by AAWNE, the initiation of fatigue cracks occurs at the place of maximum stress concentration in the zone of fusion with the base material. The lack of reinforcement of the weld on the specimens produced by FSW allows avoiding the high stress concentration at the weld interface with the base material. However, in their surface a small geometric irregularity near the edge of the thermomechanical action zone is ob-

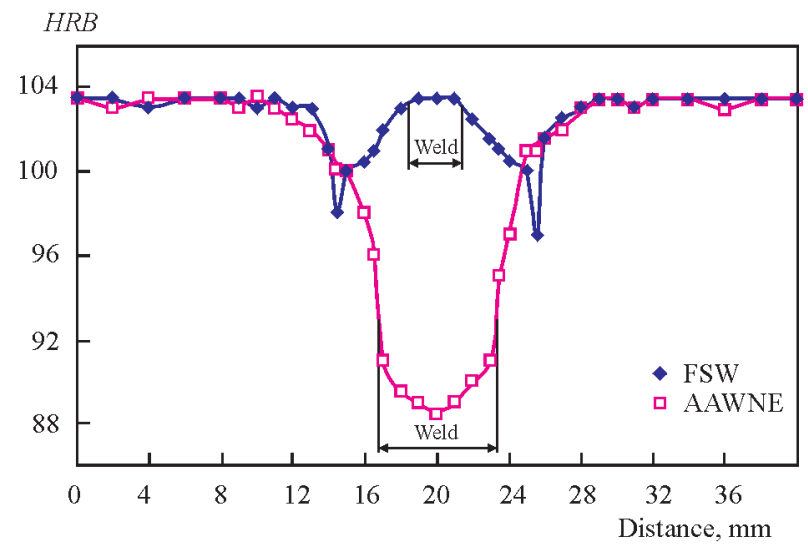

Figure 4. Distribution of hardness in welded joints of alloy D16 of $2 \mathrm{~mm}$ thickness, produced using FSW and AAWNE

served, which is formed due to the immersion of the tool collar into the metal being welded. Therefore, the initiation of fatigue cracks in specimens of such welded joints occurs precisely in this place (Figure 5, $d, e$ ).

As a result of carried out fatigue investigations it was revealed that the margin of limited endurance of welded joints produced in a solid phase by friction with stirring, on the base of $2 \cdot 10^{6}$ cycles of load changes amounts to $120 \mathrm{MPa}$ that is equal to $85 \%$ of corresponding values for the base metal (Figure 6). The characteristics of fatigue resistance are higher than the values for the joints produced by AAWNE in

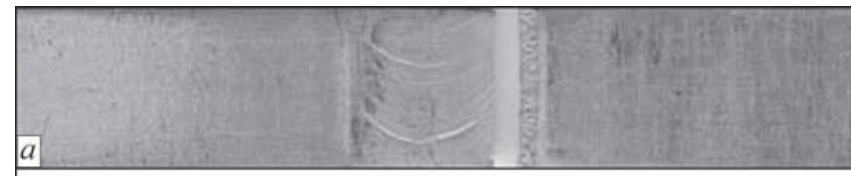

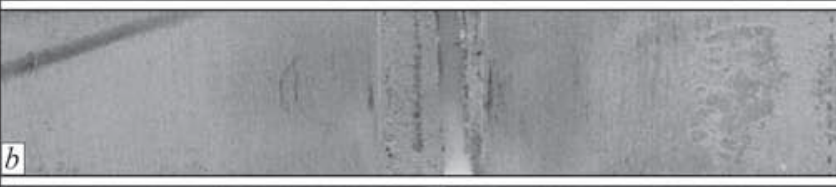

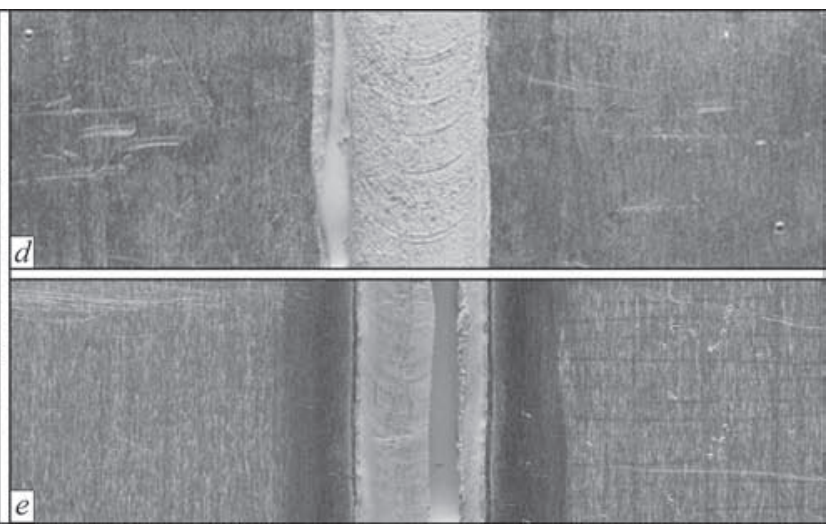

Figure 5. Fragments of specimens of welded joints produced using FSW $(a, d)$ and AAWNE $(b, e-$ with weld reinforcement; $c$ without weld reinforcement) fractured at uniaxial static tension $(a-c)$ and cyclic load $(d, e)$ 


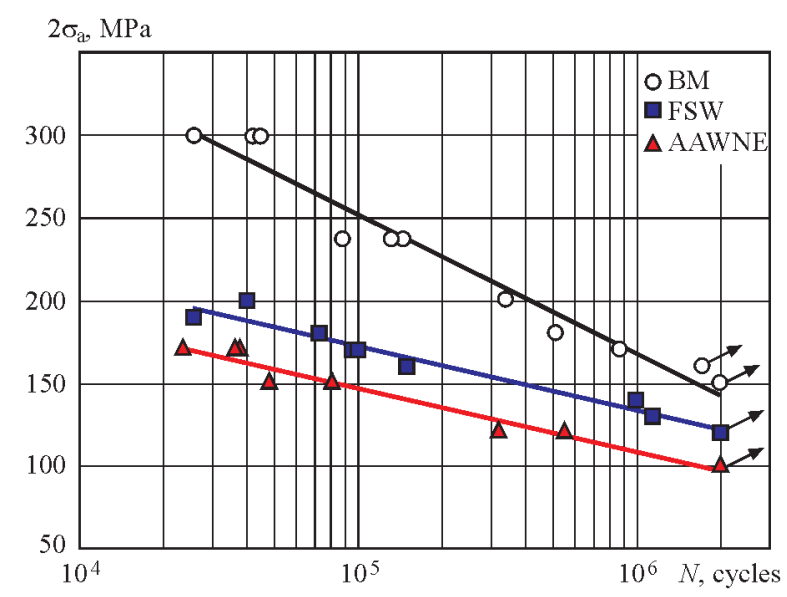

Figure 6. Curves of fatigue of base material and welded joints of aluminium alloy D16 of $2 \mathrm{~mm}$ thickness at the asymmetry of loading cycle $R_{\sigma}=0.1(\mathrm{BM}$ - base metal)

the whole region of fatigue lives of $10^{5}-2 \cdot 10^{6}$ cycles of load changes, and their margin of limited endurance on the base of $2 \cdot 10^{6}$ cycles amounts to $110 \mathrm{MPa}$, which is by $15 \%$ lower than that for the joints produced using FSW. The decrease in the values of fatigue life of welded joints produced using AAWNE is resulted mainly by decrease in hardness in weld metal, high concentration of acting stresses, caused by geometric parameters of weld and formation of residual welding stresses.

\section{Conclusions}

1. The use of FSW provides the formation of a permanent joint with a minimum level of stress concentration in the places of transition from weld to the base material and allows avoiding the formation of defects in the welds such as pores, macroinclusions of oxide film and hot cracks.

2. The physico-mechanical properties of joints produced using FSW are superior to those for the joints produced using AAWNE method.

1. Fridlyander, I.N. (2002) Aluminium alloys in aircrafts during 1970-2000 and 2001-2015. Tekhnologiya Lyogkikh Splavov, 4, 12-17.

2. Shvechkov, E.I., Zakharov, V.V., Rostova, T.D. (2003) To problem on selection of aluminium alloy grade for cover plates. Ibid., 1, 17-21.

3. Beletsky, V.M., Krivov, G.A. (2005) Aluminium alloys (composition, properties, technology, application). Ed. by I.N. Fridlyander. Kiev: KOMINTEKh.

4. Friction stir butt welding. Int. pat. application PCT/GB 92/02203. GB pat. appl. 9125978.8. Publ. 1991.

5. Pietras, A., Zadroga, L. (2003) Rozwoj metody zdrzewania tarciowego z mieszaniem materialu zgrzeiny (FSW) i mozliwosci jej zastosowania. Biul. Instytutu Spawalnictwa, 5, $148-154$.

6. Defalco, J. (2006) Friction stir welding vs fusion welding. Welding J., 3, 42-44.

7. Enomoto, M. (2003) Friction stir welding: Research and industrial applications. Welding International, 5, 341-345.

8. Sato, Y. (2002) Relationship between mechanical properties and microstructure in friction stir welded $\mathrm{Al}$ alloys. JJWS, 8 , 33-36.

9. Shibayanagi, T. (2007) Microstructural aspects in friction stir welding. J. of Japan Inst. of Light Metals, 9, 416-423.

10. Tool for friction stir welding of aluminium alloys. Pat. 54096 Ukraine. Int. Cl. K B23K 20/12. Fil. 30.04.2010. Publ. 25.10.2010.

11. Poklyatsky, A.G. (2001) Peculiarities of formation of macroinclusions of oxide film in weld metal of aluminium alloys (Review). The Paton Welding J., 3, 36-38. 


\title{
DETONATION COATINGS OF INTERMETALLIC POWDERS OF Fe-Al SYSTEM PRODUCED USING MECHANICAL ALLOYING
}

\author{
Yu.S. BORISOV ${ }^{1}$, A.L. BORISOVA ${ }^{1}$, E.A. ASTAKHOV ${ }^{1}$, T.V. TSYMBALISTA ${ }^{1}$, \\ A.N. BURLACHENKO ${ }^{1}$, M.A. VASILKOVSKAYA ${ }^{2}$ and A.I. KILDY ${ }^{1}$ \\ ${ }^{1}$ E.O. Paton Electric Welding Institute, NASU \\ 11 Kazimir Malevich Str., 03680, Kiev, Ukraine. E-mail: office@paton.kiev.ua \\ ${ }^{2}$ I.M. Frantsevich Institute of Problems of Materials Science \\ 3 Krzhyzhanivskogo Str., 03680, Kiev-142, Ukraine. E-mail:deprconf@ipms.kiev.ua
}

\begin{abstract}
Structure, composition and microhardness of detonation coatings were examined. They were received using $\mathrm{Fe}_{2} \mathrm{Al}$, $\mathrm{FeAl}$ and $\mathrm{Fe}_{2} \mathrm{Al}_{5}$ intermetallic powders, produced by mechanical alloying (MA) method, and mixtures of $\mathrm{Fe}$ and $\mathrm{Al}$ powders of equivalent compositions. An effect of «oxygen-combustible gas» relationship in the detonation mixture on oxidation process of material being sprayed was determined. The results of determination of phase composition of the coatings, deposited using different powders, show that in case of application of mechanical mixtures a layer mainly consists of the particles of $\mathrm{Fe}$ and $\mathrm{Al}$ initial mixture. A structure of coatings of MA Fe-Al-powders contains mixture of heating and oxidation products of these powders. Microhardness of the coatings varies from 4580 to $5710 \mathrm{MPa}$ depending on composition. 21 Ref., 3 Tables, 8 Figures.
\end{abstract}

Keywords : detonation spraying, iron aluminides, powders, mechanical alloying, composition of detonation mixture, coatings, phase composition, microhardness

Due to low strength properties of iron aluminides, in particular at room temperature $[1,2]$, a reasonable way of practical application of their high wear and corrosion resistance in the aggressive high-temperature gas media is development of protective coatings, including ones received by thermal spraying (TS) of Fe-Al based powders $[3,4]$. The main bulk of work in this area was carried out in the USA (Oak Ridge Nat. Lab., Idaho Nat. Lab) [5, 6] and Western Europe, namely France (University of Technology of Belfort-Montbéliard, Lille University) and Spain (Barcelona University) using plasma and HVOF spraying [7-11].

A range of investigations on examination of structure and properties of $\mathrm{Fe}-\mathrm{Al}$ coatings, produced by detonation spraying method, was carried out at Military University in Warsaw $[12,13]$. Fe-Al alloy powders, produced using $\mathrm{Fe}-28 \mathrm{Al}-2 \mathrm{Cr}$ and $\mathrm{Fe}-40 \mathrm{Al}$ $0.05 \mathrm{Zr}-0.01 \mathrm{~V}$ at. $\%$, melt spraying with inert gas, were applied as coating deposition materials at indicated operations fulfillment. The disadvantage of this method of $\mathrm{Fe}-\mathrm{Al}$ powder production is the difficulties related with melting of such alloys, initial components of which are characterized with large difference in melting temperatures and high exothermicity of alloy forming.

Simpler and less cost-based method of intermetallic powder production is application of MA process, which is realized under conditions of high-energy treatment of powder mixtures in the ball planetary-type or vibration mills $[14,15]$. This allows to significant extent remove limitations in compositions of developed intermetallics and provides the possibility of chemical and phase homogeneity of the synthesized powders. In MA all reactions are in solid phase, therefore, there is no problem related with appearance of fluctuations in a liquid phase concentration during remelting. Works [16-18] present practical application of powders of $\mathrm{Fe}-\mathrm{Al}$ intermetallics, produced by MA, for deposition of thermal coatings, including with nanosized structure.

Investigation of formation of $\mathrm{Fe}_{2} \mathrm{Al}, \mathrm{FeAl}$ and $\mathrm{Fe}-$ ${ }_{2} \mathrm{Al}_{5}$ intermetallic powders under conditions of $\mathrm{MA}$ process with examination of phase and structural transformations was carried out in work [19].

Aim of the present paper lied in examination of structure and phase composition of detonation coatings of $\mathrm{Fe}_{2} \mathrm{Al}, \mathrm{FeAl}$ and $\mathrm{Fe}_{2} \mathrm{Al}_{5}$ intermetallic powders, made by MA method, and of mechanical mixtures of $\mathrm{Fe}+\mathrm{Al}$ powders meant for production of intermetallics of the same composition in process of their spraying.

Sampling of powder particles, which were treated using a jet of detonation products in a water pool with analysis of their shape, size and structure, was carried out for evaluation of effect of parameters of

\footnotetext{
(c) Yu.S. BORISOV, A.L. BORISOVA, E.A. ASTAKHOV, T.V. TSYMBALISTA, A.N. BURLACHENKO, M.A. VASILKOVSKAYA and A.I. KILDY, 2017
} 
Table 1. Characteristic of powders based on $\mathrm{Fe}-\mathrm{Al}$ for TS

\begin{tabular}{|c|c|c|c|}
\hline Composition & Production method & $\mathrm{H}_{\mu}, \mathrm{MPa}$ & Phase composition \\
\hline $86 \mathrm{Fe}+14 \mathrm{Al}($ wt.\%) & Mechanical mixture & $1500 \pm 230(\mathrm{Fe}), 330 \pm 50(\mathrm{Al})$ & $\mathrm{Fe}, \mathrm{Al}$ \\
\hline $\mathrm{Fe}_{3} \mathrm{Al}$ & $\mathrm{MA}$ & $4060 \pm 1010$ & $\mathrm{Fe}_{3} \mathrm{Al} \mathrm{c} a=0,5787 \mathrm{~nm}$ \\
\hline $67 \mathrm{Fe}+33 \mathrm{Al}($ wt.\%) & Mechanical mixture & $1500 \pm 230(\mathrm{Fe}), 330 \pm 50(\mathrm{Al})$ & $\mathrm{Fe}, \mathrm{Al}$ \\
\hline $\mathrm{FeAl}$ & $\mathrm{MA}$ & $2530 \pm 740$ & $\mathrm{FeAl} \mathrm{c} a=0,2928 \mathrm{~nm}$ \\
\hline $45 \mathrm{Fe}+55 \mathrm{Al}($ wt.\%) & Mechanical mixture & $1500 \pm 230(\mathrm{Fe}), 330 \pm 50(\mathrm{Al})$ & $\mathrm{Fe}, \mathrm{Al}$ \\
\hline $\mathrm{Fe}_{2} \mathrm{Al}_{5}$ & $\mathrm{MA}$ & $2560 \pm 800$ & $\mathrm{Fe}_{2} \mathrm{Al}_{5}, \mathrm{additive} \mathrm{FeAl}$ \\
\hline
\end{tabular}

detonation spraying (DS) on conditions of heating of $\mathrm{Fe}-\mathrm{Al}$ powders and development of process of their oxidation. «Splat-test» was also used for analysis of shape and size of the particles, which were subjected to deformation at collision with the basis.

Effect of the following DS parameters, namely consumption of dilution gas (air) and relationship of oxygen to combustible gas ( $\beta$ ) consumption, were investigated at that. The latter have impact on temperature and velocity of the jet and detonation products. MA process was carried out by means of processing of
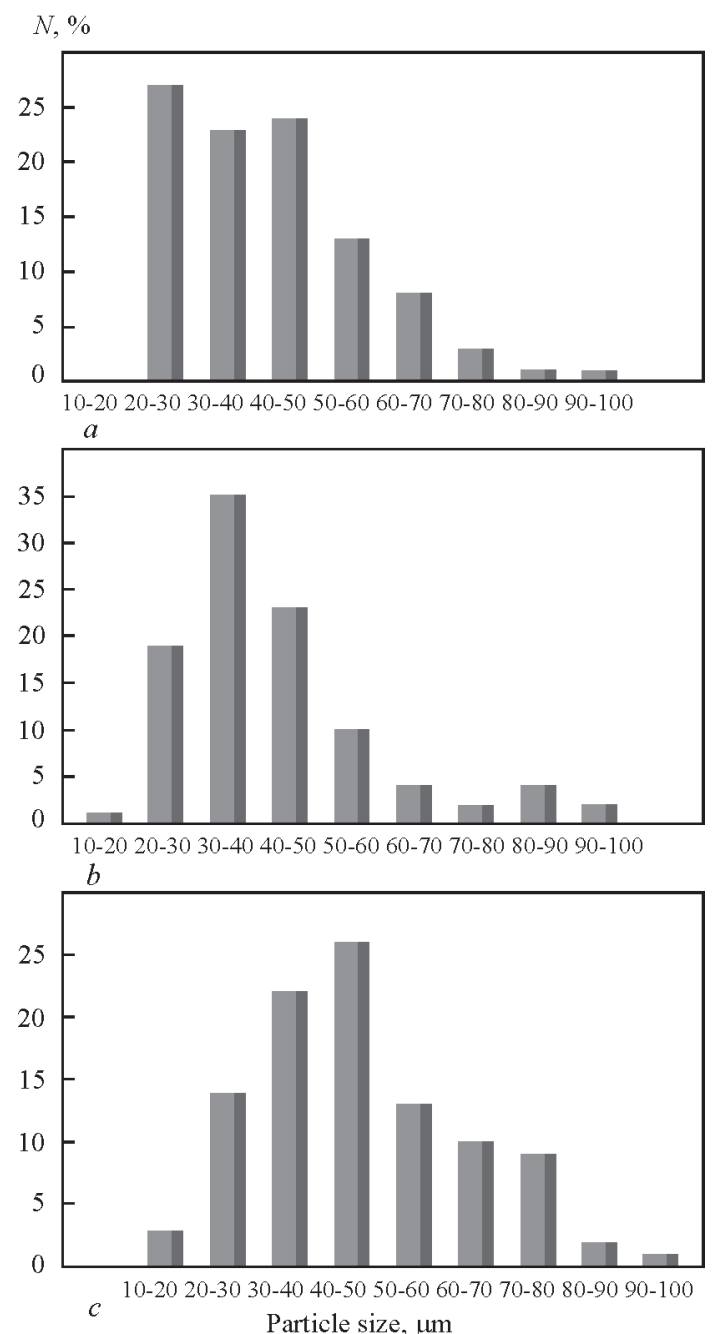

Figure 1. Block diagram of size distribution of particles of $\mathrm{Fe}_{3} \mathrm{Al}$ powder, sprayed in water at air consumption: $a-0.4 ; b-0.6$; $c-0.9 \mathrm{~m}^{3} / \mathrm{h}$ (consumption of propane-butane 0.45 , oxygen $1.55 \mathrm{~m}^{3} / \mathrm{h}$, spraying distance $110 \mathrm{~mm}$ )
$\mathrm{Fe}+\mathrm{Al}$ powder mixture in a planetary-type ball mill with crushing cylinder rate $1500 \mathrm{rpm}$, that of central axis was $1000 \mathrm{rpm}$ during 5 hours. The mechanical mixtures were made in a laboratory attritor by mixing in course of $5 \mathrm{~min}$. Powders of MA conglomerated products and mechanical mixtures of $\mathrm{Fe}+\mathrm{Al}$ powders with particles of 40-80 $\mu \mathrm{m}$ size were used for coating deposition. Table 1 shows the characteristics powders for TS.

Spraying of the coatings was carried out on «PERUN-S» unit. The following was used as the main operation parameters:

Combustible gas composition $\ldots . .$. propane-butane mixture $\left(60 \mathrm{C}_{3} \mathrm{H}_{8}+40 \mathrm{C}_{4} \mathrm{H}_{10}\right.$, vol. \%)

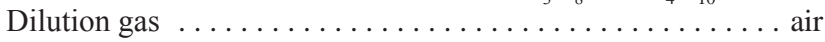

Transporting air, $\mathrm{m}^{3} / \mathrm{h} \ldots \ldots \ldots \ldots \ldots \ldots \ldots \ldots \ldots . . \ldots \ldots$ Shot frequency, min . . . . . . . . . . . . . . 400 Powder loading, mg/shot ................... 120 Depth of powder loading, $\mathrm{mm}$. . . . . . . . . . . . 250

Consumption of propane-butane made 0.45 and that of oxygen was $1.55 \mathrm{~m}^{3} / \mathrm{h}$. It was as a basic DS mode for investigation of effect of dilution air consumption on dispersion of powder being sprayed. Air consumption was varied in $0.4 ; 0.6$ and $0.9 \mathrm{~m}^{3} / \mathrm{h}$ range. Sampling of the particles in the water pool was carried out at $50 \mathrm{~mm}$ distance from unit shank edge. Figure 1 shows block diagrams of size distribution of treatment particle-products in a detonation jet of $\mathrm{Fe}$ ${ }_{3} \mathrm{Al}$ powder (Table 1). It can be concluded that breakdown of a part of conglomerated particles takes place in process of powder feeding in the unit shank and as a result of effect of detonation product jet. This provokes appearance of powder fraction of particle size less than $40 \mu \mathrm{m}$, portion of which makes $40-55 \%$ depending on dilution air consumption. The largest refining level, namely $55 \%$, was found in the case of its consumption equal $0.6 \mathrm{~m}^{3} / \mathrm{h}$ (Figure $1, b$ ).

Decrease of particle size, on the one hand, improves conditions of their heating, and, on the other hand, rises relative size of free surface that can effect a level of sprayed material oxidation.

Effect of $\beta$ index on oxidability and microhardness of coatings of $\mathrm{Fe}_{3} \mathrm{Al}$ powder was evaluated by measurement of oxygen consumption in 0.80 to $1.75 \mathrm{~m}^{3} / \mathrm{h}$ 
Table 2. Effect of relationship of consumption of oxygen and propane-butane content in detonation mixture $\beta$ on amount of oxides and microhardness of $\mathrm{Fe}-\mathrm{Al}$ coatings

\begin{tabular}{|c|c|c|c|c|}
\hline \multirow{2}{*}{$\begin{array}{c}\text { Oxygen } \\
\text { consumption, } \\
\mathrm{m}^{3} / \mathrm{h}\end{array}$} & $\begin{array}{c}\text { Relationship of oxidizer } \\
\text { and combustion gas }\end{array}$ & \multirow{2}{*}{$\mathrm{H}_{\mu}, \mathrm{MPa}$} & $\begin{array}{c}\text { Content of ox- } \\
\text { ides on XSPA } \\
\text { data (vol.\%) }\end{array}$ \\
\cline { 2 - 4 } & $\beta$ & $\beta$ & & $<5$ \\
\hline 0.8 & 1.6 & 2.04 & $3900 \pm 520$ & $\sim 5$ \\
\hline 1.05 & 2.10 & 2.54 & $4230 \pm 790$ & $\sim 10$ \\
\hline 1.3 & 2.6 & 3.04 & $4520 \pm 610$ & 40 \\
\hline 1.55 & 3.1 & 3.54 & $4620 \pm 680$ & $\sim 50$ \\
\hline 1.75 & 3.5 & 3.90 & $5767 \pm 1280$ & \\
\hline \multirow{5}{*}{$\begin{array}{l}\text { Note. Consumption of propane-butane } 0.5 ; \text { dilution air } 0.65 ; \text { trans- } \\
\text { porting air } 0.4 \mathrm{~m}^{3} / \mathrm{h} \text {; spraying distance } 110 \mathrm{~mm} .\end{array}$} \\
\hline
\end{tabular}

limits at constant consumption of propane-butane $0.5 \mathrm{~m}^{3} / \mathrm{h}$, dilution air $0.65 \mathrm{~m}^{3} / \mathrm{h}$ and transporting air $0.4 \mathrm{~m}^{3} / \mathrm{h}$. This corresponds to $\beta$ variation in $1.6-3.5$ range, and taking into account air oxygen $\beta$ ' (relationship of total oxygen (oxygen + air) to combustible gas) made 2.04-3.90. Table 2 shows the experiment results.

Content of oxides in the coating was evaluated on the results of metallographic and X-ray structural phase analysis (XSPA). Figure 2 as an example shows the fragments of $\mathrm{X}$-ray images of detonation coatings, received at different relationship of oxygen and propane-butane in the detonation mixture. On them the areas with numbers 1 and 2 refer to metallic constituent of the coating (intermetallic $\mathrm{Fe}_{3} \mathrm{Al}$ and solid solution $\mathrm{Al}$ in $\mathrm{Fe}$ ) and areas with numbers 3, 4 and 5 are the reflections from oxide phases $\left(\mathrm{Fe}_{3} \mathrm{O}_{4}, \mathrm{FeAl}_{2} \mathrm{O}_{4}\right)$. Relative content of metallic and oxide phases in the coating (Table 2) was evaluated using the relationship of their X-ray reflection intensity.

Rapid increase of oxide content at transfer of oxygen consumption from 1.3 to 1.55 and $\beta$ value from 3.0 to 3.5 can be explained by change of mode of combustible gas burning from incomplete (with formation of $\mathrm{CO}$ and $\left.\mathrm{H}_{2} \mathrm{O}\right)$ to complete one $\left(\mathrm{CO}_{2}\right.$ and $\mathrm{H}_{2} \mathrm{O}$ ). This results in rise of temperature and velocity of detonation products jet with overheating of the powder particles $[20,21]$.

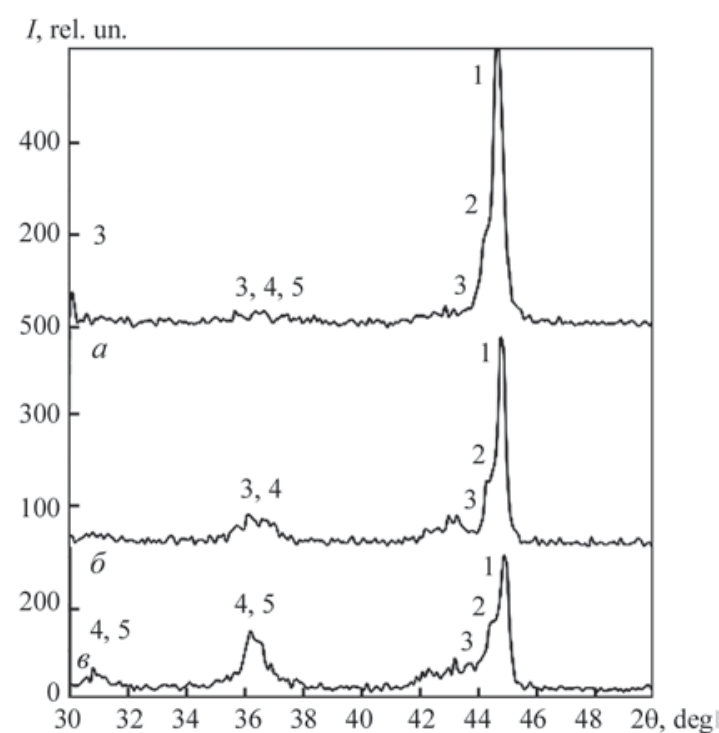

Figure 2. Fragments of X-ray image of detonation coatings, received at different relationship of oxygen and propane-butane in detonation mixture $\beta: a-2.1 ; b-2.6 ; c-3.1$ (descriptions $1-5$ see in the text)

This phenomenon was found in study of dependence of splat shape (deformed particles of sprayed powder) on spraying conditions, in particular, relationship of oxygen and combustion gas consumption. Figure 3 represents the splats, received at $\beta=2.2 ; 4.1$ and 4.6. In the second and third cases the splats were formed from the particles of overheated melt, having low ductility and including oxide phase.

A mode for spraying of detonation coatings of mechanical mixtures and MA powders of $\mathrm{Fe}-\mathrm{Al}$ system was selected based on the results of carried experiments on index of oxidation level of the sprayed material particles. This was used for producing coating samples and further examination of their structure, phase composition and microhardness:

Mixture consumption $60 \% \mathrm{C}_{3} \mathrm{H}_{8}+40 \% \mathrm{C}_{4} \mathrm{H}_{10}, \mathrm{~m}^{3} / \mathrm{h} \ldots \ldots .0 .5$

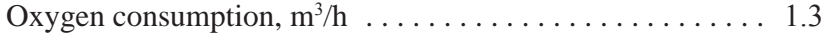
Dilution air consumption, $\mathrm{m}^{3} / \mathrm{h} \ldots \ldots \ldots \ldots \ldots \ldots \ldots$ Spraying distance, $\mathrm{mm} \ldots \ldots \ldots \ldots \ldots \ldots \ldots \ldots \ldots \ldots$

The following was determined as a result of examination of structure of the detonation coatings of

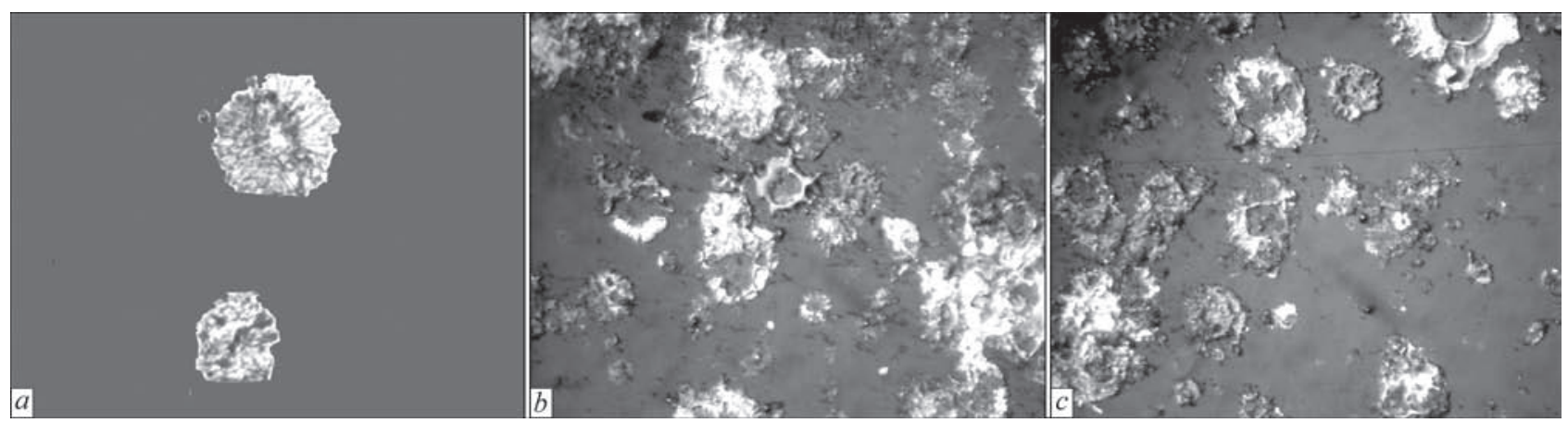

Figure 3. Splats of detonation coatings of $\mathrm{Fe}_{3} \mathrm{Al}$ at different relationship of «oxygen-propane-butane» consumption $(\times 500): \beta=2.2$ (a), 4.1 (b), 4.6 (c) 

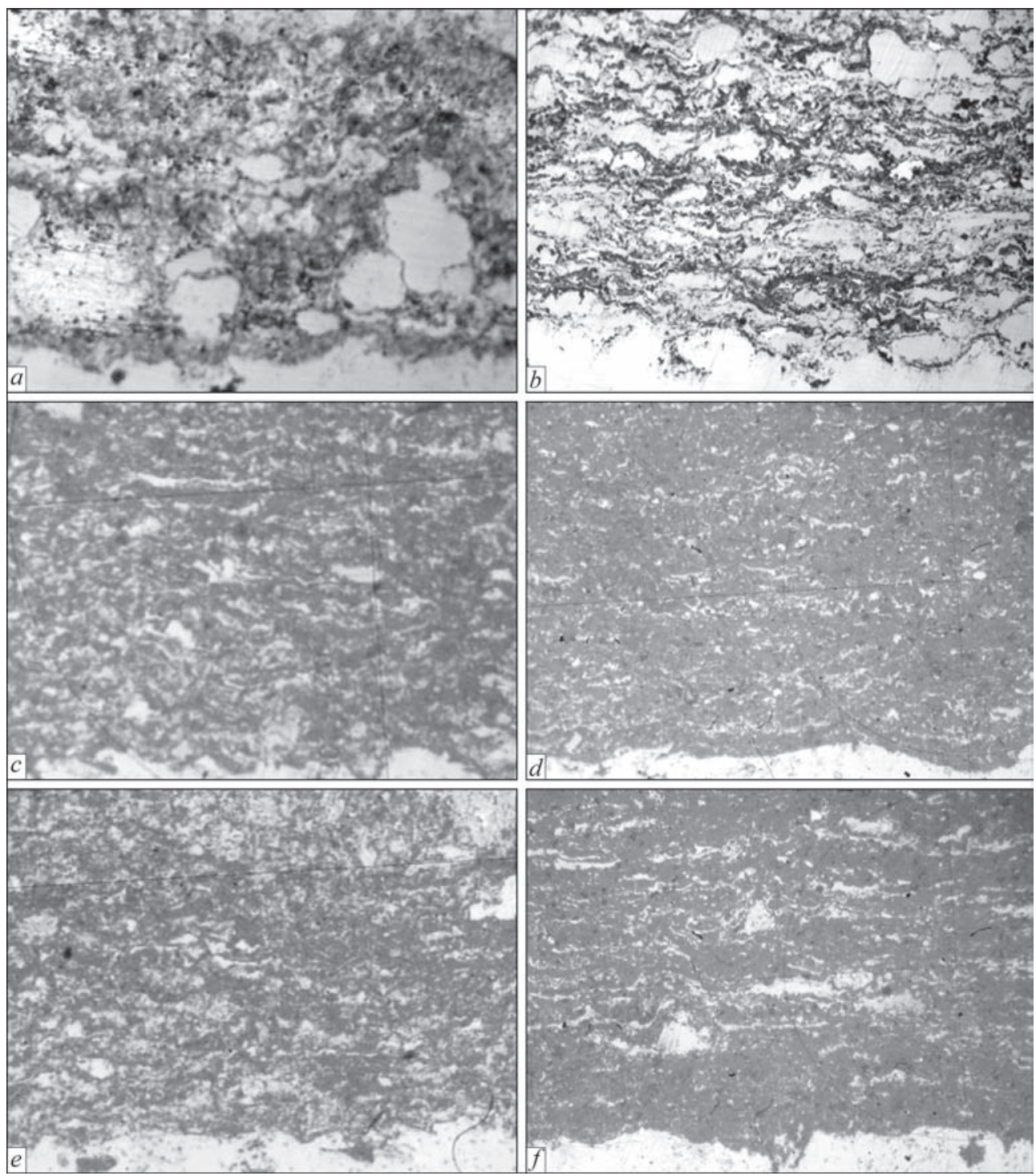

Figure 4. Microstructure $(\times 400)$ of detonation coatings: of mechanical mixture, wt. $\%: a-86 \mathrm{Fe}+14 \mathrm{Al} ; c-67 \mathrm{Fe}+33 \mathrm{Al} ; e-45 \mathrm{Fe}+$ $55 \mathrm{Al}$; of intermetallic powder: $b-\mathrm{Fe}_{3} \mathrm{Al} ; d-\mathrm{FeAl} ; f-\mathrm{Fe}_{2} \mathrm{Al}_{5}$

$\mathrm{Fe}-\mathrm{Al}$ system intermetallic powders of three compositions as well as $\mathrm{Fe}+\mathrm{Al}$ powder mixtures, meant for obtaining the same compositions in spraying.

Coarse grain dense structure is formed in process of spraying of mechanical mixtures, at that defects and delaminations at the boundary with basis are absent (Figure 4, $a, c, e$ ). Structure of coatings from MA-powders is fine, lamellar with alteration of light (metallic) and dark (oxide) lamellas (Figure 4, $b, d, f$ ).

According to XSPA data it was determined, that a level of interfacial interaction of the components does not provide realization of synthesis process of corre-
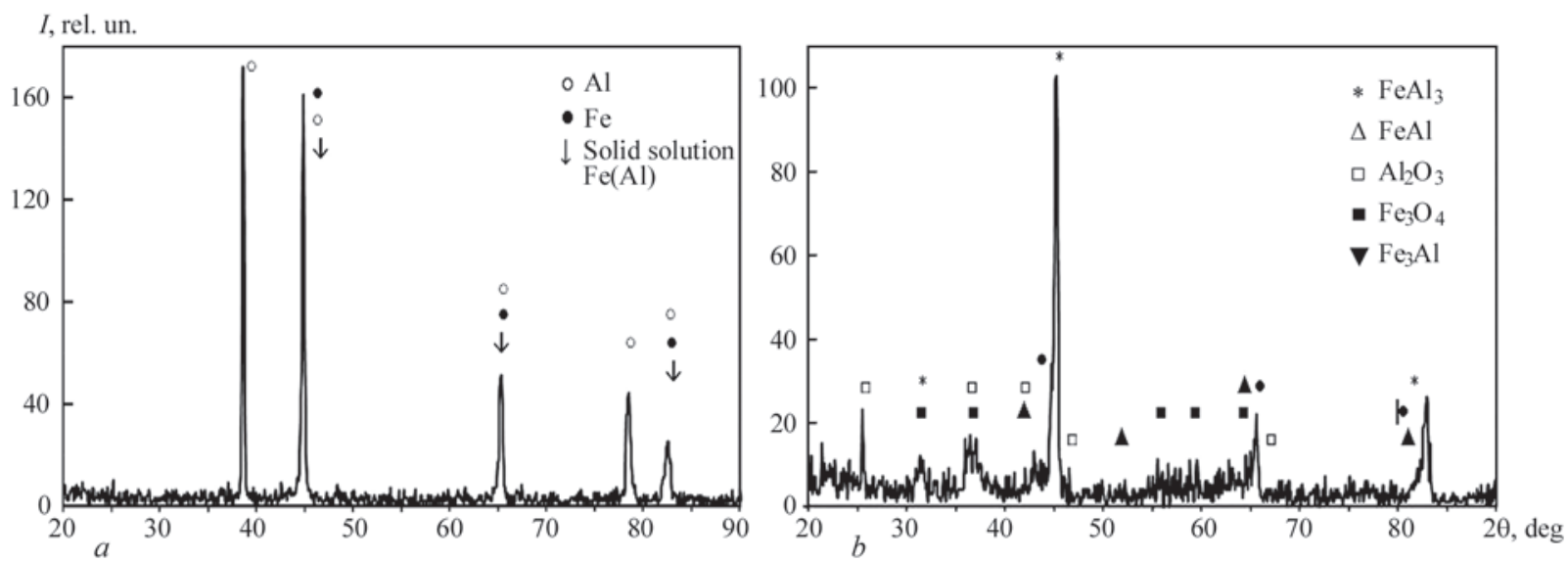

Figure 5. X-ray images of detonation coatings: $a$ - of mechanical mixture $86 \mathrm{Fe}+14 \mathrm{Al}($ wt. $\%) ; b-$ of $\mathrm{MA}-\mathrm{powder} \mathrm{Fe}{ }_{3} \mathrm{Al}$ 
Table 3. Characteristics of detonation coatings of $\mathrm{Fe}-\mathrm{Al}$ powders, produced by mechanical mixing and MA method

\begin{tabular}{|c|c|c|c|c|}
\hline \multicolumn{2}{|r|}{ Powder } & \multicolumn{3}{|r|}{ Coating } \\
\hline Composition & Method for production & $\mathrm{H}_{\mu}, \mathrm{MPa}$ & XSPA & Microstructure characteristics \\
\hline $\begin{array}{l}86 \mathrm{Fe}+14 \mathrm{Al} \\
\quad(\text { wt. } \%)\end{array}$ & Mechanical mixture & $\begin{array}{c}1490 \pm 240 \\
(650,1250)\end{array}$ & $\begin{array}{l}\text { Solid solution Fe(Al), } \\
\text { Al, Fe }\end{array}$ & $\begin{array}{l}\text { Coating is dense, coarse grain, formed of a bit fused unde- } \\
\text { formed particles of initial powders and solid solution }\end{array}$ \\
\hline $\mathrm{Fe}_{3} \mathrm{Al}$ & MA & $\begin{array}{l}4580 \pm 860 \\
(4500)\end{array}$ & $\begin{array}{l}\mathrm{Fe}_{3} \mathrm{Al}, \mathrm{FeAl}, \mathrm{FeAl}_{3} \\
\mathrm{Al}_{2} \mathrm{O}_{3}, \mathrm{Fe}_{3} \mathrm{O}_{4}, \mathrm{FeAl}_{2} \mathrm{O}_{4}\end{array}$ & $\begin{array}{l}\text { Structure is lamellar with alternating interlayers of inter- } \\
\text { metallic and oxide lamellas }\end{array}$ \\
\hline $\begin{array}{l}\text { 67Fe }+33 \mathrm{Al} \\
\quad(\text { wt. } \%)\end{array}$ & Mechanical mixture & $\begin{array}{c}3640 \pm 1210 \\
(2350,5050)\end{array}$ & $\begin{array}{c}\mathrm{Fe}, \mathrm{Al}, \mathrm{FeAl}, \mathrm{Fe}_{3} \mathrm{O}_{4}, \\
\mathrm{FeAl}_{2} \mathrm{O}_{4}\end{array}$ & $\begin{array}{l}\text { Coating is dense, structure is lamellar, with alternation of } \\
\text { oxide metallic lamellas, unmelted metallic particles are } \\
\text { found }\end{array}$ \\
\hline $\mathrm{FeAl}$ & MA & $\begin{array}{l}5575 \pm 1020 \\
(4750)\end{array}$ & $\begin{array}{l}\mathrm{Fe}, \mathrm{Fe}(\mathrm{Al}), \mathrm{FeAl}, \\
\mathrm{Fe}_{3} \mathrm{O}_{4}, \mathrm{FeAl}_{2} \mathrm{O}_{4}\end{array}$ & $\begin{array}{c}\text { Structure of coating is fine lamellar, without cracks and } \\
\text { delaminations from basis }\end{array}$ \\
\hline $\begin{array}{c}45 \mathrm{Fe}+55 \mathrm{Al} \\
\quad(\text { wt. } \%)\end{array}$ & Mechanical mixture & $\begin{array}{c}2000 \pm 700 \\
(1100,2300)\end{array}$ & $\begin{array}{l}\text { Al, } \mathrm{Fe}, \mathrm{FeAl}, \mathrm{Fe}(\mathrm{Al}) \\
\mathrm{Al}_{2} \mathrm{O}_{3}, \mathrm{Fe}_{3} \mathrm{O}_{4}\end{array}$ & $\begin{array}{c}\text { Structure of coating is coarse grain with iron particle } \\
\text { inclusions }\end{array}$ \\
\hline $\mathrm{Fe}_{2} \mathrm{Al}_{5}$ & MA & $\begin{array}{l}5710 \pm 1070 \\
\quad(6150)\end{array}$ & $\begin{array}{c}\mathrm{Fe}, \mathrm{FeAl}, \mathrm{Fe}_{2} \mathrm{Al}_{5} \\
\mathrm{Al}_{2} \mathrm{O}_{3}, \mathrm{Fe}_{3} \mathrm{O}_{4}, \mathrm{FeAl}_{2} \mathrm{O}_{4}\end{array}$ & $\begin{array}{l}\text { Coating is dense with fine lamellar structure, without } \\
\text { cracks and delaminations from basis }\end{array}$ \\
\hline
\end{tabular}

sponding to calculated intermetallic phases under conditions of detonation spraying of mechanical mixtures of $\mathrm{Fe}$ and $\mathrm{Al}$ powders, initial $\mathrm{Fe}$ and $\mathrm{Al}$ components are preserved in the coatings. Intermetallic phases are found in small quantity together with aluminum and iron oxides (Figure 5, a, 6, a, 7, a, Table 3).

Phase composition of coatings of MA powders also does not have complete correspondence with compo-

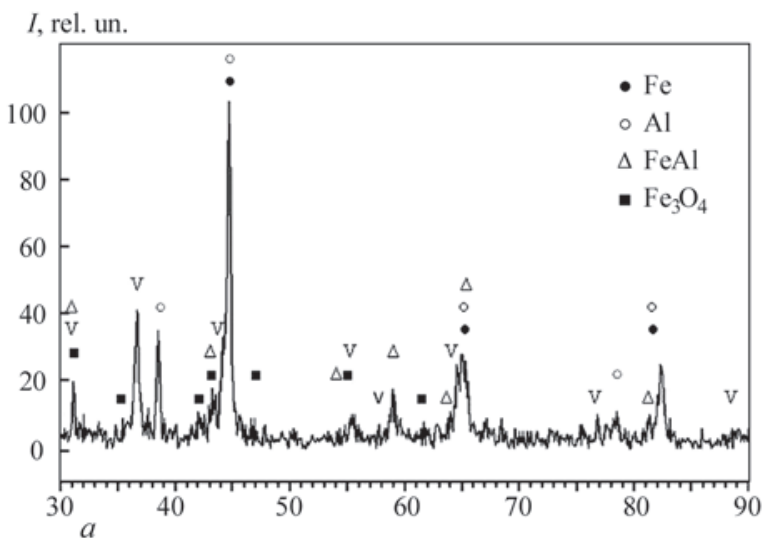

sition of the initial powders. Intermetallic powders are found in the coatings of $\mathrm{Fe}_{3} \mathrm{Al}\left(\mathrm{Fe}_{3} \mathrm{Al}, \mathrm{FeAl}, \mathrm{FeAl}_{3}\right)$, $\mathrm{FeAl}(\mathrm{FeAl}), \mathrm{Fe}_{2} \mathrm{Al}_{5}\left(\mathrm{FeAl}, \mathrm{Fe}_{2} \mathrm{Al}_{5}\right)$ powders. In the case of $\mathrm{FeAl}$ and $\mathrm{Fe}_{2} \mathrm{Al}_{5}$ powders these are mainly solid solutions of aluminum in iron. Iron, aluminum oxides and complex oxides (Figure $5, b, 6, b, 7, b$, Table 3) were formed as a result of interaction with environment.

Figure 6. X-ray images of detonation coatings: $a$ - of mechanical mixture 67Fe + 33Al (wt.\%); $b$ - of MA-powder FeAl
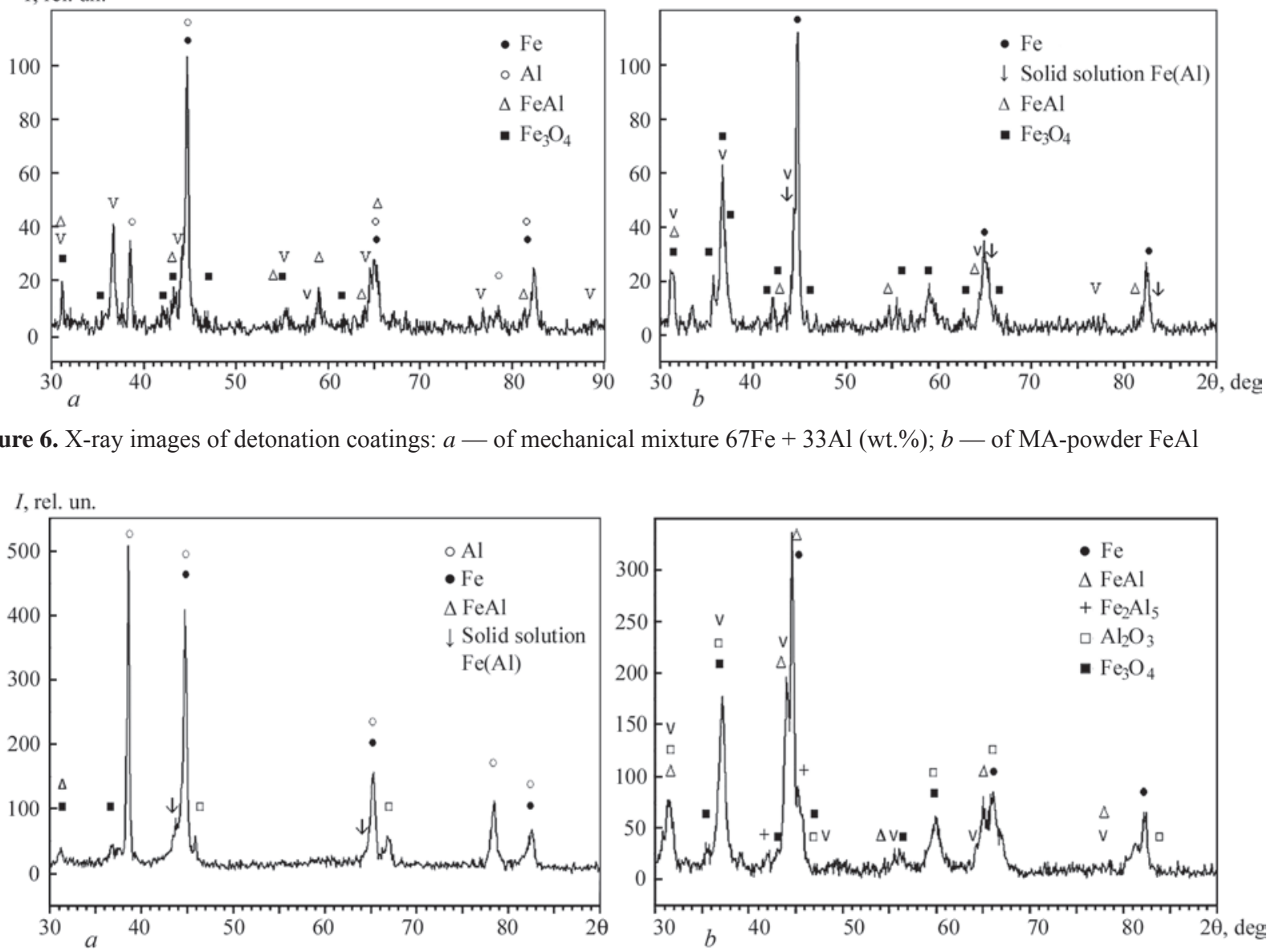

Figure 7. X-ray images of detonation coatings: $a$ - of mechanical mixture $45 \mathrm{Fe}+55 \mathrm{Al}($ wt. $\%) ; b-$ of $\mathrm{MA}_{-}$powder $\mathrm{Fe}_{2} \mathrm{Al}_{5}$ 

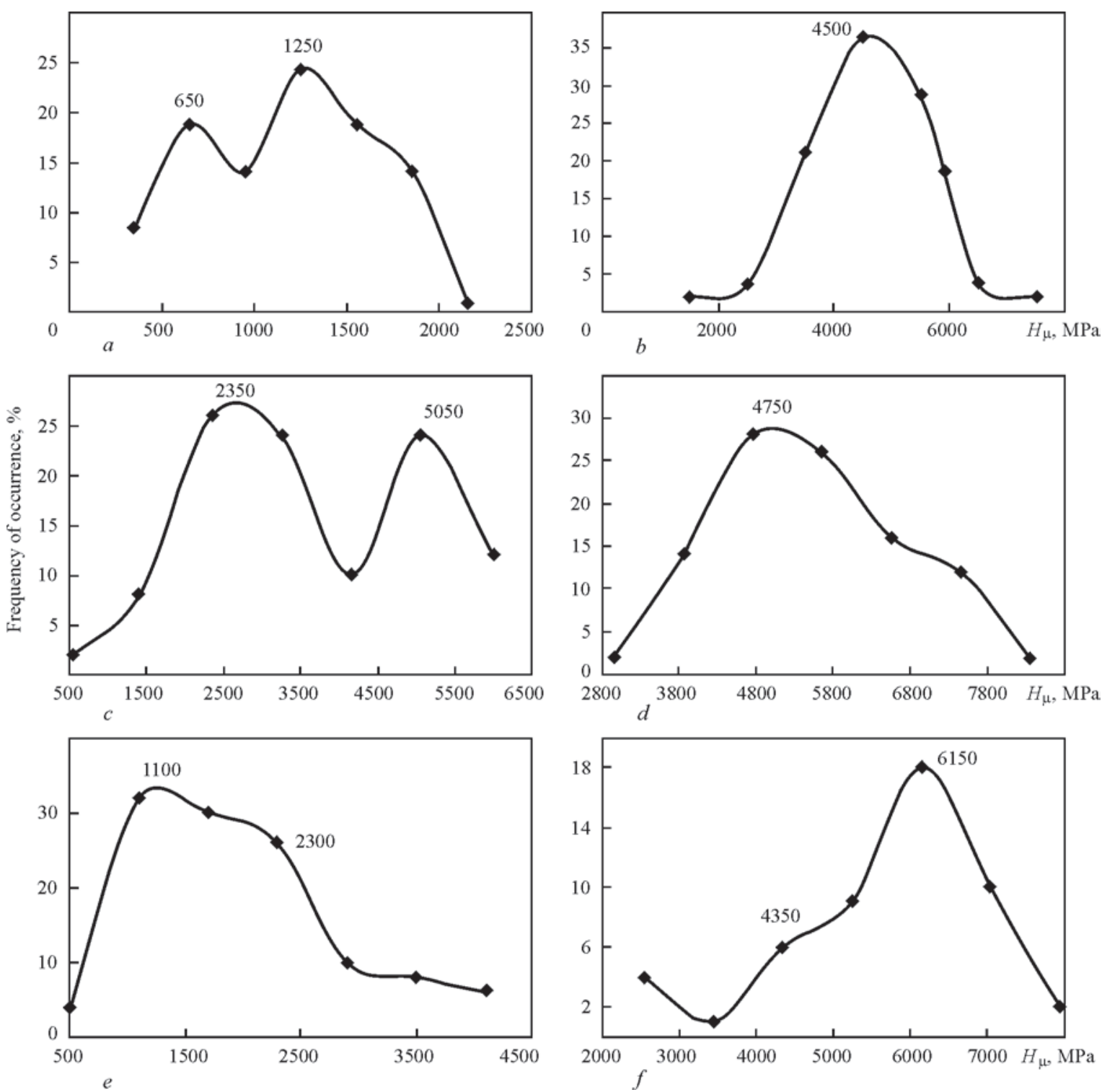

Figure 8. Variation curves of microhardness of detonation coatings, produced from mechanical mixtures $\mathrm{Fe}+\mathrm{Al}(a, c, e)$ and $\mathrm{MA}(b$, $d$, f) powders: $a, b-\mathrm{Fe}_{3} \mathrm{Al} ; c, d-\mathrm{FeAl} ; e, f-\mathrm{Fe}_{2} \mathrm{Al}_{5}$

The microhardness variation curves were plotted (Figure 8) based on the results of microhardness measurement in detonation coatings of $\mathrm{Fe}+\mathrm{Al}$ mechanical mixtures and $\mathrm{Fe}_{3} \mathrm{Al}, \mathrm{FeAl}, \mathrm{Fe}_{2} \mathrm{Al}_{5}$ MA powders. Nature of the variation curves indicates homogeneous distribution of microhardness for coatings of powder with $\mathrm{Fe}_{3} \mathrm{Al}$ initial composition (Figure 8, b). At that, average (4580 \pm 860$)$ as well as the most probable (4500 MPa) values of microhardness exceed the results for initial powder $(4060 \pm 1010 \mathrm{MPa}$, Table 1). More significant increase of coating microhardness in comparison with initial powder is observed for two other compositions ( $\mathrm{FeAl}$ and $\mathrm{Fe}_{2} \mathrm{Al}_{5}$ intermetallics). It is obviously related with presence of large amount of oxides in sprayed coatings.

\section{Conclusions}

1. Detonation $\mathrm{Fe}-\mathrm{Al}$ coatings are formed using intermetallic $\mathrm{Fe}_{3} \mathrm{Al}, \mathrm{FeAl}$ and $\mathrm{Fe}_{2} \mathrm{Al}_{5}$ powders obtained us-

ing MA method and mixture of $\mathrm{Fe}$ and $\mathrm{Al}$ powders with composition corresponding to these intermetallics.

2. It is determined that process of detonation spraying provokes variation of initial grain-size composition of $\mathrm{Fe}-\mathrm{Al}$ powder with $40-80 \mu \mathrm{m}$ conglomerated structure resulting in appearance of 40-55 wt.\% fraction of 10-40 $\mu \mathrm{m}$ size.

3. Analysis of development of oxidation process in sprayed material of $\mathrm{Fe}-\mathrm{Al}$ coating, carried with the help of XSPA and splat-test, showed dependence of content of oxide phase on relationship of oxygen to propane-butane amount in detonation mixture $\beta$. Rapid increase of oxide content from approximately 5 to $30-40 \mathrm{wt} . \%$ takes place at rise of $\beta$ more than 3.5.

4. It is determined that conditions of detonation spraying using mechanical mixtures of $\mathrm{Fe}+\mathrm{Al}$ powders do not allow ensuring active interfacial interaction between the components and forming intermetallic phases. Structure of such coatings mainly consists 
of separate particles of components. When using MA $\mathrm{Fe}-\mathrm{Al}$ powders, dense detonation coatings with cermet structure, consisting of metallic phases mixture (intermetallics, solid solutions, metals) and oxidation products, are formed.

5. Structure and phase composition of the detonation coatings of $\mathrm{MA} \mathrm{Fe}-\mathrm{Al}$ intermetallics powders indicate significant development of process of their oxidation, that results in partial loss of the intermetallic structure with formation of $\mathrm{Fe}_{3} \mathrm{O}_{4}$, $\mathrm{Al}_{2} \mathrm{O}_{4}$ and $\mathrm{FeAl}_{2} \mathrm{O}_{4}$ phases. Coatings' microhardness depends on composition of initial powder and rises at transfer from $\mathrm{Fe}_{3} \mathrm{Al}$ to $\mathrm{Fe}_{2} \mathrm{Al}_{5}$, from 4580 to $5710 \mathrm{MPa}$.

1. Deevi, S.C., Sikka, V.K. (1996) Nickel and iron aluminides: an overview on properties, processing and applications. Intermetallics, 4, 357-375.

2. Stoloff, N.S. (1998) Iron aluminides: present status and future prospects. Mater. Sci. \& Engineering, 258 (Issue 1/2), 1-14.

3. Cinca, N., Guilemany, J.M. (2012) Thermal spraying of transition metal aluminides: An overview. Intermetallics, 24, 6-72.

4. Cinca, N., Guilemany, J.M. (2013) An overview of intermetallics research and application: Status of thermal spray coatings. J. of Materials Research and Technology, 2(1), 1-11.

5. Totemeier, T.C., Swank, W.D. (2002) Microstructure and stresses in HVOF sprayed iron aluminide coatings. J. Thermal Spray Techn., 11(3), 2-9.

6. Wright, R.N., Totemeier, T.C. (2002) Microstructure and properties of iron aluminide coatings. Idaho National Engineering and Environmental Laboratory.

7. Gang Ji et al. (2002) Surface engineering by thermal spraying nanocrystalline coatings: The case of iron aluminide. Materiaux, 1-3.

8. Gang Ji, Elkedim, O., Grosdidier, T. (2005) Deposition and corrosion resistance of HVOF sprayed nanocrystalline iron aluminide coatings. Surface \& Coatings Technology, 190, 406-416.

9. Guilemany, J.M. et al. (2006) Studies of Fe-40Al coatings obtained by high velocity oxy-fuel. Ibid., 201, 2072-2079.

10. Guilemany, J.M., Cinca, N. (2007) High-temperature oxidation of $\mathrm{Fe}-40 \mathrm{Al}$ coatings obtained by HVOF thermal spray. Intermetallics, 15, 1384-1394.

11. Guilemany, J.M. et al. (2009) $\mathrm{FeAl}$ and $\mathrm{NbAl}_{3}$ intermetallic-HVOF coatings: Structure and properties. J. Thermal Spray Techn., 18, Issue 4, 536-545.

12. Senderowski, C., Bojar, Z. (2008) Gas detonation spray forming of $\mathrm{Fe}-\mathrm{Al}$ coatings in the presence of interlayer. Surface \& Coatings Technology, 202, 3538-3548.

13. Senderowski, C. et al. (2010) Microstructure characterization of D-gun sprayed Fe-Al intermetallic coatings. Intermetallics, 18(7), 1405-1409.

14. Suryanarayana, C. (2001) Mechanical alloying and milling. Progress in Mater. Sci., 46, 1-184.

15. Arunachalam, V.S. (1990) Mechanical alloying. In: Actual problems of powder metallurgy. Moscow: Metallurgiya.

16. Gang Ji, Grosdidier, T., Morniroli, J.P. (2007) Microstructure of a high-velocity oxy-fuel thermal-sprayed nanostructured coating obtained from milled powder. Metallurg. and Mater. Transact. A, 38A, 2455-2463.

17. Kumar, S. et al. (2006) Characterization and comparison between ball milled and plasma processed iron-aluminium thermal spray coatings. Surface \& Coatings Technology, 201, 1267-1275.

18. Grosdidier, T., Tidu, A., Liao, H.L. (2001) Nanocrystalline $\mathrm{Fe}-40 \mathrm{Al}$ coating processed by thermal spraying of milled powder. Scripta Materialia, 44, 387-393.

19. Borisova, A.L. et al. (2015) Phase and structural transformations in forming of intermetallics powders of $\mathrm{Fe}-\mathrm{Al}$ system by MA method. Poroshk. Metallurgiya, 7/8, 135-143.

20. Shorshorov, M.Kh., Kharlamov, Yu.A. (1978) Physical-chemical principles of gas detonation spraying of coatings. Moscow: Nauka.

21. Zverev, A.I., Sharivker, S.Yu., Astakhov, E.A. (1979) Detonation spraying of coatings. Leningrad: Sudostroenie. 


\title{
COMPARATIVE EVALUATION OF METHODS OF ARC AND HYBRID PLASMA-ARC WELDING OF ALUMINUM ALLOY 1561 USING CONSUMABLE ELECTRODE
}

\author{
V.N. KORZHIK ${ }^{1,2}$, N.A. PASHCHIN ${ }^{2}$, O.L. MIKHODUJ' ${ }^{2}$, A.A. GRINYUK ${ }^{2}$, \\ A.A. BABICH ${ }^{1,2}$ and V.Yu. KHASKIN ${ }^{1,2}$ \\ ${ }^{1}$ Guangdong Welding Institute (E.O. Paton Chinese-Ukrainian Institute of Welding), Guangzhou, PRC \\ ${ }^{2}$ E.O. Paton Electric Welding Institute, NASU \\ 11 Kazimir Malevich Str., 03680, Kiev, Ukraine. E-mail: office@paton.kiev.ua
}

\begin{abstract}
In addition to the traditional pulsed arc welding using consumable electrode at reverse polarity, it is advisable to apply hybrid plasma-arc welding using consumable electrode to increase the service life and reliability of welded structures of aluminum alloys. The works on determination of technological modes of hybrid plasma-arc welding of aluminum alloy 1561 of $5 \mathrm{~mm}$ thickness and the comparison of the processes of traditional consumable electrode arc welding and hybrid plasma-arc welding, taking into account the residual stress-strain state of the resulting butt welded joints, as well as evaluation of the prospects for replacement of traditional arc welding by hybrid one were carried out. During determination of technological modes of hybrid plasma-arc and pulsed arc welding of the aluminum alloy 1561, it was found that at the same speeds the both methods provide approximately equal energy input. At the same time the mastered technology of hybrid welding provided the reduction in the wire diameter from 1.6 to $1.2 \mathrm{~mm}$, which resulted in $25-50 \%$ smaller width of the weld as compared to arc welding. Reduction in the area of the weld facial part as compared to the root part area in the hybrid welding method led to approximately 3 times decrease in the level of residual distortion of welded plates, and 15-20\% decrease in residual stresses along the weld line. 6 Ref., 1 Table, 10 Figures.
\end{abstract}

Keywords : aluminum alloy, consumable electrode arc welding, hybrid plasma-arc welding, modes, speckle-interferometry, stress-strain state

Thin-sheet welded structures of alloys on aluminum base find the more and more spreading in modern industry [1]. Such structures are widely applied in aerospace engineering, shipbuilding, automotive industry, railway transport, etc. [2]. In manufacture of structures and products of aluminum alloys, different welding technologies are used to provide the quality formation of permanent joints, for example, pulsed arc welding using consumable electrode at the reverse polarity (further - arc welding). However, in a number of cases (for example, to increase the service life and reliability of welded structures) it is advisable to use more advanced technologies. They include the hybrid plasma-arc welding using consumable electrode with an axial electrode wire feed through the tube electrode of the plasmatron (further — hybrid plasma-arc welding) [3].

The aim of this work is to determine technological modes of hybrid plasma-arc welding of aluminum alloy 1561 of thickness $\delta=5 \mathrm{~mm}$, to compare the traditional consumable electrode arc welding processes and hybrid plasma-arc welding taking into account the residual stress-strain state of the produced butt joints, as well as to evaluate prospects of replacing traditional arc welding by the hybrid one.

The mastering of technological methods of hybrid plasma-arc and arc welding was performed on the plates of aluminum alloy 1561 of $320 \times 102.5 \mathrm{~mm}$ size. At the same time, the special complex of equipment was applied designed at the E.O. Paton Electric Welding Institute [4]: inverter welding power source for argon-arc welding using non-consumable electrode TIGAC-DCEVO 450/ TRobot, plasma module FPM, EVOSpeedStar 520 TSRobot, units of autonomous cooling, plasmatron for machine hybrid plasma-arc welding using consumable electrode with an axial wire feed, multiposition laboratory manipulator based on welding column and rotator, common system for the control of hybrid welding complex. Welding was carried out according to the technological scheme shown in Figure 1.

In the course of experiments the longitudinal butt welds were produced on the long side of specimens (Figure 2). One of the main criteria for selection of modes for welding specimens of alloy 1561 was the quality formation of welds the accompanying minimization of pore formation. The used welding modes (welding speed $v_{\mathrm{w}}$, welding current $I_{\mathrm{a}}$, arc voltage $U_{\mathrm{a}}$, diameter of welding wire $d_{w}$ ) and geometric characteristics of plates $\left(f_{1}-f_{3}\right.$ are the longitudinal deflections, $\Delta_{1}, \Delta_{2}$ are transverse deflections at the beginning and at the end of joint, respectively) are presented in Table. The appearance of macrosections of welded joints is shown in Figure 3. The mastered and tested hybrid welding technology provided the reduction in the wire 

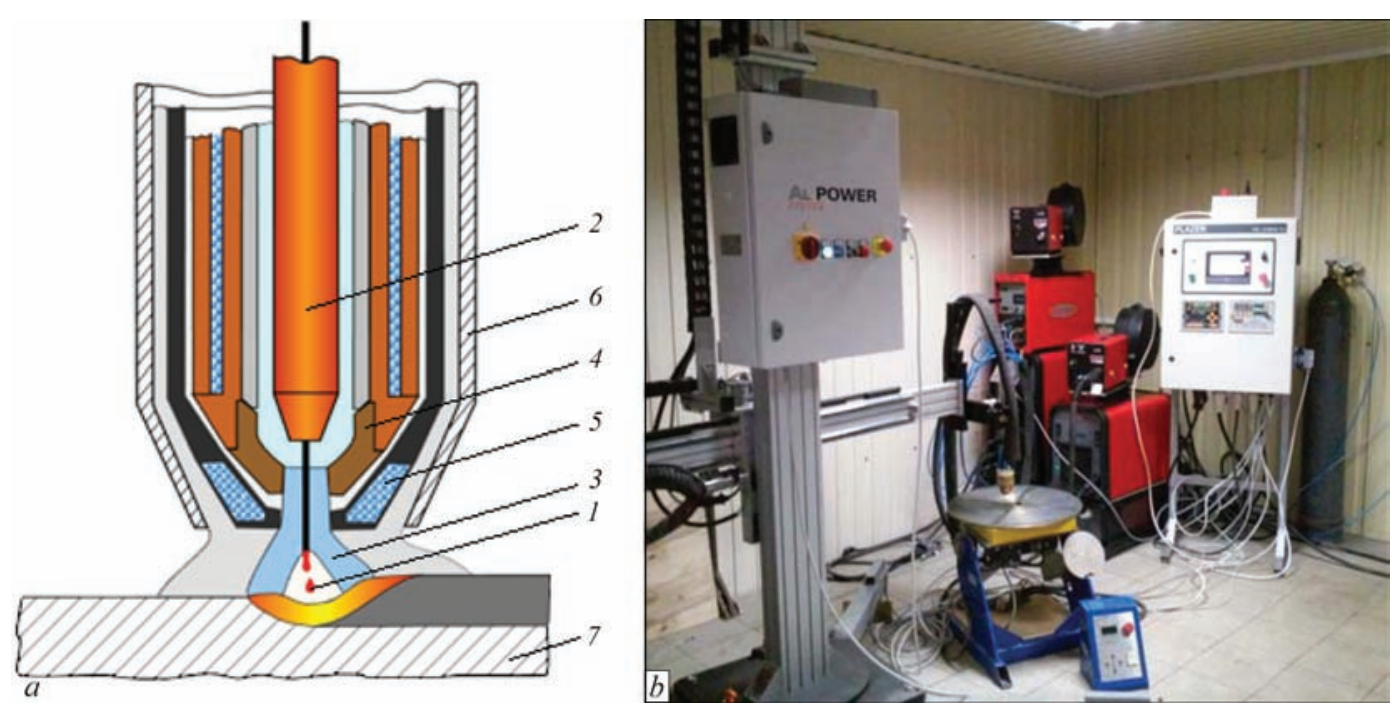

Figure 1. Technological scheme $(a)$ and complex of equipment $(b)$ for the consumable electrode hybrid plasma-arc welding: 1 - arc of consumable electrode; 2 - feeding tip of consumable electrode; 3 - constricted direct arc; 4 - tubular electrode of plasmatron (anode); 5 - plasma-forming nozzle; 6 - protective nozzle; 7 - specimen being welded

diameter from 1.6 to $1.2 \mathrm{~mm}$ at the same thickness of welded plates and the same values of energy input (Table). As far as is shown in [5], the volume of deposited metal is directly proportional to the diameter of electrode wire, thus resulting in a decreased width of the weld at equal welding speeds.

At the selected modes the energy inputs of the compared welding processes are approximately the same and are of the order of $600 \mathrm{~J} / \mathrm{mm}$. However, in the case of hybrid plasma-arc welding the welds have a width which is (as compared to the traditional arc): by $25 \%$ smaller along the weld reinforcement and down

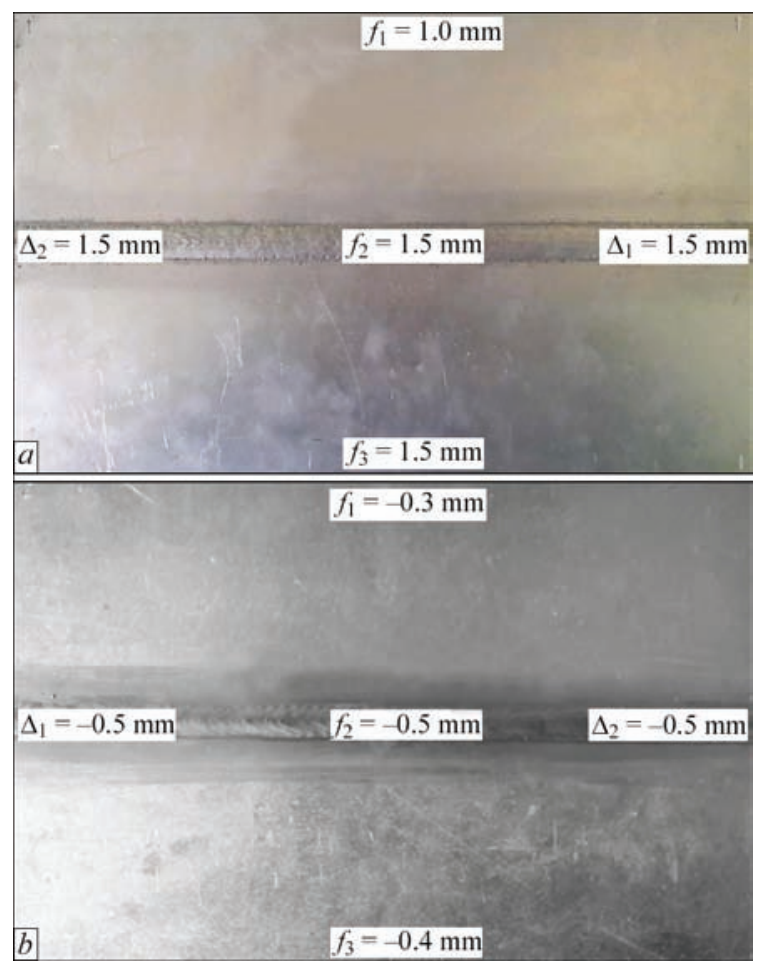

Figure 2. Appearance of facial surface and geometric characteristics of welded joints of alloy 1561 plates made by the arc $(a)$ and hybrid plasma-arc welding $(b)$ to $50 \%$ in its middle section (Figure 3 ). Moreover, the height of the upper bead reinforcement during hybrid welding is reduced approximately by twice as compared to the similar parameter for arc welding. It is seen from Figure 3 that the longitudinal fillet angle of weld section decreases, and the radius of the weld transition to the base metal, on the contrary, increases. This, in its turn, leads to decrease in the stress concentration factor. It can be assumed that the shape of weld penetration, characteristic for hybrid welding, determines a lower level of residual stress-strain state of butt joints. To check this assumption by the method of electron speckle interferometry, the parameters of stress-strain state of welded plates were measured.

The method is based on the measurement of displacements at elastic unloading of the metal volume at the investigated points on the surface of the specimen, caused by drilling of blind holes with a diameter and depth of $1.0 \mathrm{~mm}$ [6]. By comparing the parameters of the stress state and residual shape changing on a specific specimen of welded joint made by arc and hybrid welding, the efficiency of each of the processes was determined from the positions of stress-strain state.

The geometric sizes of the plates welded by arc and hybrid methods, as well as schemes for measurement of residual stresses, are presented in Figure 4. The measurements of longitudinal (along the weld

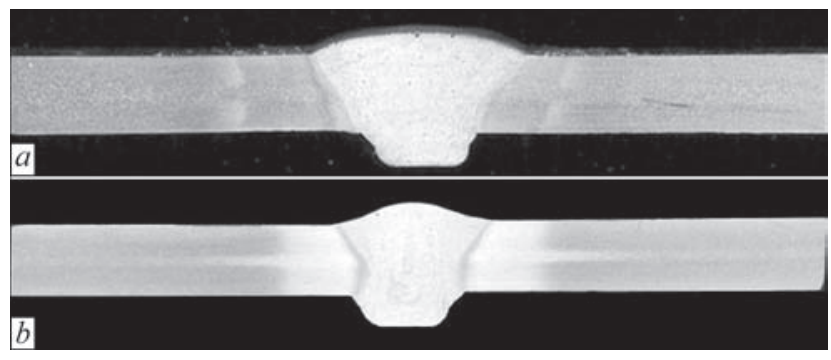

Figure 3. Appearance of macrosections of welded joints of alloy 1561 plates: $a$ - arc welding; $b$ - hybrid plasma-arc welding 
Modes of arc and hybrid plasma-arc welding with close energy inputs (of the order of $600 \mathrm{~J} / \mathrm{mm}$ ) and geometric characteristics of welded alloy 1561 plates $(\delta=5 \mathrm{~mm})$

\begin{tabular}{|c|c|c|c|c|c|c|c|c|c|c|c|}
\hline \multicolumn{12}{|c|}{ Type of welding } \\
\hline \multicolumn{6}{|c|}{ MIG } & \multicolumn{6}{|c|}{ Plasma-MIG } \\
\hline$V_{\mathrm{w}}, \mathrm{mm} / \mathrm{s}$ & $I_{\mathrm{a}}, \mathrm{A}$ & $U_{\mathrm{a}}, \mathrm{V}$ & $d_{\mathrm{w}}, \mathrm{mm}$ & $f_{1} / f_{2} / f_{3}, \mathrm{~mm}$ & $\Delta_{1} \Delta_{2}$ & $V_{\mathrm{w}}, \mathrm{mm} / \mathrm{s}$ & $I_{\mathrm{MIF}} / I_{\text {plasma }}, \mathrm{A}$ & $U_{\text {MIG }} / U_{\text {plasma }}, \mathrm{V}$ & $d_{\mathrm{w}}, \mathrm{mm}$ & $f_{1} / f_{2} / f_{3}, \mathrm{~mm}$ & $\Delta_{1} \Delta_{2}$ \\
\hline 10 & 240 & 26.5 & 1.6 & $1.0 / 1.5 / 1.2$ & $1.5 / 1.5$ & 10 & $145 / 149$ & $17.4 / 25.5$ & 1.2 & $\begin{array}{c}-0.3 /-0.5 /- \\
0.4\end{array}$ & $-0.5 /-0.5$ \\
\hline
\end{tabular}

line) $\sigma_{x}$ component of a plane stressed state were performed in three sections $S 1-S 3$ on the facial side of the plate (Figure 4,a) and in one section $S 5$ on the back side (Figure $4, b$ ). The duplication of measurements of $\sigma_{x}$ on the facial side of the plate was carried out in order to provide the validity of results.

The specimen, made by arc welding (Table, Figures 2, $a$ and $3, a$ ), has longitudinal deflections $f_{1}-f_{3}$ in the range of values $1.0-1.5 \mathrm{~mm}$, directed away from the facial surface. The values of the transverse deflections $\Delta_{1}-\Delta_{2}$ are stable along the length of welded joint and amount to $1.5 \mathrm{~mm}$. The peculiarities of this forming are determined by the shape of weld penetration (Figure 3,a), characterized by the misalignment of the line of applying shrinkage shortening and a neutral axis of the section. The result of this misalign-
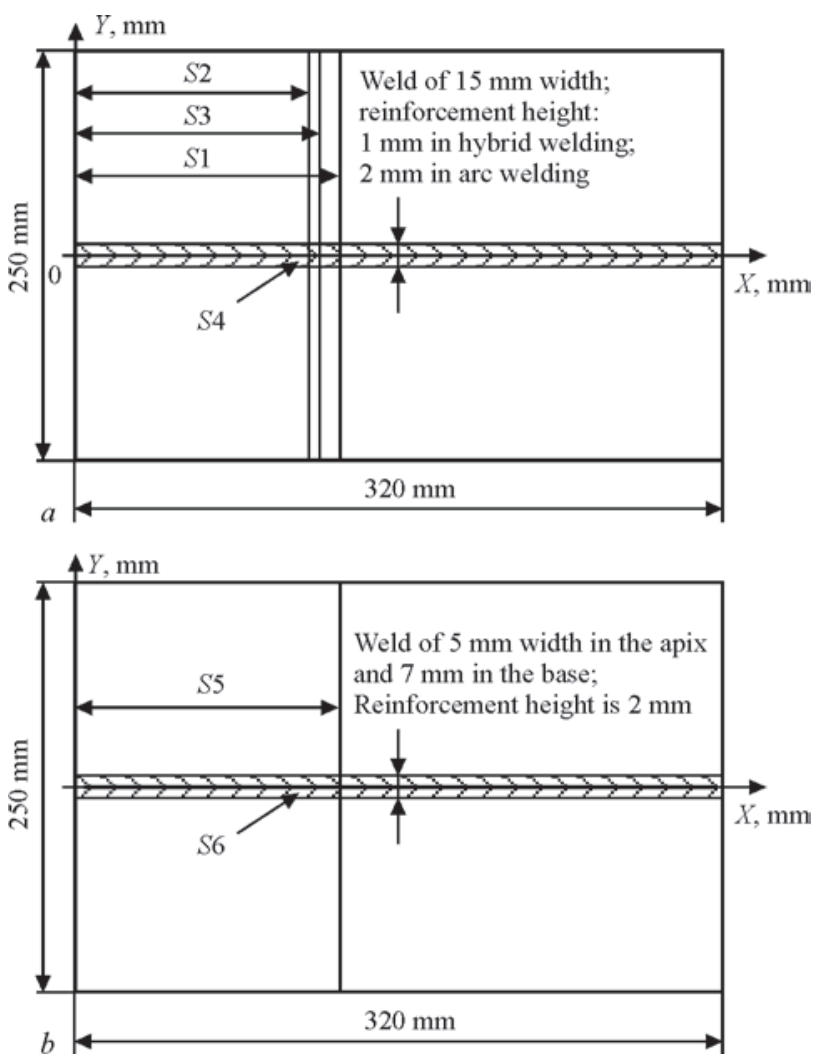

Figure 4. Schemes for measurements of residual stresses on butt welded joints of aluminum alloy 1561, made by arc and hybrid methods: $a$ - facial (upper) side, sections $S 1-S 3$ - measurements across the weld, $S 4$ - along the weld line; $b$ - back (bottom) side, section $S 5$ - across the weld, $S 6$ - along the weld; along the axis $X$ the sections are located at the distance: $S 1-166$, $S 2-148, S 3-155, S 5-168 \mathrm{~mm}$; along the axis $Y$ the sections $S 4$ and $S 6$ passed along the zero mark ment is the bending moment, causing distortion of the plate in the longitudinal direction. The stability of the values $\Delta$ along the length of the plate is related to its geometric characteristics, providing a uniform heat removal from the surface during welding thermal deformational cycle. The distribution of residual longitudinal stresses $\sigma_{x}$ in the cross-sections of welded plate after MIG welding is shown in Figure 5.

It can be seen from Figure 5 that in the weld center on the facial and back surfaces of the plate there is a local decrease in tensile stresses $\sigma_{x}$ to $45-50$ and $100 \mathrm{MPa}$, respectively. The peak values $\sigma_{x}$ on the facial and back surfaces are located in the fusion zone and reach 100 and $140 \mathrm{MPa}$, respectively. The reactive compressive stresses $\sigma_{x}$ on the facial and back surfaces reach the maximum values $-50--80$ and $-25--60 \mathrm{MPa}$ at the longitudinal edges of the plate, respectively. The shape of diagram $\sigma_{x}$ is connected with a small width of the plate, at which the compressive stresses in its cross-section do not reach zero values. When comparing the $\sigma_{x}$ diagrams on both sides of the plate, one can see that there is a significant bending stress component, which is confirmed by the obtained shape of the specimen distortion.

The distribution of residual longitudinal stresses $\sigma_{x}$ in the welded plate along the weld line (Figure 6) confirms the results obtained for the cross-section S1 (Figure 5). It can be seen from the Figure that the diagrams $\sigma_{x}$ on both sides of the plate are characterized by a difference in peak values, which determines the significant bending component of stress-strain state of the plate and confirms the characteristics of its shape changing.

The specimen, made by hybrid welding (Table, Figure $2, b$ and $3, b$ ), has longitudinal deflections $f_{1}-f_{3}$ of

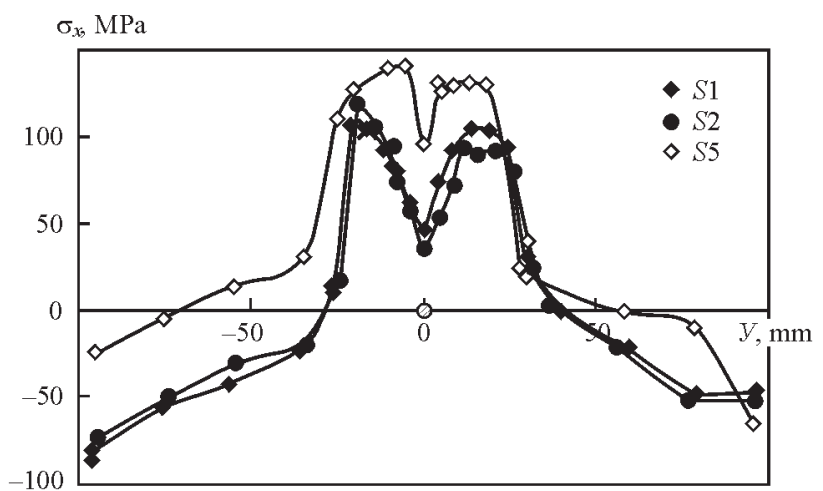

Figure 5. Residual welding stresses $\sigma_{x}$ on the facial side of the alloy 1561 joint, made by arc welding, in the cross-sections $S 1$ and $S 2$ and on the back side - in the section $S 5$ 


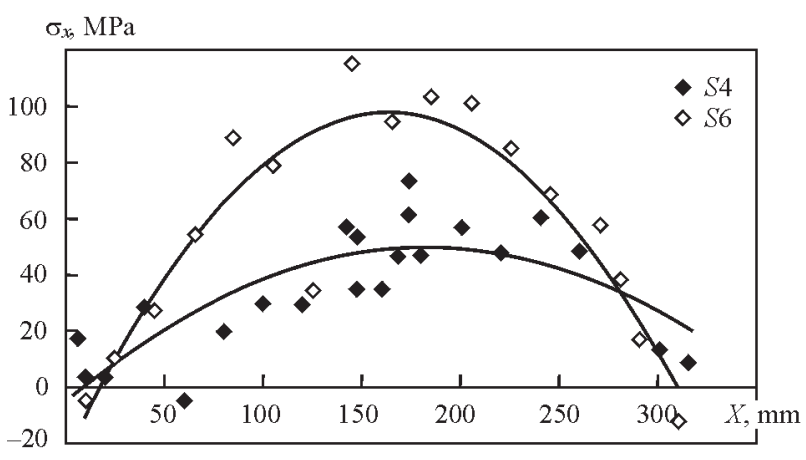

Figure 6. Residual welding stresses $\sigma_{x}$ on the facial side of the 1561 alloy joint made by the arc welding in the longitudinal section along the weld line S4 and the back - in the section S6

the value of $-0.3--0.5 \mathrm{~mm}$, directed towards the facial surface. The values of transverse deflections $\Delta_{1}-\Delta_{2}$ are stable in the length of the welded joint and are also equal to $-0.5 \mathrm{~mm}$. The features of this shape changing are determined by the shape of weld penetration (Figure $3, b)$, which is characterized by a practical coincidence of line of applying shrinkage shortening and neutral axis of weld section. A comparison of shapes of welds, produced by arc and hybrid methods (Figure 3), shows that the area of weld section in hybrid welding is by $30 \%$ smaller than that in arc welding.

The plate made by hybrid method is characterized by a smaller volume of longitudinal shrinkage shortening of weld metal and, correspondingly, by a smaller value of longitudinal shrinkage force $P_{\text {shs }}$ than the specimen after arc welding. This is connected with a noticeable decrease in the area of the upper relatively horizontal longitudinal axis of the weld part during hybrid welding (Figure 3,b) as compared to the arc welding (Figure 3,a). Moreover, in both cases, the area of the lower part remains the same. Considering the practical coincidence of the line of applying the longitudinal $P_{\mathrm{shr}}$ and longitudinal neutral axis, as well as the smaller value of $P_{\text {shr }}$, it can be concluded that the plate welded in a hybrid method, is subjected to a significantly smaller bending moment than that after arc welding. This fact explains the smaller value (to three times) of the plate distortion in the longitudinal direction than in arc welding. The stability of $\Delta$ along the length of the plate, as well as their small values after hybrid welding, are connected with the weld shape, which is characterized by a more uniform penetration (as compared to the arc welding) across the thickness of the plate, and also by geometric characteristics of the specimen, providing a stable heat removal from its surfaces during welding thermal deformational cycle.

The distribution of residual longitudinal stresses $\sigma_{x}$ in the cross-sections of facial and back sides of the plate welded by the hybrid method is shown in Figures 7, 8, and their comparison is shown in Figure 9. It can be seen from the Figures that in the weld center on the facial and back surfaces of the plate, there is a local decrease in tensile stresses $\sigma_{x}$ to $45-50$ and $100 \mathrm{MPa}$, respectively. The peak values $\sigma_{x}$ on the facial and back surfaces are

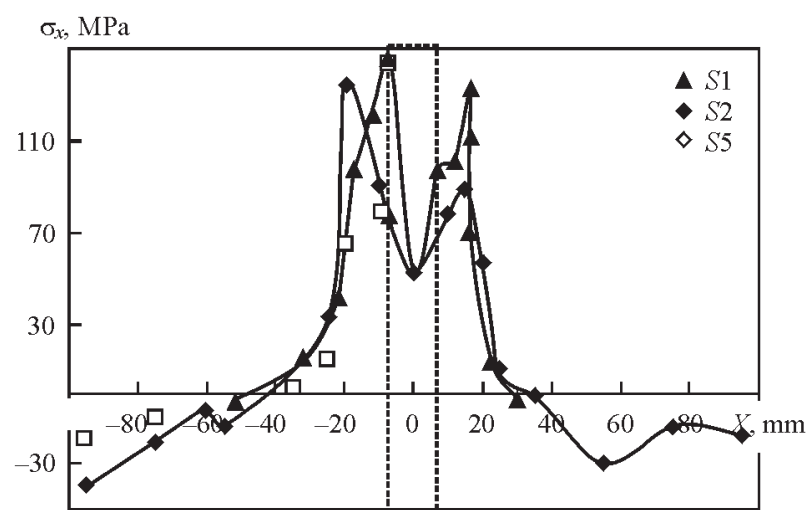

Figure 7. Residual welding stresses $\sigma_{x}$ on the facial side of the 1561 alloy joint, made by the hybrid welding, in cross-sections S1-S3; dashed line shows contours of the weld

located in the fusion zone and reach 140 and $150 \mathrm{MPa}$, respectively. The reactive compressive stresses $\sigma_{x}$ on the facial and back surfaces reach the maximum values of $-20--40 \mathrm{MPa}$ at the longitudinal edges of the plate. This shape of a diagram of compressive stresses $\sigma$, as in the case of arc welding, is connected with a small width of plate at which the compressive stresses in its cross-section do not reach zero values. Comparing the diagrams $\sigma_{x}$ on both sides of the plate, it can be seen that unlike the arc welding, the bending component of stresses in the reactive zone of the stress diagram for hybrid welding is negligible, which determines the smaller value of specimen distortion as compared to the arc method (Table).

It should be noted that analyzing the residual stressed states of plates made by arc and hybrid welding (Figures 5,9) some discrepancy between the level of tensile stresses and deflection values can be noted. Thus, the peak values of tensile stresses $\sigma_{x}$ for the considered welding methods unlike the deflection values, are close enough as well as values of bending stress components in the active zone (in the weld center). This fact can be explained by a small longitudinal rigidity of welded plates being investigated as well as by the features of stress-strain states characteristic for the arc and hybrid welding.

The diagrams $\sigma_{x}$ in the reactive zone of compressive stresses reach free longitudinal edges (Figures 5 and 9). At the same time, the stresses at the edges of

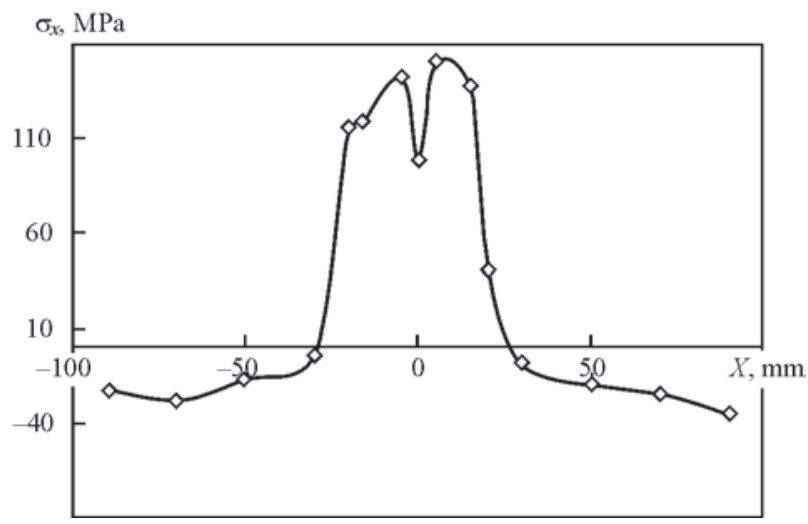

Figure 8. Residual welding stresses $\sigma_{x}$ on the back side of the 1561 alloy joint, made by hybrid welding, in cross section $S 5$ 


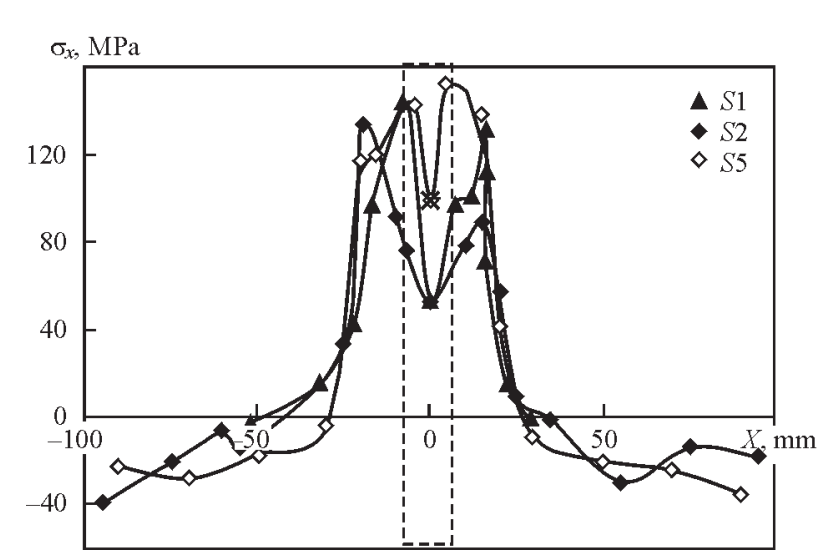

Figure 9. Residual welding stresses $\sigma_{x}$ on the facial side of 1561 alloy joint, made by the hybrid welding, in cross-sections S1and $S 2$ and on the back side - in section S5; dashed line shows weld contours

the plate during hybrid welding are significantly lower than in arc welding, which causes its smaller longitudinal deflections and, correspondingly, a higher level of tensile stresses $\sigma_{x}$. Thus, the level of tensile stresses $\sigma_{x}$ in a bent plate welded by arc method, is comparable to the level of $\sigma_{x}$ in a plane plate welded by hybrid method. It can be concluded that by comparing the stressed states of the plates made by hybrid and arc welding with equal values of deflections, the values of $\sigma_{x}$ in the latter will be higher.

The distribution of residual longitudinal stresses $\sigma_{x}$ in the welded plate along the weld line (Figure 10) confirms the results obtained for the cross-section S1 (Figure 9). It can be seen from the Figure that the diagrams $\sigma_{x}$ on both sides of the plate made by hybrid welding, are characterized by a smaller difference in peak values than in arc welding, which determines the bending component of stress-strain state of the plate and confirms the characteristics of its shape changing (Table).

The comparison of values of the stresses $\sigma_{x}$ along the weld line in the plates made by hybrid and arc welding showed $15-20 \%$ decrease in their level in the case of hybrid welding, which can help to increase the service life of such welded joints under the load in this direction. Such an increase in service life of joints, loaded along the weld, can positively affect the results of welding the stringer panels and shells of special aircrafts of aluminum alloys.

\section{Conclusions}

1. It was established in the course of determination of technological modes of the hybrid plasma-arc and pulsed arc welding of 1561 aluminum alloy of $5 \mathrm{~mm}$ thickness that at the same welding speeds the both methods provide an approximately equal energy input. At the same time, the mastered hybrid welding technology provided the reduction in the diameter of the applied wire from 1.6 to $1.2 \mathrm{~mm}$, which resulted in $25-50 \%$ decreased width of the weld as compared to the arc welding.

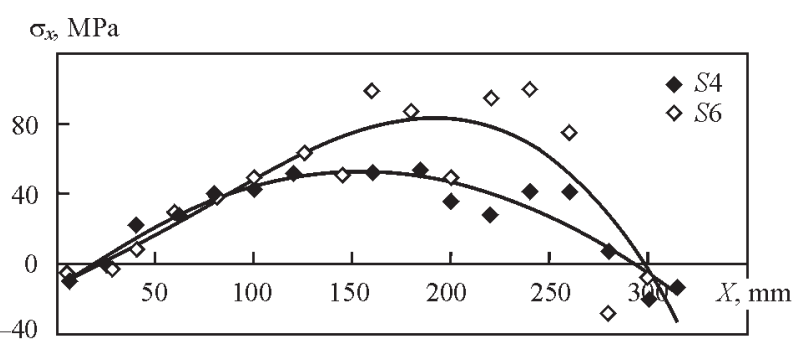

Figure 10. Residual welding stresses $\sigma_{x}$ on the facial side of the 1561 alloy joint, made by hybrid welding, in longitudinal section along the line of weld $S 4$ and on back side — in section $S 6$

2 . The reduction in the area of the facial part of the weld as compared to the area of the root part in the hybrid method of welding resulted in approximately 3 times decrease in the level of residual distortion of welded plates, and in 15-20\% decrease of residual stresses $\sigma_{x}$ along the weld line.

3 The diagrams of stresses $\sigma_{x}$ along the weld line on both sides of the plate being butt welded by the hybrid method, are characterized by a smaller difference in peak values than in arc welding, which determines approximately three times lower bending component of stress-strain state of the plate and is confirmed by the characteristics of its shape changing.

4. The further investigations of stress-strain state of butt joints made by hybrid welding are advisable to be carried out using plates of $500 \times 500 \times 5 \mathrm{~mm}$ size, which provide the compressive stresses at the edges close to zero.

The work was performed under the support of the Program of Foreign Experts of the People's Republic of China No.WQ20124400119, the Innovation Group Program of Guangdong Province, PRC No.201101C0104901263 of the Guangdong Science and Technology Project No. 2015A050502039, the Guangdong Science and Technology Project No.2016B050501002.

1. Khaskin, V.Yu. (2013) Development of laser welding of aluminium alloys at the E.O.Paton Electric Welding Institute (Review). The Paton Welding J., 5, 51-55.

2. Zusin, V.Ya., Serenko, V.A. (2004) Welding and surfacing of aluminium and its alloys. Mariupol: Renata.

3. Grinyuk, A.A., Korzhik, V.N., Shevchenko, V.E. et al. (2015) Main tendencies in development of plasma-arc welding of aluminium alloys. The Paton Welding J., 11, 31-41.

4. Grinyuk, A.A., Korzhik, V.N., Shevchenko, V.E. et al. (2016) Hybrid technologies of welding aluminium alloys based on consumable electrode arc and constricted arc. Ibid., 5/6, 98-103.

5. Shonin, V.A., Poklyatsky, A.G. (2001) Low-cycle fatigue of welded butt joints made from alloy AMg6 in inert atmosphere. Ibid., 3, 18-22.

6. Lobanov, L.M., Pivtorak, V.A., Savitsky, V.V. et al. (2006) Procedure for determination of residual stresses in welded joints and structural elements using electron speckle-interferometry. Ibid., 1, 24-29. 


\title{
FORMATION OF WELDED JOINTS OF MAGNESIUM ALLOYS IN PULSE MULTIPASS ELECTRON BEAM WELDING
}

\author{
V.M. NESTERENKOV, L.A. KRAVCHUK, Yu.A. ARKHANGELSKY and Yu.V. ORSA \\ E.O. Paton Electric Welding Institute, NASU \\ 11 Kazimir Malevich Str., 03680, Kiev, Ukraine. E-mail: office@paton.kiev.ua
}

\begin{abstract}
The work studies the peculiarities of formation of the joints of cast magnesium alloy ML10 of $8 \mathrm{~mm}$ thickness in pulse vacuum electron beam welding. The investigations were carried out on specimens of alloy of $\mathrm{Mg}-\mathrm{Zn}-\mathrm{Zr}-\mathrm{Nd}$ doping system at optimum pulse repetition frequency and increased welding rate. It is determined that welding in several passes with step increase of electron beam current in the pulse is necessary for providing high quality of formation and strength properties of welded joints. It is shown that strength characteristics of welded joints are at the level not lower than $92 \%$ of similar base metal properties. 11 Ref., 1 Table, 5 Figures.
\end{abstract}

Keywords : electron beam welding, magnesium alloys, pulse welding mode, welded joint strength, thermal cycle, weld metal microstructure, HAZ, base metal

In comparison with known methods of fusion welding, pulse electron beam welding (PEBW) is characterized with high specific energy concentration, low values of heat input, small width of heat-affected zone (HAZ), narrow penetration zone and insignificant deformations of parts being welded [1-4].

PEBW can be easily mechanized and automated, and movement of electron beam employing a deflecing system of electron beam gun on a set trajectory (circle, ellipse, arc, dash, triangle, rectangle etc.) significantly expands capabilities of this process. Keeping the set specific power of the beam and parameters of penetration zone at variation of working distance from electron gun to part surface sets PEBW apart from arc methods of fusion welding, and can promote its wide application in welding of wrought and cast magnesium alloys in critical designation parts.

Investigations of effect of PEBW on formation of welded joints of magnesium alloys were carried out on UL-209M unit with computer control of all parameters and systems, developed at the E.O. Paton Electric Welding Institute of the NAS of Ukraine [5]. UL209M unit is equipped with power complex based on ELA-60/60 and electron beam gun, which is moved inside the vacuum chamber on linear coordinates $X, Y$, $Z$ as well as turned about the $Y-Y$ axis through $0-90^{\circ}$ angle. At accelerating voltage $U_{\text {acc }}=60 \mathrm{kV}$ electron beam gun with metallic tungsten cathode of $3 \mathrm{~mm}$ diameter provides current range of electron beam $I_{\text {pulse }}=$ $=0-500 \mathrm{~mA}$ as well as performance of technological beam scanning in process of electron beam welding. Accuracy of coordinate positioning of the electron beam gun at least $0.1 \mathrm{~mm}$ is provided and mating of the electron beam with the joint using RASTR system with at least $0.1 \mathrm{~mm}$ accuracy is ensured [6].

Pulse operation mode was realized at connection of pulse generator of HAMEG HM8130 type to the input of power complex ELA-60/60. It provided $100 \%$ modulation of the electron beam on current. Shape and value of welding current pulse was fixed directly before welding of specimens or prototypes of the parts on beam trap (Faraday cup) with the help of electron beam oscillograph TECTRONIX TDS 1002, scheme of connection of which is given in Figure 1.

Works [7] include investigations on formation of welded joints of magnesium alloys of different doping systems by arc welding methods. However, analysis of works on weldability of magnesium alloys showed

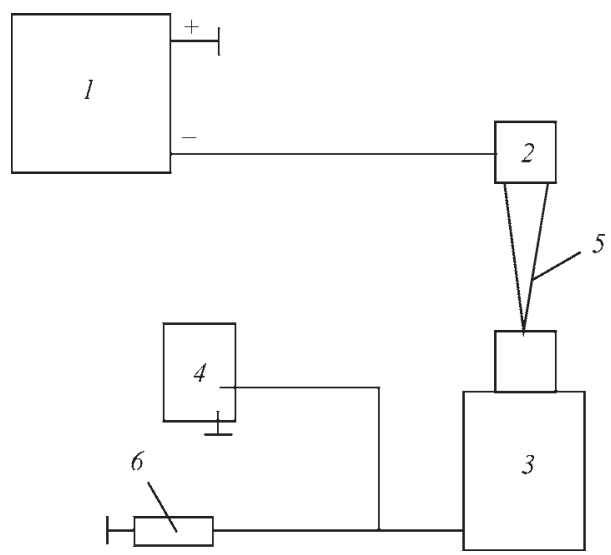

Figure 1. Scheme of registration of parameters of pulse electron beam: 1 - power complex ELA-60/60; 2 - electron beam gun; 3 - massive target of beam trap; 4 - oscillograph; 5 - electron beam; 6 - resistor $R=10 \mathrm{Ohm}$ 
virtually no data on formation of welded joints of magnesium alloys using electron beam in pulse mode.

Earlier carried investigations [7] indicate that cast magnesium alloy of $\mathrm{Mg}-\mathrm{Zn}-\mathrm{Zr}-\mathrm{Nd}$ doping system can be satisfactorily welded using arc methods under condition of mandatory preheating of the welded edges from external source to $200-250^{\circ} \mathrm{C}$.

The main problem in welding of magnesium alloys is prevention of hot cracking in welded joints as well as producing the welds without undercuts from face and root part of the weld.

E.O. Paton Electric Welding Institute of the NAS of Ukraine carried the investigations on formation of defect-free joints of cast magnesium alloy ML10 (0.1-0.7 \% Zn, 0.4-1.0\% Zr, 2.2-2.8\% Nd, Mg the rest), made by PEBW and performance in a single technological cycle of additional cleaning of nearweld surfaces with a fine focused low power electron beam, preheating of abutting edges to temperature around $200-250{ }^{\circ} \mathrm{C}$ and concurrent heating by the beam in process of multipass welding. Formation of face and root beads of the weld without undercuts and depression is reached through application of local technological scanning of the electron beam on ellipse, at that larger semi-axis is oriented along the welding direction. Alloy ML10 of $\mathrm{Mg}-\mathrm{Zn}-\mathrm{Zr}-\mathrm{Nd}$ doping system differs by increased corrosion resistance, good cast properties, small susceptibility to microporosity, can be satisfactorily welded using arc methods, thermally hardened by quenching and artificial aging. The alloy has long operation period at temperatures to $250{ }^{\circ} \mathrm{C}$. Specimens of $150 \times 150 \times 8 \mathrm{~mm}$ size were used for adjustment of modes and PEBW procedure using a scheme with vertical electron beam in flat position.

During the investigations the specimens were welded without filler materials, and assembly of specimens for welding was carried out with the minimum possible gaps. Preparation of welded edges for welding was performed by means of degreasing with organic solvents and scrapping to $0.1 \mathrm{~mm}$ depth directly before specimen loading in a unit vacuum chamber. Cleaning and preheating of the surfaces with the fine focused electron beam having circular or sawtool scanning was performed after specimen loading in the vacuum chamber and reaching working vacuum.

In PEBW significant effect on welded joint quality together with time parameters of the electron beam (duration of pulse and duration of pause) has a welding rate, choice of which determines the level of overlapping of separate penetration areas. In other words, known diameter of the electron beam on the part and amplitude of its local scanning makes its pass in the pause between the pulses a decisive factor for forma- tion of quality welded joint. Expression for welding rate at seam PEBW can be written as:

$$
V_{\text {PEBW }}=\frac{(1-K) f_{\text {pulse }} S\left(A_{\text {loc }}+d_{\mathrm{b}}\right)}{S-1},
$$

where $K$ is the coefficient of overlapping of welding spots; $f_{\text {pulse }}$ is the pulse frequency, Hz; $S=\tau_{\text {pulse }}+\tau_{\text {pause }}$ / $\tau_{\text {pulse }}$ is the relative pulse duration; $\tau_{\text {pause }}$ is the pause duration; $\tau_{\text {pulse }}$ is the pulse duration; $d_{\mathrm{b}}$ is the diameter of electron beam on the part, $\mathrm{mm}$; $A_{\text {loc }}$ is the amplitude of local scanning of electron beam (for example, if you choose $K=0.8$; $\tau_{\text {pulse }}=5 \mathrm{~ms}, \tau_{\text {pause }}=5 \mathrm{~ms} ; f_{\text {pulse }}=$ $=100 \mathrm{~Hz} ; d_{\mathrm{b}}=0.5 \mathrm{~mm} ; A_{\text {loc }}=1 \mathrm{~mm}, V_{\text {PEBW }}=60 \mathrm{~mm} / \mathrm{s}$ is gotten).

It is known fact that pre- and concurrent heating of the part reduce possibility of appearance of solidification cracks, since this decreases intensity of growth of elasto-plastic deformations in weld metal solidification. Reduction of difference between the maximum temperature in welding and initial part temperature provokes decrease of cooling rate at different areas of welded joint, improve their structure and increase elasticity. In heating to $200-250{ }^{\circ} \mathrm{C}$ drop of tensile longitudinal stresses can reach $50 \%$ [8].

Investigations using modulated electron beam and its local oscillations on different trajectories and with different amplitudes were carried out for solving a quality problem in welded joints of magnesium alloys of up to $\delta_{\mathrm{m}}=15 \mathrm{~mm}$ thickness, changing shape of weld penetration and its solidification during welding through forced variation of parameters of oscillation of liquid metal in a vapor-gas channel. A range of frequency of electron beam current pulses on the part $f_{\text {pulse }}=20-250 \mathrm{~Hz}$ at relative duration of modulation of current beam $S=1.2-5.0$ was studied. It is determined that beam modulation frequency $f_{\text {pulse }}=70-120 \mathrm{~Hz}$ eliminates weld expansion in the root part, namely the place of appearance of the formation defects, and improves weld shape, i.e. side penetration walls become virtually parallel. The most favorable penetration shape was received at modulation frequency $f_{\text {pulse }}=$ $=100-120 \mathrm{~Hz}$. Decrease of modulation frequency below $f_{\text {pulse }}=60 \mathrm{~Hz}$ results in increase of penetration depth, however, shape of weld approaches to shape of the welds made without beam modulation.

In our case PEBW of magnesium alloy ML10 of $\delta_{\mathrm{m}}=8 \mathrm{~mm}$ thickness was carried out in several passes by step-by-step rise of beam current in the pulse and preheating during cleaning of near-weld zone using the fine focused electron beam. In parallel welding thermal cycle was measured with the help of thermal couple of K type (chromel-alumel, GOST 6615-94) of $0.5 \mathrm{~mm}$ diameter, caulked at $2 \mathrm{~mm}$ distance from weld axis. Figure 2 shows that preheating temperature of specimen during cleaning using electron beam in 


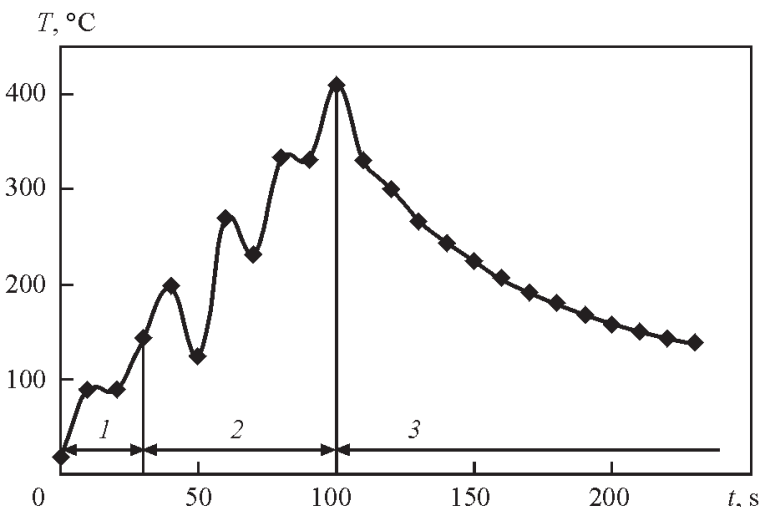

Figure 2. Thermal cycle of near-weld zone in PEBW of specimen of magnesium alloy ML10 of $150 \times 50 \times 8 \mathrm{~mm}$ size: 1 - cleaning using fine focused electron beam in two passes; 2 - welding in four passes with step-by-step increase of beam current in pulse; 3 - cooling after welding

two passes $\left(U_{\text {acc }}=60 \mathrm{kV}, I_{\mathrm{b}}=10 \mathrm{~mA}, V_{\mathrm{f}}=10 \mathrm{~mm} / \mathrm{s}\right.$, $\left.\Delta I_{\mathrm{f}}=0 \mathrm{~mA}, A_{\text {circ }}=10 \mathrm{~mm}, l_{\text {work }}=200 \mathrm{mM}\right)$ made approximately $140{ }^{\circ} \mathrm{C}$ and can be regulated by variation of beam power and number of passes. A mode of pulse welding in four passes with concurrent preheating made:

the first pass: $U_{\text {acc }}=60 \mathrm{kV}, I_{\text {pulse }}=15 \mathrm{~mA}$; $v_{\mathrm{w}}=10 \mathrm{~mm} / \mathrm{s}, \Delta I_{\mathrm{f}}=0 \mathrm{~mA}, A_{\text {ellipse }}=1.5 / 0.5, l_{\text {work }}=$ $=200 \mathrm{~mm}, \tau_{\text {pulse }}=5 \mathrm{~ms}, \tau_{\text {pause }}=5 \mathrm{~ms}, f_{\text {pulse }}=100 \mathrm{~Hz}$. The larger semi-axis of ellipse is oriented along the welding direction, the second pass: $I_{\text {pulse }}=25$; the third -35 and the fourth $-45 \mathrm{~mA}$. Other parameters in the second, third and fourth passes are preserved.

Detection of structure of welded joints on cast magnesium alloy ML10 was performed using chemical etching in $10 \%$ solution of citric acid. The examinations were carried out on optical microscope Neophot-32, hardness was measured on hardness gage M-400 of LECO Company, digital image of structures was taken with the help of Olympus camera. The welded joint of magnesium alloy ML10 of $\delta_{\mathrm{m}}=8 \mathrm{~mm}$ thickness (Figure 3) was made in a mode of multipass PEBW using the flat position scheme by vertical electron beam on substrate of the same material. It can

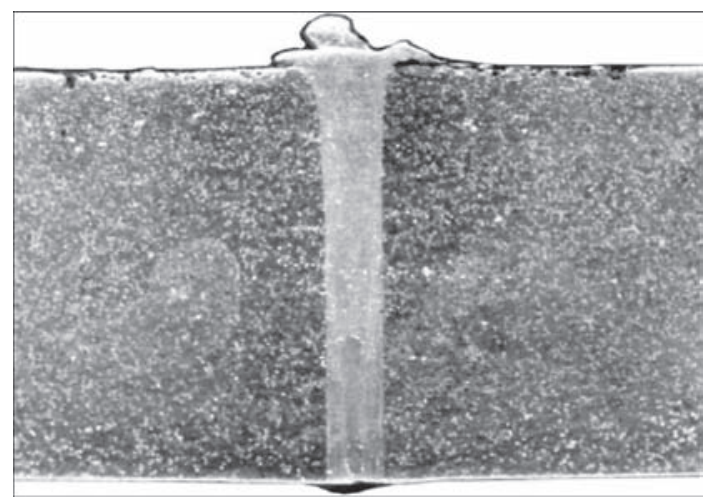

Figure 3. Macrostructure $(\times 10)$ of welded joint of magnesium alloy ML10 of $\delta_{\mathrm{m}}=8 \mathrm{~mm}$ thickness
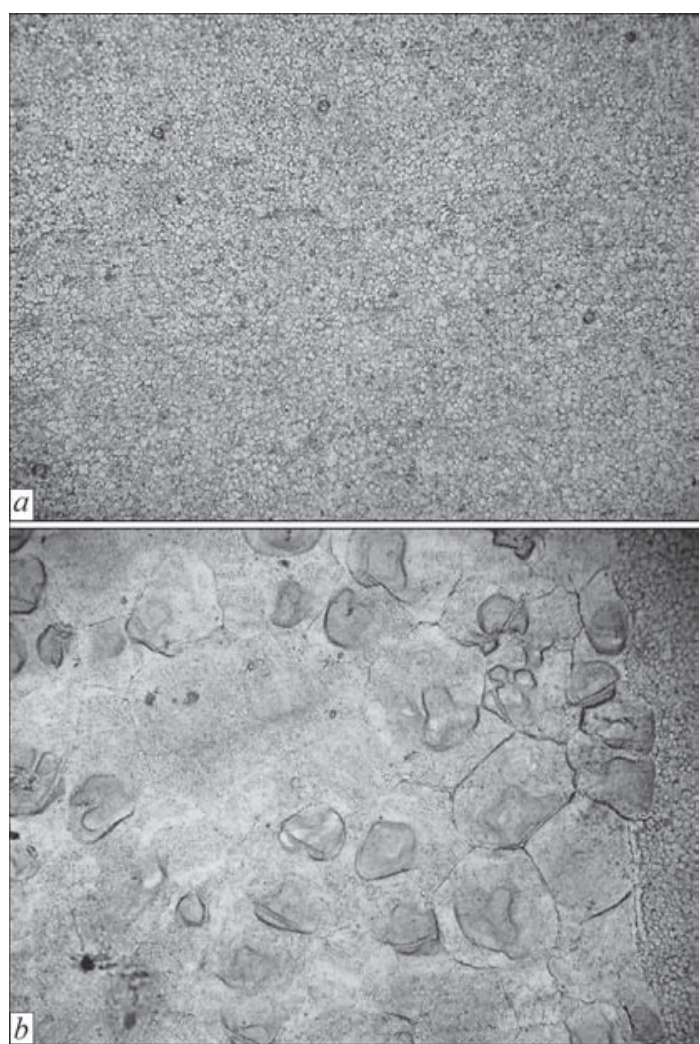

Figure 4. Microstructure $(\times 200)$ of welded joint of magnesium alloy ML10, made in PEBW mode: $a$ - weld seam; $b$ - weld, HAZ, base metal

be seen on its macrosection that weld side walls are virtually parallel in all penetration depth, no expansion is present in the root part, undercuts and depression on the weld face are absent as well as cracks.

Structure of weld metal on ML10 alloy is fine disperse (cell size 10-12 $\mu \mathrm{m}$ ) at all weld height (Figure $4, a$ ) and consists of $\alpha$-solid solution with located along the boundaries grains of eutectic and intermetallic phase $(\mathrm{MgZr})_{12} \mathrm{Nd}$. Weld metal hardness makes HV0.5-394-490 MPa, that agrees with the results of investigations, given in work [9].

A fusion line with the base metal is virtually equal and well expressed. In some places, coarse HAZ grains displace the fusion line into the weld metal

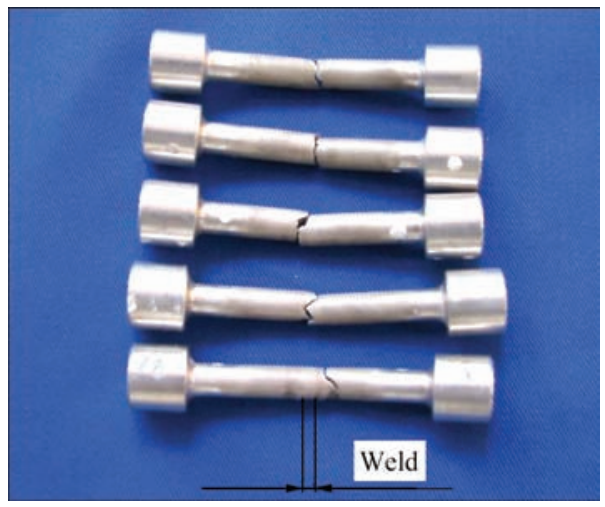

Figure 5. Specimens after mechanical breaking tests of welded joints of ML10 magnesium alloy 
Mechanical properties of cast magnesium alloy ML10 after pulse EBW

\begin{tabular}{|c|c|c|c|c|c|c|c|}
\hline \multirow{2}{*}{$\begin{array}{c}\text { Object for exam- } \\
\text { ination }\end{array}$} & \multicolumn{6}{|c|}{ Mechanical properties } & \multirow{2}{*}{ Fracture place } \\
\cline { 2 - 8 } & $\sigma_{\mathrm{t}}, \mathrm{MPa}$ & $\sigma_{0.2}, \mathrm{MPa}$ & $\delta, \%$ & $\psi, \%$ & $\sigma_{\mathrm{t} \mathrm{w}} / \sigma_{\mathrm{t} \mathrm{BM}}$ & $a_{\mathrm{H}}, \mathrm{kJ} / \mathrm{m}^{2}$ & \\
\hline Base metal & 220 & 140 & 5.0 & 11 & - & 62.7 & - \\
\hline Welded joint & 202 & 135 & 6.5 & 12 & 0.92 & 82.0 & Along fusion line, HAZ \\
\hline
\end{tabular}

(Figure $4, b$ ). HAZ metal structure is coarse grain, eutectics is uniformly located, metal hardness makes HV0.5-409-539 MPa.

Base metal structure is the same as in HAZ metal. It differs by coarser grain size $(70-80 \mu \mathrm{m})$ and number of spherical eutectic formations (Figure $4, b$ ).

The mechanical tests were used for quality control of welded joints of magnesium alloy ML10. In addition to $\sigma_{t}$ value, other parameters of welded joint strength, namely $\sigma_{0.2}, \delta$ and $Y$ were determined as a result of breaking tests.

Specimens of the base metal ML10 in as-delivered condition and of welded joints produced by PEBW method were manufactured for performance of strength tests. Breaking tests of welded joints were carried out on cylinder specimens of gauge length diameter $d_{\mathrm{s}}=3 \mathrm{~mm}$.

It follows from Figure 5 that breaking of the specimens of magnesium alloy ML10 after PEBW takes place mainly on fusion line and HAZ. Ductility of welded joints $\psi$ rises insignificantly in comparison with the base metal ductility and toughness $a_{\mathrm{H}}$ increases approximately per $30 \%$. Coefficient of strength of the welded joints, produced in PEBW mode with preheating in cleaning with the fine focused electron beam and further welding in four passes by means of step-by-step enlargement of beam current in pulse, reaches the value $\sigma_{\mathrm{tw}} / \sigma_{\mathrm{tbm}}=0.92 \%$ (Table).

Analysis of microstructure in different zones of welded joint of magnesium alloy ML10 shows that the weld metal structure in PEBW virtually does not differ from that which occurs for alloys in as-cast condition. Lower value of grain and thickness of intercrystalline layers in comparison with the weld structure, which occurs in arc methods of welding [10,11], are observed taking into account high solidification rates in PEBW.

\section{Conclusions}

1. It is determined that high quality of formation and strength properties of welded joints of magnesium al- loy ML10 is reached by application of multipass pulse EBW with step-by-step rise of beam current in each pass.

2. It is determined that the side penetration walls become virtually parallel in PEBW with application of local beam scanning on ellipse.

3. It is shown that strength characteristics of welded joints of cast magnesium alloy ML10 are at the level not lower that $92 \%$ of the same base metal properties.

1. Matting, A., Sepold, G. (1967) Beitrag zum Schweissen mit Impuls-gesteuerten Elektronenstrahlen.: DVS-Bericht 1. Schweisstechnik, 123-133.

2. Indenbrand, H.-D., Schlenk, R. (1970) Untersuchungen zum Elektronenstrahlimpulsschweissen. Ibid., 6, 253-257.

3. Khudyshev, A.F., Slavin, G.A. (1971) Investigation of technological peculiarities of pulse electron beam welding of thin sheets. Fizika i Khimiya Obrabotki Materialov, 3, 13-19.

4. Khokhlovsky, A.S., Lopatko, A.P., Krylov, V.G. (1978) Weldability of magnesium-based alloy by electron beam. In: Electron beam welding. Moscow: House of Sci.-Techn. Information, 68-72.

5. Nazarenko, O.K., Nesterenkov, V.M., Neporozhny, Yu.V. (2001) Design and electron beam welding of vacuum chambers. The Paton Welding J., 6, 40-42.

6. Paton, B.E., Nazarenko, O.K., Nesterenkov, V.M. et al. (2004) Computer control of electron beam welding with multi-coordinate displacements of the gun and workpiece. Ibid., 5, 2-5.

7. (1978) Magnesium alloys. In: Transact. of A.A. Baikov Institute of Metallurgy. Moscow: Nauka.

8. Kanz, H.G. (1959) Eigenspannungen verwerfungen und Masshaltigkeit beim Schweissen. Schweissen und Scheiden, 11(3), 139-142.

9. Majstrenko, A.L., Nesterenkov, V.M., Strashko, R.V. et al. (2016) Hybrid technology combining electron beam welding and friction stir welding in the processes of repair of aircraft structure elements of magnesium alloys. The Paton Welding J., 5/6, 91-97.

10. Bondarev, A.A., Nesterenkov, V.M. (2013) Investigation of weldability of magnesium alloy MA2 by electron beam in vacuum. Kompressornoe Energeticheskoe Mashinostroenie, 2, 21-28.

11. Bondarev, A.A., Nesterenkov, V.M. (2014) Technological peculiarities of welding of wrought magnesium alloys by electron beam in vacuum. The Paton Welding J., 3, 16-20. 


\title{
INFLUENCE OF TEMPERATURE OF HEATING IN VACUUM ON BEHAVIOUR OF OXIDE FILM ON THE SURFACE OF $\gamma$-TiAl INTERMETALLIC ALLOY
}

\author{
Yu.V. FALCHENKO, L.V. PETRUSHINETS and V.E. FEDORCHUK \\ E.O. Paton Electric Welding Institute, NASU \\ 11 Kazimir Malevich Str., 03680, Kiev, Ukraine. E-mail: office@paton.kiev.ua
}

\begin{abstract}
The paper deals with the influence of temperature of heating in vacuum and soaking time on oxide film recovery on the surface of $\gamma$-TiAl intermetallic alloy. Analysis of publications on diffusion welding of titanium aluminides showed a considerable scatter of parameters in welding modes recommended by the authors (temperature, pressure and process time). Influence of concentration of oxygen contained in oxide layer on contact surfaces of samples, on their adhesion during heating in vacuum was analyzed. It is experimentally established that with increase of the temperature of heating pre-oxidized samples of titanium aluminide from 900 up to $1200{ }^{\circ} \mathrm{C}$, the nature of surface relief in the contact zone changes from flat to voluminous one. It is found that heating of oxidized samples of $\gamma$-TiAl intermetallic alloy under vacuum at $1200{ }^{\circ} \mathrm{C}$ for $20 \mathrm{~min}$ at $5 \mathrm{MPa}$ pressure allows reducing oxygen content in the butt joint 5 times from 40.99 to $6.12-7.74$ wt.\%. 18 Ref., 2 Tables, 7 Figures.
\end{abstract}

Ke yw ords : $\gamma$-TiAl intermetallic alloy, oxide, vacuum, heating temperature

$\gamma$-TiAl-based intermetallic alloys are regarded as promising materials for manufacturing components of aviation equipment, operating at elevated temperatures. The advantage of such alloys over other alloys is due mainly to low specific density and high heat resistance.

References [1,2] showed the possibility to produce $\gamma$-TiAl welded joints with application of multilayer foils of Al-Ti system. Here optimum welding modes were determined: heating temperature $T=1200{ }^{\circ} \mathrm{C}$, compression pressure $P=20 \mathrm{MPa}$, time of soaking at pressure $t=20 \mathrm{~min}$.

Works of other authors [3-7] show considerable differences as to the applied welding modes (Table 1). So, [3] recommends welding temperature $T=1350{ }^{\circ} \mathrm{C}$ at pressure $P=10 \mathrm{MPa}$ and process time $t=45 \mathrm{~min}$. In References $[4,5]$ the following welding mode is believed to be optimum: $T=1150-1200^{\circ} \mathrm{C}$ at pressure $P=15-20 \mathrm{MPa}$ and process time $t=60 \mathrm{~min}$. The authors of [6] recommend substantial increase of welding process time up to $t=180 \mathrm{~min}$ at temperature
$T=1100^{\circ} \mathrm{C}$ and pressure $P=20 \mathrm{MPa}$. In Reference [7] satisfactory results were obtained at application of increased values of pressure $P=300 \mathrm{MPa}$ and interlayer from titanium alloy VT1.

It is known that weldability of titanium alloys is determined by their gas absorption, thickness of oxide film on contact surfaces, as well as structural transformations in the metal [8]. In vacuum diffusion welding of titanium-based alloys cleaning of the surfaces being welded from oxide films is associated with their dissolution in the metal, as well as development of tensile stresses in the butt at pressure application, leading to cracking of harder and more brittle oxide films, and with recrystallization processes.

At heating in vacuum complex physical-chemical processes proceed on contact surface of the abutted parts, associated with autovacuuming of their internal volume, heating of gas inside it, sorption and desorption and oxide film destruction. So, Reference [9] shows the principal possibility of metal autovacuum-

Table 1. Recommended modes of welding $\gamma$-TiAl intermetalic alloys

\begin{tabular}{|c|c|c|c|c|}
\hline \multirow{2}{*}{ Alloy, at.\% } & \multicolumn{3}{|c|}{ Welding mode } & \multirow{2}{*}{ Source } \\
\hline & $T,{ }^{\circ} \mathrm{C}$ & $P$, MPa & $t$, min & \\
\hline $\mathrm{Ti}-48 \mathrm{Al}-2 \mathrm{Mn}-2 \mathrm{Nb}$ & 1350 & 10 & 45 & [3] \\
\hline Ti-38Al & 1200 & 20 & 60 & [4] \\
\hline Ti-47Al-4 (Cr, Nb, Mn, B) & 1150 & 15 & 60 & [5] \\
\hline Ti-47Al-4 (Cr, Nb, Mn,B) & 1100 & 20 & 180 & [6] \\
\hline $\mathrm{Ti}-44.7 \mathrm{Al}-4.65 \mathrm{Nb}-2.73 \mathrm{Mn}-0.31 \mathrm{~B}$ & 850 & 300 & 20 & [7] \\
\hline
\end{tabular}


ing at heating and self-cleaning of contact surfaces from oxide films.

The authors of [10], based on investigation of titanium alloys VT1, OT4, VT6 come to the conclusion that the process of oxide film dissolution in the alloy metal matrix is controlled by oxygen diffusion in it. Analysis of kinetic curves of oxide dissolution in VT1 alloy is indicative of decaying nature of the process of oxide dissolution. Unlike VT1 alloy, in aluminium-containing alloys OT4 $(3.5 \mathrm{Al}, 1.5 \mathrm{Mn})$ and VT6 $(6 \mathrm{Al}, 4.5 \mathrm{~V})$ the nature of oxide film dissolution is more complicated. Oxidation in air of titanium alloys, doped with aluminium, is accompanied by formation of a layer with higher aluminium content on their surface.

Research performed in [8] showed that annealing at heating temperature $T=700{ }^{\circ} \mathrm{C}$ for $12-15 \mathrm{~min}$ under the conditions of autovacuuming of samples from OT4-1 alloy (1.5Al, 1.0Mn) with initial oxide film thickness of about $54 \mathrm{~nm}$ (light-blue colour) ensures its discoloration that corresponds to oxide film thickness of about $20 \mathrm{~nm}$.

By the data of [11] with increase of heating temperature and development of physical contact between the surfaces being welded, conditions are in place for «non-oxidizing» annealing that leads to oxygen dissolution in titanium, and chemical compounds of aluminides remain in the butt joint zone in the form of films. Welded joint formation will be controlled by diffusion process of lowering aluminium concentration to the level, when existence of its chemical compounds is impossible.

Thus, it can be assumed that to produce joints from intermetallic alloys based on titanium aluminides, having increased aluminium content, the question of oxide film recovery on contact surfaces of the samples, is also important.

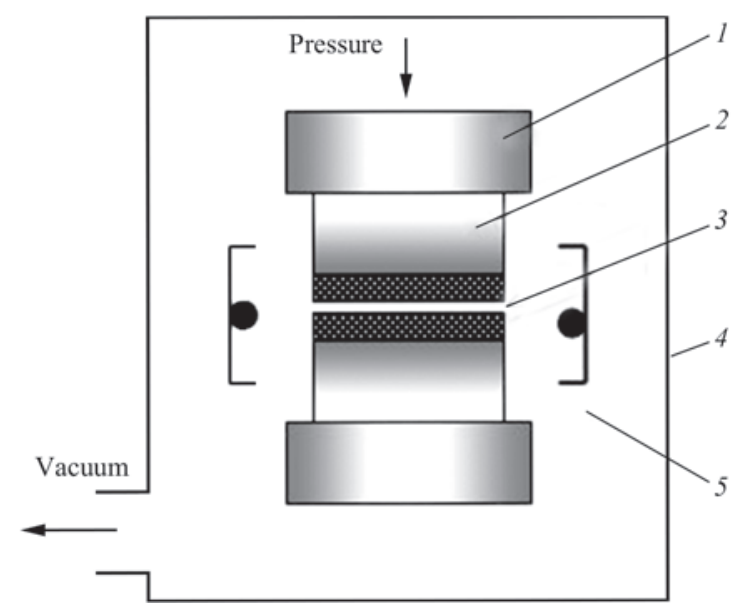

Figure 1. Schematic of conducting experiments in U-394M unit (for description of 1-5 see the text)
Known are works devoted to investigation of oxidation resistance of both intermetallic alloys based on $\gamma$-TiAl [12-14], and of coatings on these alloys $[15,16]$.

For $\gamma$-TiAl intermetallic alloys, however, the influence of technological parameters of diffusion welding on physical-chemical state of the contact surface has not been studied. In this connection the objective of the work consisted in studying the influence of heating temperature on dissolution of oxide film on $\gamma$-TiAl surface.

Materials and methods of investigation. Investigations were conducted on samples of $\gamma$-TiAl intermetallics (Ti-33.36Al-4.97Nb-2.68Cr, wt.\%). Sample size was $10 \times 8 \times 3 \mathrm{~mm}$. Sample surfaces were polished on P400 sandpaper. Sample heating was performed in U-394M unit (Figure 1). Samples were heated at the rate $v=150{ }^{\circ} \mathrm{C} / \mathrm{min}$ up to $800{ }^{\circ} \mathrm{C}$ temperature and soaked for $5 \mathrm{~min}$, which was followed by their oxidation in air.

Furtheron samples of intermetallics (2) with a layer of oxide on contact surfaces (3) were placed in the abutted condition between the dies (1) and heated in the unit vacuum chamber (4) by slot-type electron beam heater (5) up to temperature: $T=900,1050$ and $1200{ }^{\circ} \mathrm{C}$ for $t=20 \mathrm{~min}$ in vacuum $B=1.33 \cdot 10^{-3} \mathrm{~Pa}$. Sample preloading force was $P=5 \mathrm{MPa}$. After cooling to $20^{\circ} \mathrm{C}$ the samples were taken out of vacuum chamber and separated. Sample surfaces were studied by the methods of optical and electron microscopy. Micromechanical characteristics of surface metal layer were evaluated using PMT-3 instrument with $2 \mathrm{~N}$ load.

It should be noted that basic methods for studying the kinetics of interaction of titanium alloys with oxygen, conducted in 1970-1980, were as follows: interference indication, ellipsometry and gravimetry. In our case, investigation of the structure and determination of its elemental composition were conducted by the method of X-Ray microanalysis (XRMA) in an analytical complex, consisting of scanning electron microscope JSM-35 CF of JEOL, and X-ray spectrometer with dispersion by $\mathrm{X}$-ray quantum energy (model INCA Energy-350 of Oxford Instruments Company). As noted in a number of works $[17,18]$ this method has been applied with success to study the kinetics of metal oxidation.

Experimental results and discussion. After oxidation the sample surface had dense oxide film of dark-gray colour (Figure 2). Microhardness of $\gamma$-TiAl intermetallic alloy in the initial state is equal to 4.6 GPa. A significant increase in microhardness up to $13 \mathrm{GPa}$ is found after oxidation.

According to the data of [6], oxide film of darkgray colour on $\gamma$-TiAl surface consists of $\mathrm{TiO}_{2}$ (rutile) and $\alpha-\mathrm{Al}_{2} \mathrm{O}_{3}$. 


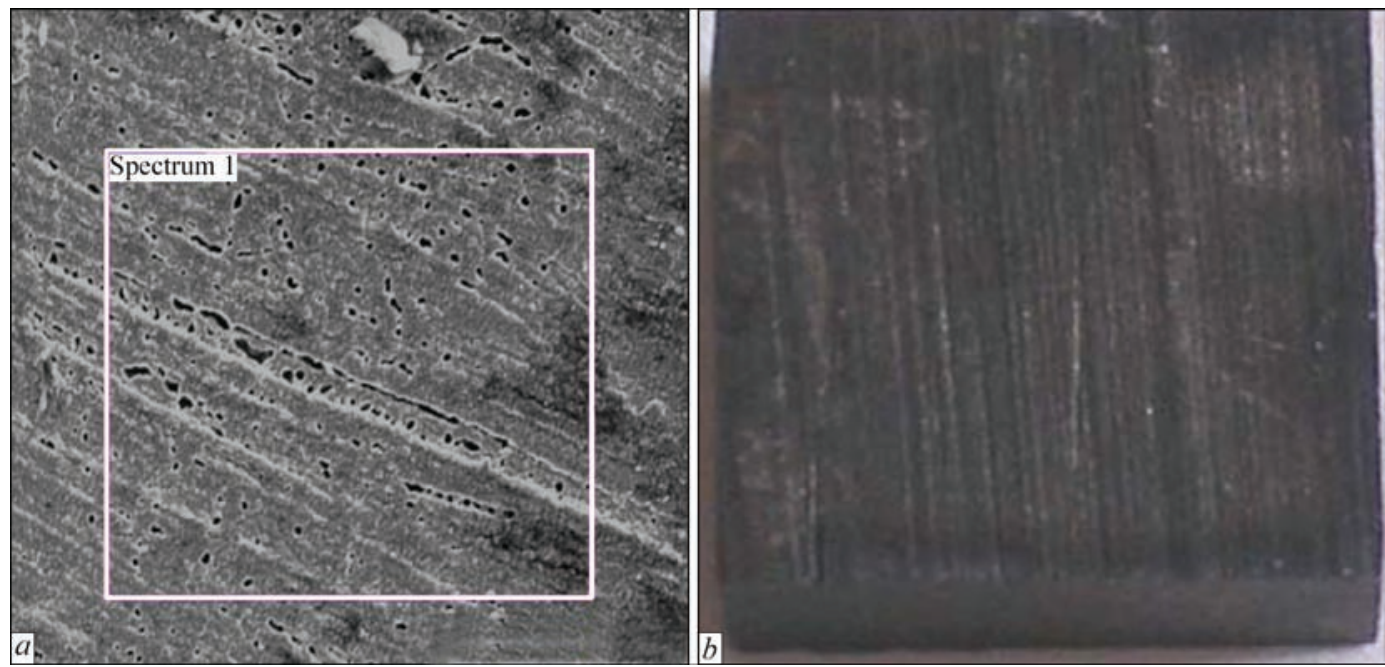

Figure 2. Appearance of the surface of $\gamma$-TiAl sample after heating in vacuum and oxidation in air: $a-$ electron $(\times 250)$; $b-$ optical $(\times 25)$ microscopy
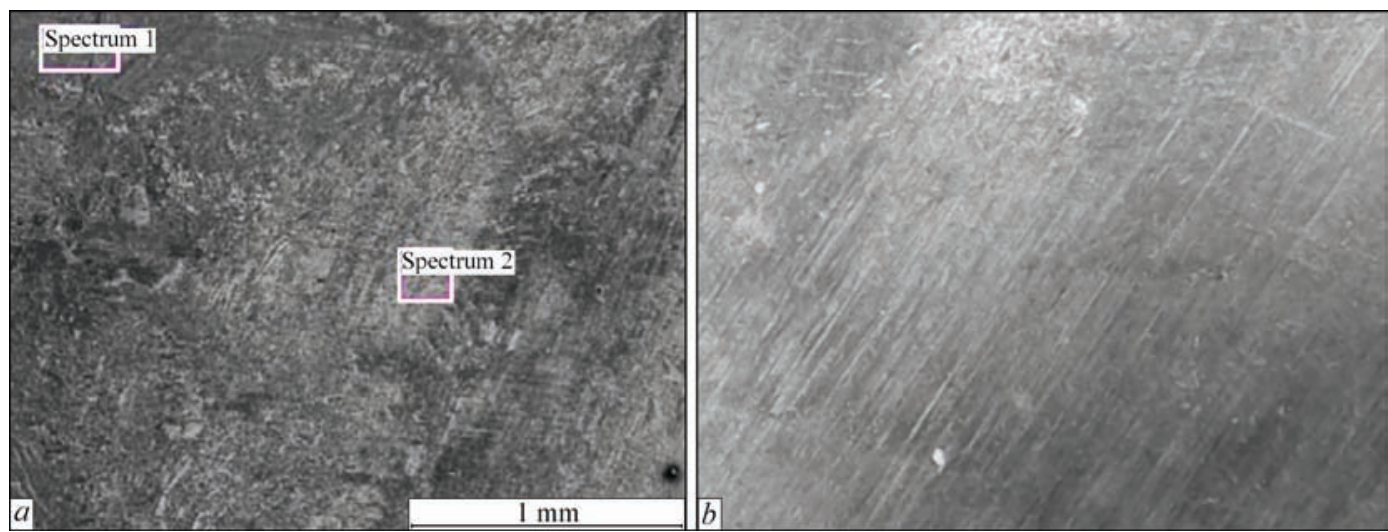

Figure 3. Appearance of $\gamma$-TiAl sample after heating in vacuum at $900{ }^{\circ} \mathrm{C}: a$ - electron $(x 30)$; $b$ - optical $(\times 50)$ microscopy

After oxidation, oxygen content on the sample surface is equal to $40.99 \mathrm{wt} . \%$ (Table 2).

As shown by our studies, autovacuuming of samples (Figure 1) at their heating in vacuum up to $900^{\circ} \mathrm{C}$ and soaking for $20 \mathrm{~min}$, allows lowering oxygen content on the contact surface from 40.99 to 28.62 $29.32 \mathrm{wt} . \%$. Individual areas of adhesion are found on sample surface. Their total number, however, is small (Figure 3). It should be also noted that autovacuuming of samples also results in the change of colour of their contact surfaces from dark-gray to gray. Such a change of surface colour, in our opinion, can be associated with oxygen dissolution in the sample metal that is in agreement with the data of works $[8,10]$.
Increase of the temperature of sample soaking in vacuum to $1050{ }^{\circ} \mathrm{C}$ leads to appearance of longer regions of adhesion with oxygen content of 13.0113.89 wt.\% (Figure 4). In addition to adhesion regions having the colour of unoxidized metal, individual regions of light-grey colour are also observed on contact surface of the samples.

At further increase of heating temperature up to $1200{ }^{\circ} \mathrm{C}$, the nature of surface relief changes significantly (Figure 5), transforming from flat into a voluminous one. Separation ridges are observed in adhesion portions, presence of which is indicative of bonding of these parts of contact surfaces.

Table 2. Element content on the surface of $\gamma$-TiAl sample

\begin{tabular}{|c|c|c|c|c|c|c|}
\hline \multirow{2}{*}{ Treatment mode } & \multirow{2}{*}{ Point number } & \multicolumn{5}{|c|}{ Element content, wt.\% } \\
\cline { 2 - 7 } & & {$[\mathrm{O}]$} & $\mathrm{Ti}$ & $\mathrm{Al}$ & $\mathrm{Cr}$ & $\mathrm{Nb}$ \\
\hline After oxidation & 1 & 40.99 & 36.48 & 17.83 & 1.38 & 3.31 \\
\hline \multirow{2}{*}{ Heating at $900{ }^{\circ} \mathrm{C}$} & 1 & 28.62 & 41.80 & 22.50 & 2.44 & 4.64 \\
\cline { 2 - 7 } & 2 & 29.32 & 44.71 & 21.32 & 1.79 & 3.03 \\
\hline \multirow{2}{*}{ Heating at $1050^{\circ} \mathrm{C}$} & 1 & 13.01 & 53.22 & 27.47 & 2.29 & 4.01 \\
\hline \multirow{2}{*}{ Heating at $1200{ }^{\circ} \mathrm{C}$} & 2 & 13.89 & 53.84 & 25.46 & 2.20 & 4.62 \\
\cline { 2 - 7 } & 1 & 6.12 & 77.56 & 11.58 & 0.00 & 4.74 \\
\cline { 2 - 7 } & 2 & 7.74 & 67.06 & 16.70 & 1.26 & 7.25 \\
\hline
\end{tabular}




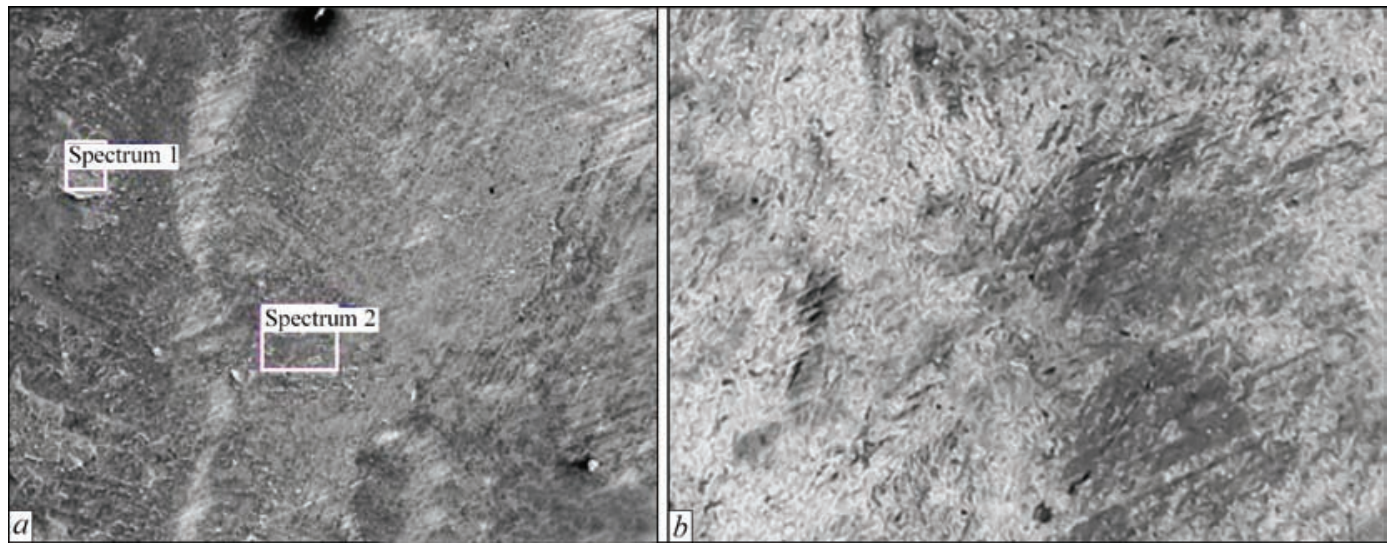

Figure 4. Appearance of $\gamma$-TiAl sample after heating in vacuum at $1050{ }^{\circ} \mathrm{C}: a$ - electron $(\times 30)$; $b$ - optical $(\times 50)$ microscopy
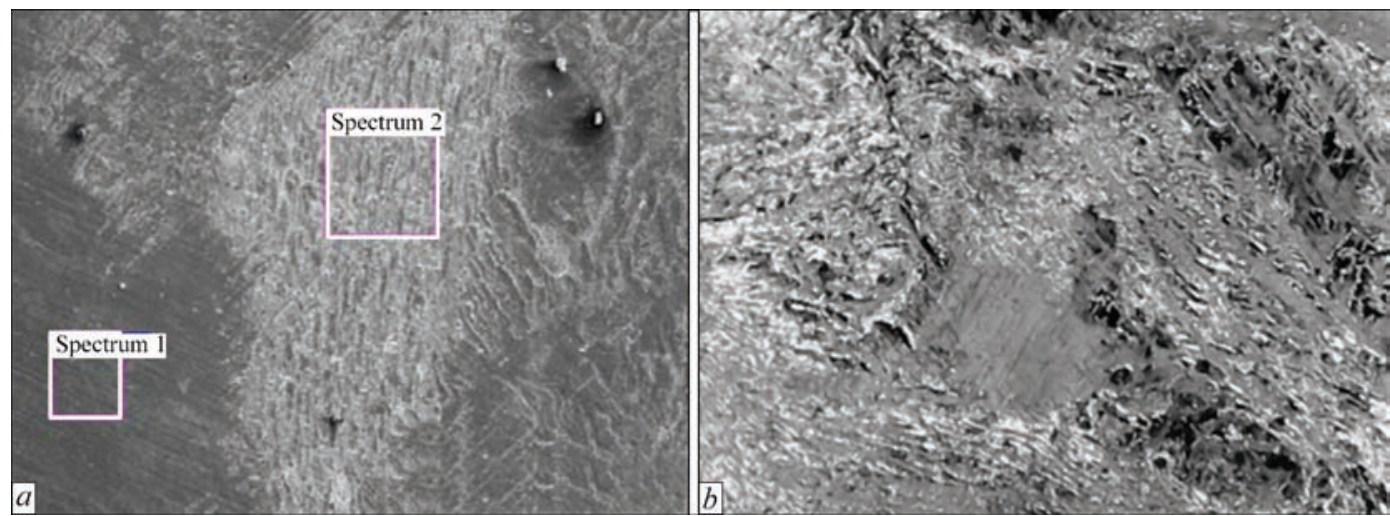

Figure 5. Appearance of $\gamma$-TiAl sample after heating in vacuum at $1200{ }^{\circ} \mathrm{C}$ : $a$ - electron $(\times 30)$; $b$ - optical $(\times 50)$ microscopy

At heating temperature of $1200{ }^{\circ} \mathrm{C}$ adhesion areas take up $90 \%$ of sample surface. Soaking at this temperature ensures complete discoloration of the contact surface that is similar to the mechanism of self-cleaning of doped titanium alloys from oxides [8]. Oxygen content on the surface of $\gamma$-TiAl samples is equal to $6.12-7.74$ wt.\%. Evaluation of micromechanical characteristics on the sample surface after their autovacuuming at $T=1200{ }^{\circ} \mathrm{C}$ shows that microhardness decreases from 13 (after oxidation) to $6.5 \mathrm{GPa}$, as a result of oxygen dissolution in the matrix of intermetallics.

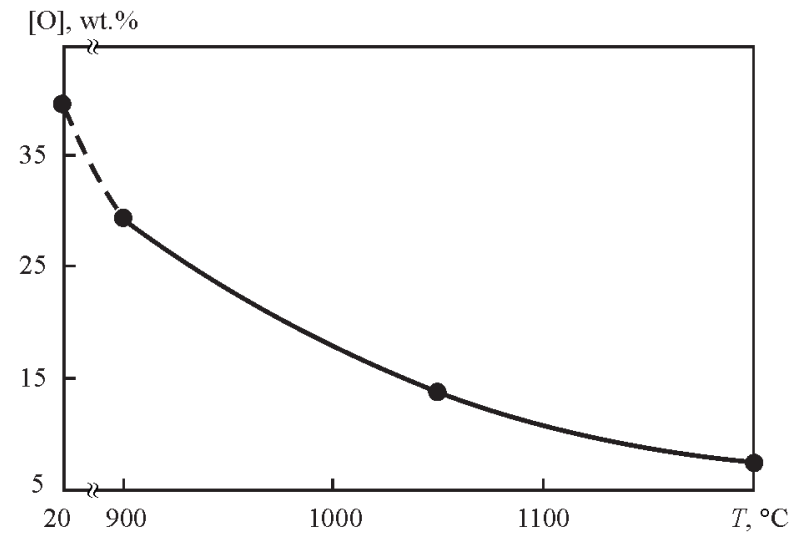

Figure 6. Influence of heating temperature on oxygen content on contact surface of $\gamma$-TiAl samples
Figure 6 is the graph of heating temperature influence on oxygen content on contact surface of $\gamma$-TiAl samples.

As is seen from the graph, titanium aluminide heating at $1200{ }^{\circ} \mathrm{C}$ for $20 \mathrm{~min}$ in vacuum allows oxygen content in the butt to be reduced 5 times: from 40.99 after oxidation to $6.12-7.74$ wt.\%.

Experimental results agree with those of [6], in which the influence of diffusion welding parameters on formation of physical contact in the butt joint was studied on $\gamma$-TiAl alloy. The authors of the work come to the conclusion that optimum welding temperature

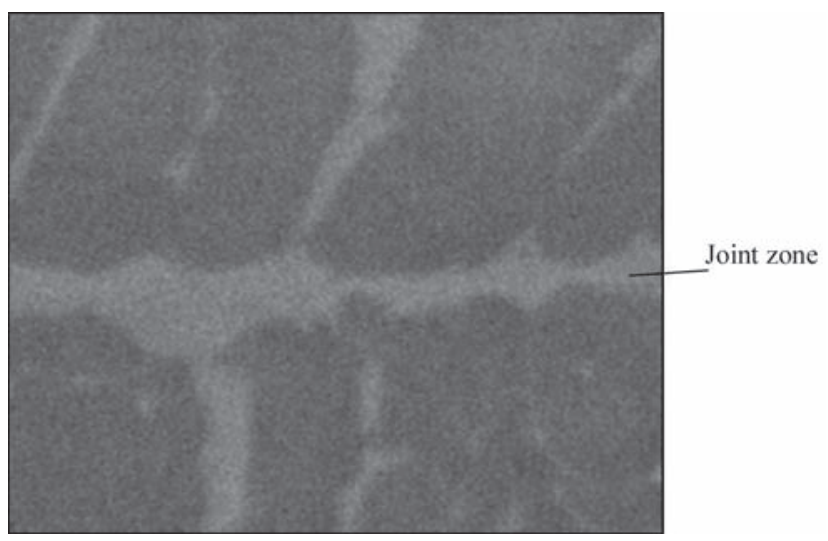

Figure 7. Microstructure $(\times 3000)$ of the zone of $\gamma$-TiAl joint produced at diffusion welding in the following mode: $T=1200{ }^{\circ} \mathrm{C}$, $t=20 \min , P=7 \mathrm{MPa}$ 
is $T=1200{ }^{\circ} \mathrm{C}$ at soaking time $t=60 \mathrm{~min}$, and pressure $P=10 \mathrm{MPa}$ that in the authors' opinion allows producing welded joints without residue of oxide film in the butt weld.

As shown by our studies, vacuum diffusion welding of $\gamma$-TiAl intermetallic alloy in the following mode: $T=1200{ }^{\circ} \mathrm{C}, t=20 \mathrm{~min}, P=70 \mathrm{MPa}$, also provides joints (Figure 7), which have no defects in the form of micropores or residue of oxide inclusions.

Thus, it is shown in the case of investigation of oxygen content on $\gamma$-TiAl surfaces after oxidation in air and heating in vacuum, that sample heating up to $1200{ }^{\circ} \mathrm{C}$ at soaking for $20 \mathrm{~min}$ promotes reduction of oxygen cotent on contact surfaces by more than 5 times from 40.99 in as-oxidized state up to $6.12-7.74 \mathrm{wt} . \%$. Analysis of fracture surface of samples after their autovacuuming shows that dissolution of oxide film in intermetallic alloy matrix in the contact zone results in complete discoloration of the mated surfaces that is similar to the mechanism of self-cleaning of doped titanium alloys from oxides. Vacuum diffusion welding of $\gamma$-TiAl (Ti-33.36Al-4.79Nb-2.68Cr, wt.\%) in the following mode: temperature $T=1200{ }^{\circ} \mathrm{C}$, pressure $P=70 \mathrm{MPa}$, process time $t=20$ min provides formation of defectfree joints.

1. Ustinov, A.I. et al. (2008) Diffusion welding of $\gamma$-TiAl based alloys through nanolayered foil of $\mathrm{Ti} / \mathrm{Al}$ system. Intermetallics, 16(8), 1043-1045.

2. Kharchenko, G.K., Falchenko, Yu.V., Petrushinets, L.V. (2012) Diffusion welding in vacuum of intermetallic $\gamma$-TiAl alloy with VT8 titanium alloy. Visnyk ChDTU. Ser. Tekhnichni Nauki, 1, 131-135.

3. Godfrey, S.P., Threadgill, P.L., Strangwood, M.S. (1993) High temperature phase transformation kinetics and their effects on diffusion bonding of Ti48Al-2Mn-2Nb. J. de Physique IV, 3(11), 485-488.
4. Bohm, K.-H., Cam, G., Kocak, M. (1997) Charakterisierung diffusionsgeschweisster Titanaluminide. Schweissen und Schneiden, 9, 660-671.

5. Cam, G., Bohm, K.-H., Kocak, M. (1999) Diffusionsschweissen feingegossener Titanaluminide. Ibid., 8, 470-475.

6. Nakao, Y., Shinozaki, K., Hamada, M. (1991) Diffusion bonding of intermetallic compound TiAl. ISIJ Int., 31(10), 1260-1266.

7. Yushtin, A.N., Zamkov, V.N., Sabokar, V.K. et al. (2001) Pressure welding of intermetallic alloy $\gamma$-TiAl. The Paton Welding J., 1, 33-37.

8. Karakozov, E.S. et al. (1977) Diffusion welding of titanium. Moscow: Metallurgiya.

9. Kuchuk-Yatsenko, S.I. et al. (1998) Self-cleaning from oxides of abutted surfaces in solid phase welding with heating (Analytical review). Avtomatich. Svarka, 2, 16-23.

10. Peshkov, V.V., Kholodov, V.P. (1985) Kinetics of oxide films dissolution in titanium during diffusion welding. Svarochn. Proizvodstvo, 4, 35-37.

11. Bondar, A.V. et al. (1998) Diffusion welding of titanium and its alloys. Voronezh: VGU.

12. Fishgojt, L.A., Meshkov, L.L. (1990) Corrosion-electrochemical properties of intermetallics of titanium-aluminium system. Vestnik MGU. Ser. 2. Khimiya, 40(6), 369-372.

13. Malecka, J. (2013) The surface layer degradation of $\gamma$-TiAl phase based alloy. J. of Achievements in Materials and Manufacturing Engineering, 58(5), 31-37.

14. Milman, Yu.V. et al. (2012) Influence of alloying on heat resistance of aluminium intermetallics based alloy of Al-Ti-Cr system with L12 type structure. Dopovidi NANU, 4, 87-93.

15. Chu, M.S., Wu, S.K. (2004) Improvement in the oxidation resistance of $\alpha 2-\mathrm{Ti} 3 \mathrm{Al}$ by sputtering $\mathrm{Al}$ film and subsequent interdiffusion treatment. Surface and Coating Technology, 179, 257-264.

16. $W u$ Xiang-qing et al. (2010) Effects of additives on corrosion and wear resistance of micro-arc oxidation coatings on TiAl alloy. Transact. of Nonferrous Met. Soc. China, 20, 1032-1036.

17. Solntsev, K.A. et al. (2008) Specifics of titanium oxidation kinetics in producing of rutile by oxidizing design of thin-wall ceramics. Neorganicheskie Materialy, 44(8), 969-975.

18. Pogrebnyak, A.D. et al. (2008) Structure and properties of coatings produced by electroplating-plasma oxidation on substrate of $\mathrm{Al}-\mathrm{Cu}$ and $\mathrm{Al}-\mathrm{Mg}$ alloys. Fizicheskaya Inzheneriya Poverkhnosti, 6(1/2), 43-50. 


\title{
DEVELOPMENT OF ELECTRIC ARC SPRAY COATINGS FOR RECONDITIONING RODS OF HYDRAULIC CYLINDERS OF MINING EQUIPMENT, USING FLUX-CORED WIRES*
}

\author{
T.R. STUPNITSKY, M.M. STUDENT, V.I. POKHMURSKY and M.B. TYMUS \\ G.V. Karpenko Physico-Mechanical Institute, NASU \\ 5 Nauchnaya Str., 79060, Lvov, Ukraine. E-mail: student-m-m@ipm.lviv.ua
}

\begin{abstract}
The paper outlines the main requirements to flux-cored wires based on ferroalloys of $\mathrm{Fe}-\mathrm{Cr}-\mathrm{C}$ and $\mathrm{Fe}-\mathrm{Cr}-\mathrm{B}$ systems with more than $12 \mathrm{wt} . \%$ chromium for electric arc spraying of wear- and corrosion-resistant coatings. It is found that, unlike steel, presence of $12 \mathrm{wt}$ \% chromium in flux-cored wire charge does not ensure corrosion resistance of coatings in neutral water solutions. The causes for that were studied. It is experimentally established that corrosion resistance of coatings containing more than $12 \mathrm{wt} . \%$ chromium is inversely proportional to their chemical microheterogeneity. High effectiveness of application of coating impregnation with inhibited $3 \%$ solution of Hydroway 1060 to prevent aggressive environment penetration through pores in the coating to the substrate is demonstrated. Synergistic compositions of sodium benzoate + benzyl benzoate inhibitors were developed, which provide up to $99.14 \%$ degree of corrosion protection of the coating steel substrate. 12 Ref., 1 Table, 8 Figures.
\end{abstract}

Keywords : arc spray coatings, flux-cored wires, ferroalloys, chemical heterogeneity, corrosion resistance, oxide, carbide, boride, inhibitor

A considerable part of structural elements of critical machines and mechanisms, in particular, hydraulic cylinders of mine, mining and utility equipment, are exposed to corrosion-abrasion wear during long-term operation under stringent loading conditions in neutral water environments (Figure 1).

In most of the cases, electrolytical chromium plating method is used for protection from corrosion-abrasion wear. However, because of its carcinogenic

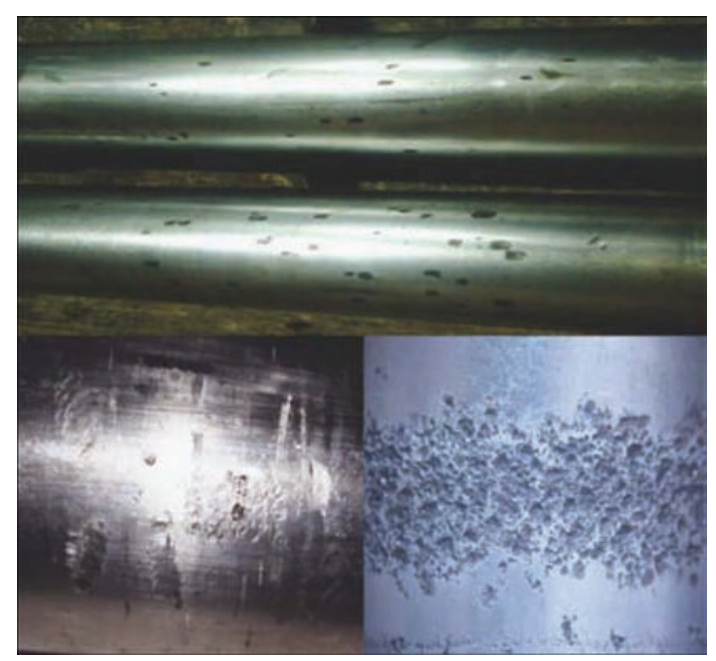

Figure 1. Damage of rod surface: local corrosion, bruises, burrs, abrasive wear wastes, alternative technologies are actively sought in industrialized countries. Leading world companies (Metco, Castolin, TAFA, Deloro, Nanosteel) apply thermal coating technologies for this purpose [1-3]. Among these technologies electric arc spraying of coatings is characterized by high productivity at the lowest cost that attracts particular interest [4-6]. Solid stainless wires of $40 \mathrm{Kh} 13$ or $08 \mathrm{Kh} 18 \mathrm{~N} 10 \mathrm{~T}$ type are often used to form corrosion-resistant electric arc spay coatings (EASC). However, coatings from them are characterized by low hardness and wear resistance and quite high cost $[7,8]$.

Methodological aspects of research. Flux-cored wires ( $\mathrm{FCW}$ ) of $\mathrm{Fe}-\mathrm{Cr}-\mathrm{C}$ and $\mathrm{Fe}-\mathrm{Cr}-\mathrm{B}$ systems were manufactured in a sheath of low-carbon steel $08 \mathrm{kp}$ (rimmed). Used as charge materials were powders of high-carbon ferrochromium, ferrochromeboron, chromium, ferrosilicium, ferrophosphorus and self-fluxing alloy PG-10N-01. Coefficient of FCW filling was equal to $25-27 \%$. Electric arc spray coatings $1.2-1.5 \mathrm{~mm}$ thick were applied with FMI-2 metallizer from $08 \mathrm{Kh} 18 \mathrm{~N} 10 \mathrm{~T}$ steel and FCW of optimized compositions of $1.8 \mathrm{~mm}$ diameter on samples from $12 \mathrm{Kh} 1 \mathrm{MF}$ steel. Modes of coating deposition were as follows: current of $150 \mathrm{~A}$, arc voltage of $32-34 \mathrm{~V}$.

\footnotetext{
${ }^{*}$ Work was performed within the framework of NASU Program «Problems of Life and Safe Operation of Structures, Constructions and Machines» in 2013-2015.
} 
Spraying was performed by an air jet under pressure of 0.4-0.8 MPa from $150 \mathrm{~mm}$ distance.

Completeness of fusion of the charge and sheath in coatings (chemical microheterogeneity) was assessed by the coefficient of microheterogeneity $\left(K_{\mathrm{MH}}\right)$ introduced by us [9], and by electrochemical procedure of moving capillary [10]. $K_{\mathrm{MH}}$ coefficient characterizes the deviation of the content of each of the alloying elements within an individual lamel from its average content in the coating. In order to determine $K_{\mathrm{MH}}$ coefficient, integral content of a specific alloying element in a section of $100 \mathrm{~mm}^{2}$ area was compared with its local content in rectangular sections of $35.10^{-4} \mathrm{~mm}^{2}$ area, which by their size are comparable with average area of lamels in coatings. Determination of coating $K_{\mathrm{MH}}$ was performed in not less that 10 sections, located at a distance of minimum $5 \mathrm{~mm}$ from each other by the width of the spraying spot, which was equal to 25-30 mm. $K_{\mathrm{MH}}$ value of these sections was averaged.

Corrosion properties were determined in potentiodynamic mode in SVA-1BM unit by three-electrode schematic: working electrode (sample) — reference electrode (silver-chlorine of EVL-1M1 type) - auxiliary electrode (platinum). Rate of change in potential was equal to $2 \mathrm{mV} / \mathrm{s}$. Corrosion currents were determined by extrapolating linear sections of polarization curves to corrosion potential.

Investigation results and their discussion. When EASC are produced by spraying $\mathrm{FCW}$ of $\mathrm{Fe}-\mathrm{Cr}-\mathrm{C}$ and $\mathrm{Fe}-\mathrm{Cr}-\mathrm{B}$ systems, no common pool is formed and chromium-containing charge does not completely dissolve in the steel sheath melt, because of the transience of wire melting processes. This results in strong chemical microheterogeneity of the coatings that significantly influences their corrosion resistance.

It is found that unlike solid consumables, presence of $12 \mathrm{wt} . \%$ chromium in FCW charge does not provide corrosion resistance of EASC in neutral water environments. This is caused by the following:

- non-uniform distribution of chromium in coating lamels, because of their high chemical microheterogeneity. Drops, forming from FCW melt (unlike drops formed from solid wire), have markedly different composition, which is determined by the completeness of fusion of charge components with each other and with the steel sheath;

- transition of a certain part of chromium into carbides (for $\mathrm{Fe}-\mathrm{Cr}-\mathrm{C}$ alloying system) and into borides (for $\mathrm{Fe}-\mathrm{Cr}-\mathrm{B}$ alloying system) that essentially reduces its content in the coating solid solution;

- depletion of chromium content in the coating solid solution as a result of oxide formation from a certain part of it.

It is experimentally established that during spraying of EASC with $\mathrm{FCW}$ of $\mathrm{Fe}-\mathrm{Cr}-\mathrm{C}$ and $\mathrm{Fe}-\mathrm{Cr}-\mathrm{B}$ systems, coatings of the following three types can form, depending on the completeness of fusion of FCW charge and its steel sheath (Figure 2). FCW charge does not fuse with the steel sheath melt, and chemically microheterogeneous coating forms, which consists of lamels formed separately from the steel sheath with inclusions of refractory charge particles (Figure 2,a). Here, the lamels differ strongly by their chemical composition and chromium concentration in them. $K_{\mathrm{MH}}$ for this type of coatings practically is in the range of $0.3-0.99$. This is type I. FCW charge is partially fused with the sheath. In this case, coating lamels differ less by chemical elements content, in particular, also by chromium concentration. For this coating $K_{\mathrm{MH}}$ can be in the range of $0.1-0.3$ (Figure 2, b). This is type II. Charge components are completely fused with each other and its sheath, forming chemically homogeneous melt (Figure 2,c). This is type III. In this case, FCW calculated chemical composition corresponds to actual composition of each formed coating lamel by more than $90 \%$, and $K_{\mathrm{MH}}$ will be less than 0.1 .

It is found that to provide corrosion resistance to coatings from FCW in neutral water environments their microstructure should correspond to third coating type (Figure 2,c) and should have $K_{\mathrm{MH}}$ equal to not less than 0.1 by chromium.

As shown by experimental data, presence of just high-carbon ferrochromium (FCW 140Kh14) does

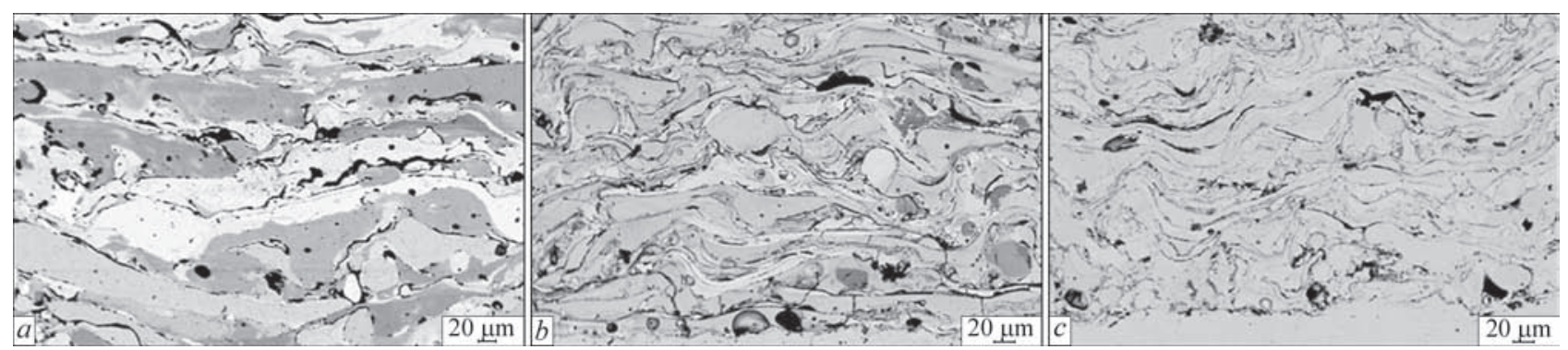

Figure 2. EASC typical structures, depending on the degree of fusion of FCW charge components with its sheath: $a$ - just high-chromium charge; $b$ - high-chromium charge with addition of PG-10N-01; $c$ - high-chromium charge with addition of ferrosilicium and ferrophosphorus 


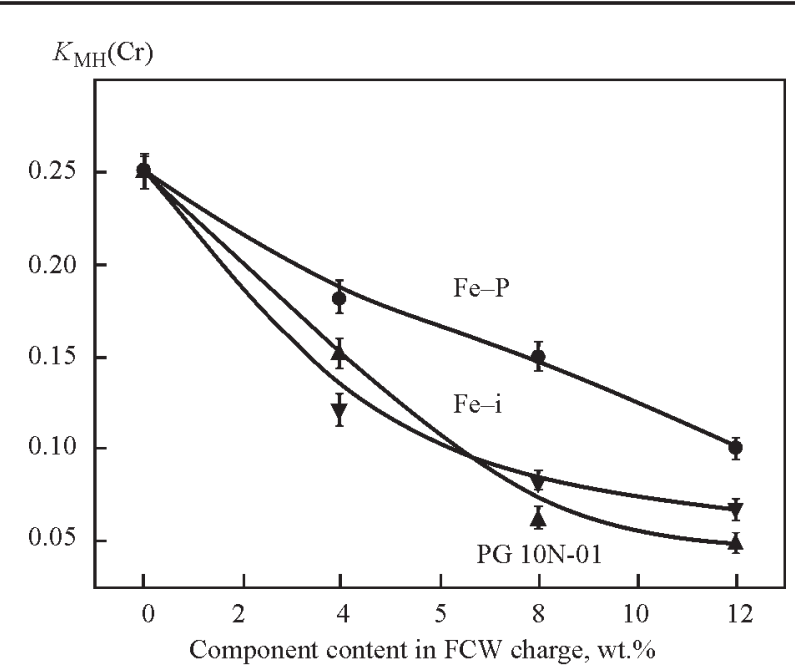

Figure 3. Influence of the content of FCW charge components on coefficient $K_{\mathrm{MH}}(\mathrm{Cr})$

not provide sound fusion of FCW charge and sheath (Figure 2,a). It is found that powders of ferrosilicium (Fe-Si), ferrophosphorus (Fe-P) or self-fluxing alloy (PG-10N-01) should be added to FCW charge (alongside ferrochromium or ferrochomeboron, which provide the required chromium content and hardness to the coating), in order to improve fusion and achieve uniform distribution of chromium in coating lamels. These powders can form low-temperature eutectics between FCW charge components and its sheath. It was found that this allows reducing chemical heterogeneity of coatings to the level of $K_{\mathrm{MH}}(\mathrm{Cr})=0.05$ (Figure 3).

It is experimentally established that eutectic melting of charge components promotes formation of a considerable quantity of low-melting melt inside FCW, in which refractory components of ferrochromium are dissolved (Figure 4). This also provides smelting of the melt with the inner surface of FCW sheath already at 2-3 mm distance from the arc active spots. As a result, chemical heterogeneity of the coatings is strongly reduced, as the time of metal staying in the liquid phase becomes longer (Figure 5).

To prevent chromium transition into oxides during drop formation at coating spray-deposition, it is pro-

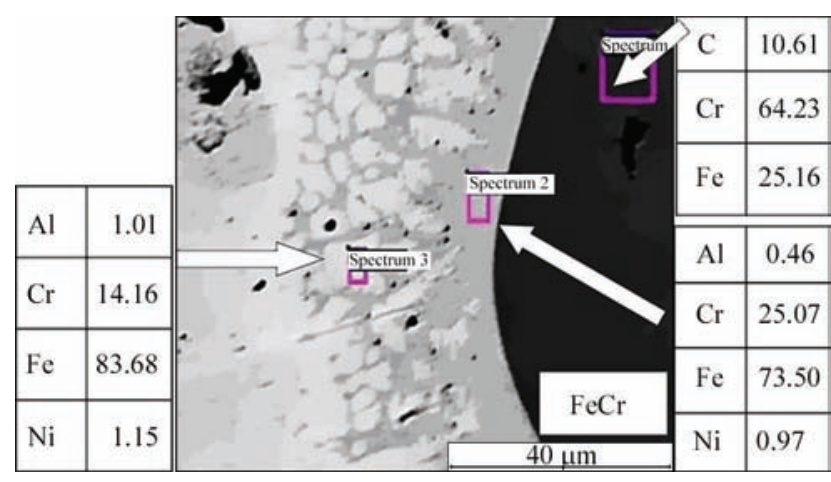

Figure 4. Ferrochromium dissolution in the melt of 140Kh14N2TYu FCW posed to add to FCW charge composition such elements as $\mathrm{Al}, \mathrm{Ti}, \mathrm{Si}, \mathrm{B}$ in which free energy of oxide formation is smaller than that for chromium oxides, and for this reason the oxides of these elements form faster. Thus, addition of up to $2 \mathrm{wt} . \% \mathrm{Al}$ or Si to FCW charge partially prevents formation of chromium-containing oxides and leads to running of alumo- and silicothermic reactions of chromium reduction from its oxides. On the whole, this promotes transition of almost entire quantity of chromium from the composition of FCW charge into the coating solid solution.

At the same time, it is impossible to prevent formation of chromium-based carbides and borides during solidification of coating drops on the sprayed surface. Therefore, the quantity of chromium which will participate in their formation should be taken into account and compensated. For $\mathrm{FCW}$ of $\mathrm{Fe}-\mathrm{Cr}-\mathrm{C}$ and $\mathrm{Fe}-\mathrm{Cr}-\mathrm{B}$ systems calculation formulas are proposed for determination of the quantity of chromium in them (taking into account the quantity to be consumed in formation of carbides and borides), sufficient to provide EASC corrosion resistance in neutral water environments [11]. When performing calculations by the proposed formulas, it was found that for coatings from FCW of $\mathrm{Fe}-\mathrm{Cr}-\mathrm{B}$ system it is necessary to provide greater content of chromium than for coatings from FCW of $\mathrm{Fe}-\mathrm{Cr}-\mathrm{C}$ system. After all, chromium-containing carbides form only in the coating ferritic phase, the quantity of which in the coating structure can be easily limited by FCW charge component composition, whereas chromium-containing borides in coatings from FCW of $\mathrm{Fe}-\mathrm{Cr}-\mathrm{B}$ system form in all the present phases. Performed calculations allowed optimizing the compositions of $140 \mathrm{Kh} 14 \mathrm{~N} 2 \mathrm{TYu} \mathrm{FCW}$ of $\mathrm{Fe}-\mathrm{Cr}-\mathrm{C}$ system and 70Kh20RZGS2 Yu FCW of Fe$\mathrm{Cr}-\mathrm{B}$ system by the quantity of chromium in them.

Corrosion properties of coatings. Electrochemical studies showed that corrosion resistance $\left(I_{\text {corr }}\right)$ of coatings of $\mathrm{Fe}-\mathrm{Cr}-\mathrm{C}$ system in $3 \%$ water solution of $\mathrm{NaCl}$ is inversely proportional to their chemical mi-

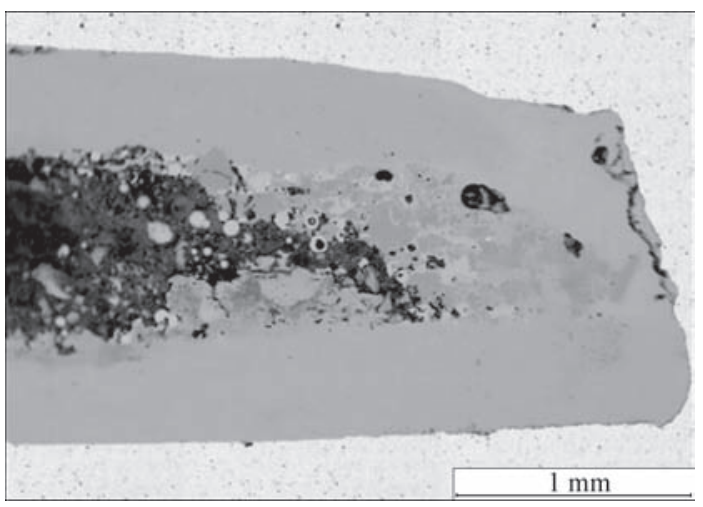

Figure 5. Influence of the content of self-fluxing alloy PG-10N-01 in FCW charge on smelting of the charge and sheath 


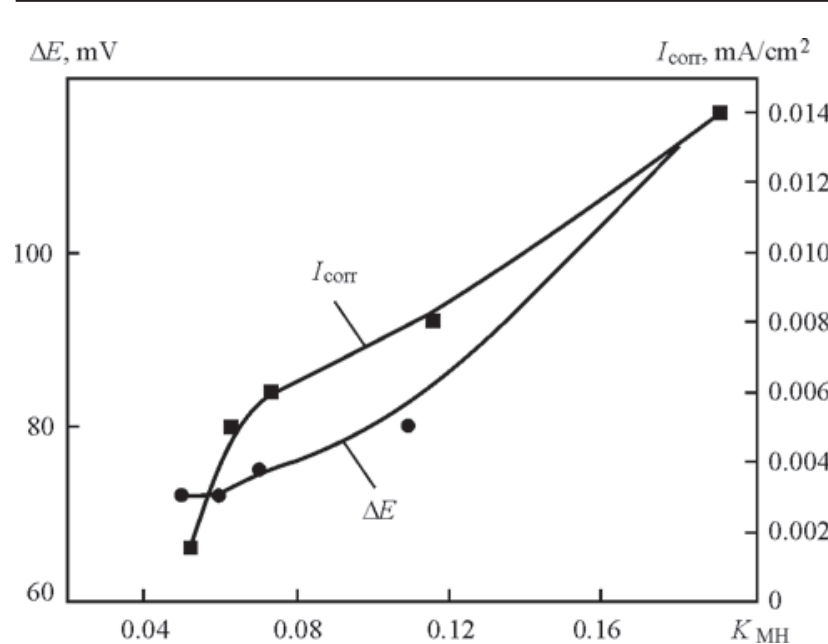

Figure 6. Dependencies of density of corrosion current $I_{\text {corr }}$ and electrochemical microheterogeneity of coating $\Delta E$ on coefficient $K_{\mathrm{MH}}$ in $3 \%$ water solution of $\mathrm{NaCl}$

croheterogeneity by the content of chromium, determined by $K_{\mathrm{MH}}$ coefficient, as well as electrochemical microheterogeneity, determined by the technique of moving capillary, which were found to correlate with each other (Figure 6). With reduction of $K_{\mathrm{MH}}$ coefficient $(\mathrm{Cr})$ from 0.2 to 0.05 the density of corrosion current decreases practically by an order from 0.014 to $0.0015 \mathrm{~mA} / \mathrm{cm}^{2}$, and comes to the level of corrosion currents of $0.0008 \mathrm{~mA} / \mathrm{cm}^{2}$, which were recorded for a coating, formed from stainless wire $08 \mathrm{Kh} 18 \mathrm{~N} 10 \mathrm{~T}$. At the same time, it was found that increasing corrosion resistance of the coatings proper does not allow providing reliable protection of metal bases, on which coatings were formed, from the impact of corrosive environment, as a result of their natural porosity.

To prevent penetration of working environment through the pores inside the coating (to the metal base), it was proposed to pre-impregnate the coatings with mineral oil I-20, or $3 \%$ water solution of Emulsol of Hydroway-1060 grade, which is used as working fluids in hydraulic cylinders for various purposes.

Preliminary studies indicated the need for development of effective inhibited compositions based on sodium benzoate, sodium silicate and benzyl benzoate, which are environmentally safe.

At long-term testing of coatings in "acid rain» environment, their electrode potential stopped at the level of $-450 \mathrm{mV}$ (Figure 7), that means that the fluid had passed through the spray-deposited coating to the steel base. After coating impregnation with $3 \%$ solution of Hydroway-1060 Emulsol its potential effectively shifts to positive values and stops at the level of $-265 \mathrm{mV}$, whereas impregnation with $3 \%$ solution of Hydroway-1060 Emulsol, inhibited by a synergistic composition from a mixture of $1 \mathrm{~g} / 1$ of sodium benzoate (SB) and $1 \mathrm{~g} / 1$ of benzyl benzoate (BB), shifts its potential to the positive region and sets it as the level

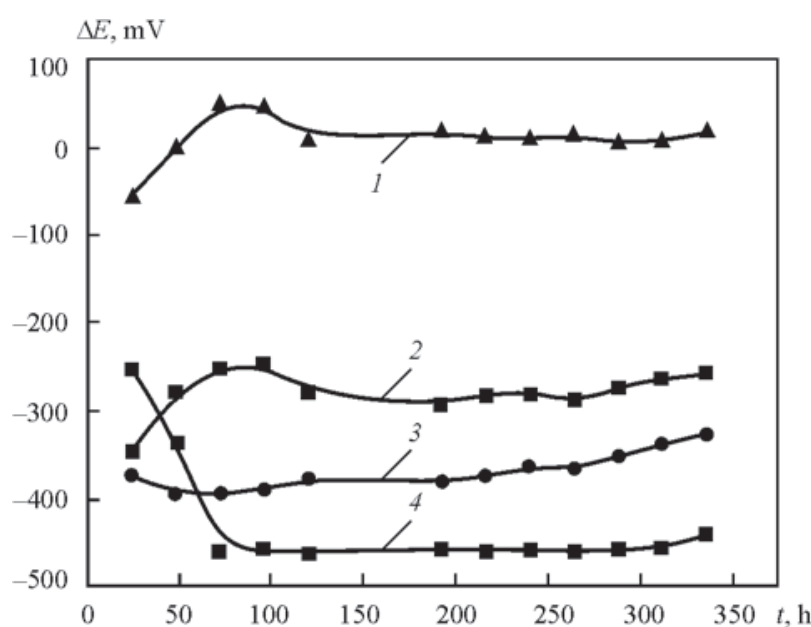

Figure 7. Change of electrode potential $\Delta E$ of coating from $140 \mathrm{Kh} 14 \mathrm{~N} 2 \mathrm{TYu}$ FCW with the time of its soaking in the environment of «acid rain», impregnated with different fluids: $1-3 \%$ Emulsol + SB + BB; 2 - 3\% Emulsol; 3 - I20 oil; 4 - without impregnation

of $20 \mathrm{mV}$. Now, this means that this inhibited working fluid for hydraulic cylinders not only prevents fluid access inside the coatings to the steel base, but also effectively inhibits its surface, as well as the forming surfaces - the interlamelar space of the coatings.

After exposure for $168 \mathrm{~h}$ the electrode potential shifts to the anode zone, that characterizes formation of specific compounds on the surface, having iron cations and benzoate anions in their composition. A characteristic feature of benzoate-containing compounds is their adsorbing on the steel surface, creating rather dense passive film, which prevents interaction of corroding environment and steel surface. This results in a significant reduction of corrosion currents of coating

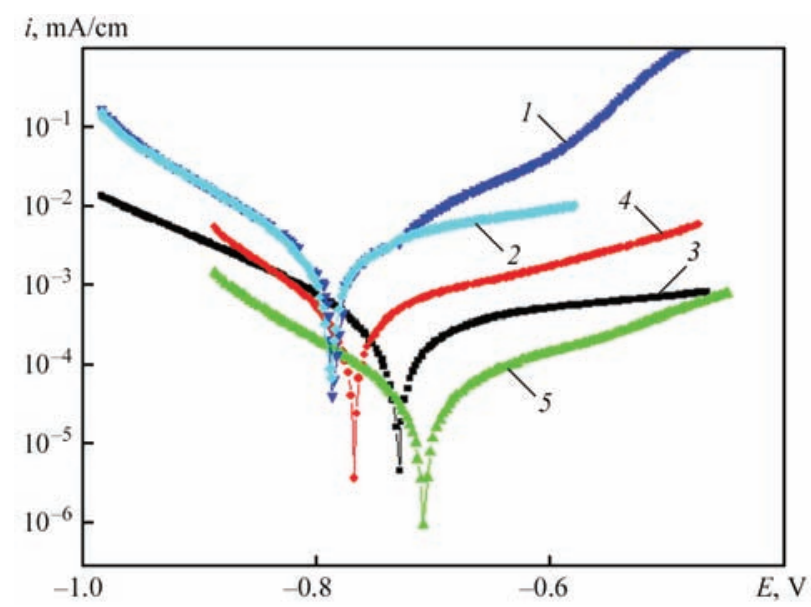

Figure 8. Corrosion resistance of coating substrate $-12 \mathrm{Kh} 1 \mathrm{MF}$ steel, in the solution of $3 \% \mathrm{NaCl}$ and $3 \%$ emulsion of Hydroway-1060 Emulsol, inhibited with synergistic composition, soaking for $168 \mathrm{~h}$. Environment composition is 1:1. 1- 12Kh1MF in $3 \% \mathrm{NaCl}$; $2-12 \mathrm{Kh} 1 \mathrm{MF}$ in $3 \%$ water emulsion of Emulsol; $3-1 \mathrm{~g} / 1$ of sodium benzoate; $4-1 \mathrm{~g} / 1$ of sodium benzoate + $1 \mathrm{~g} / \mathrm{l}$ of sodium silicate; $5-1 \mathrm{~g} / \mathrm{l}$ of sodium benzoate $+1 \mathrm{~g} / \mathrm{l}$ of benzyl benzoate 
Density of corrosion current of $12 \mathrm{Kh} 1 \mathrm{MF}$ steel at application of various inhibitors

\begin{tabular}{|c|c|c|c|c|c|}
\hline \multirow{2}{*}{$\begin{array}{c}\text { Corrosion current } \\
\text { density }\end{array}$} & \multicolumn{5}{|c|}{$12 \mathrm{Kh} 1 \mathrm{MF}$ steel in chlorine-containing environment with different inhibitors } \\
\cline { 2 - 6 } & $12 \mathrm{Kh} 1 \mathrm{MF}+3 \% \mathrm{NaCl}$ & $12 \mathrm{Kh}^{2} \mathrm{MF}^{*}$ & $\mathrm{SB}^{*}$ & $\mathrm{SB}+\mathrm{SS}^{*}$ & $\mathrm{SB}^{*} \mathrm{BB}^{*}$ \\
\hline$I_{\text {corr }} \cdot 10^{-4}, \mathrm{~mA} / \mathrm{cm}^{2}$ & 8.94 & 5.9 & 2.72 & 0.86 & 0.72 \\
\hline \multicolumn{7}{|c|}{$T=168 \mathrm{~h}$} & 3.96 & 0.35 \\
\hline$I_{\text {corr }} \cdot 10^{-4}, \mathrm{~mA} / \mathrm{cm}^{2}$ & 14.4 & 22.2 & 2.13 & \\
\hline *3 $\%$ emulsion of Emulsol in chloride-containing medium.
\end{tabular}

substrate material, compared to current in an uninhibited environment (Figure 8).

As a result of conducted electrochemical studies in chloride-containing medium, the synergism phenomenon is observed at the combination of $3 \%$ emulsion of Emulsol with $1 \mathrm{~g} / \mathrm{l}$ of sodium benzoate and $1 \mathrm{~g} / \mathrm{l}$ of benzyl benzoate, as $I_{\text {corr }}$ is reduced up to 6 times, compared with the case, when individual inhibitors were used (see Table).

Calculation of the effectiveness of the action of inhibitors performed by the formula for determination of the degree of protection [12], showed that inhibition in $3 \%$ emulsion of Hydroway-1060 Emulsol in chloride-containing environment of sodium benzoate provides the degree of protection $\mathrm{Z}(\mathrm{SB})=90.41$, and that of sodium silicate $\mathrm{Z}(\mathrm{SB}+\mathrm{SS})=82.16$, whereas the solution of $1 \mathrm{~g} / \mathrm{l}$ of sodium benzoate $+1 \mathrm{~g} / \mathrm{l}$ of benzyl benzoate provides the best degree of corrosion protection of $12 \mathrm{Kh} 1 \mathrm{MF}$ steel $(\mathrm{Z}(\mathrm{SB}+\mathrm{BB})=99.14)$. During coating service in inhibited Emulsol environment metal inhibition proceeds through formation of adsorption passive films on the surface that is the result of interaction of cations of ionized metal with ionic residue of inhibitors.

\section{Conclusions}

1. 140Kh14N2TYu, 70Kh20RZGS2Yu flux-cored wires of $\mathrm{Fe}-\mathrm{Cr}-\mathrm{C}$ and $\mathrm{Fe}-\mathrm{Cr}-\mathrm{B}$ systems were developed, which allow forming electric arc spray coatings with low coefficient of chemical microheterogeneity $K_{\mathrm{MH}}(\mathrm{Cr})=0.05-0.07$ and with corrosion resistance on the level of coating sprayed with stainless wire from $08 \mathrm{Kh} 18 \mathrm{~N} 10 \mathrm{~T}$ steel, as well as wear resistance on the level of galvanic chromium coating.

2. Synergistic compositions of inhibitors were developed, which are added to $3 \%$ emulsion of Hydro- way-1060 Emulsol and effectively protect both the electric arc spray coating, and metallic material of its substrate from corrosion in chloride-containing environment with degree of protection $\mathrm{Z}(\mathrm{SB}+\mathrm{BB})=$ $=99.14 \%$.

1. Picas, J.A., Forn, A., Matthaus, G. (2006) HVOF coatings as an alternative to hard chrome for pistons and valves. Wear, 261, 477-488.

2. Aguero, A. et. al. (2011) HVOF-deposited WCCOCr as replacement for hard $\mathrm{Cr}$ in landing gear actuators. J. Thermal Spray Techn., 20(6), 1292-1309.

3. Flitney, B. (2007) Alternatives to chrome for hydraulic actuators. Sealing Technology, 10, 8-12.

4. Markovich, S.I. (2007) Increase in wear resistance of machine parts by electric arc spraying of composite coatings using dissimilar wires: Syn. of Thesis for Cand. of Techn. Sci. Degree. Kiev.

5. Poletaev, V.A., Tretyakova, N.V. Karamov, I.A. (2007) Examination of metallized electric pump parts for wear resistance. Vestnik IGEU, 3, 1-4.

6. Baldaev, L.Kh. et al. (2007) Efficiency of application of modern thermal spraying methods for corrosion and wear protection of chemical industrial equipment. Khimicheskaya Tekhnika, 11, 32-33.

7. Janpin, K., Jiansirisomboon, S. (2011) Characterization and microstructure of thermal sprayed stainless steel/magnesium oxide nanocomposite coatings. J. of the Microscopy Society of Thailand, 4(1), 56-59.

8. Dallaire, S., Legoux, J.-P., Levert, H. (1995) Abrasion wear resistance of arc-sprayed stainless steel and composite stainless steel coatings. J. Thermal Spray Techn., 4(2), 163-168.

9. Wielage, B. et al. (2013) Iron-based coatings arc-sprayed with cored wires for applications at elevated temperatures. Surface and Coating Technology, 220, 27-35.

10. Khoma, M.S., Sisin, G.M. (2010) Influence of corrosion in environment with different $\mathrm{pH}$ on local electrode potentials of steels. Fiz.-Khim. Mekhanika Materialiv, 3, 92-97.

11. Stupnytskyi, T.R. et al. (2016) Optimization of the chromium content of powder wires of $\mathrm{Fe}-\mathrm{Cr}-\mathrm{C}$ and $\mathrm{Fe}-\mathrm{Cr}-\mathrm{B}$ systems according to the corrosion resistance of electric-arc coating. Materials Sci., 52(2), 165-172.

12. (1981) Refer. book on chemistry. Ed. by A.M. Sukhotin. Leningrad: Khimiya. 


\title{
LASER WELDING OF THIN-WALL FILTER ELEMENTS OF STEEL 08Kh18N10T*
}

\author{
V.D. SHELYAGIN, V.Yu. KHASKIN, A.V. BERNATSKY and A.V. SIORA \\ E.O. Paton Electric Welding Institute, NASU \\ 11 Kazimir Malevich Str., 03680, Kiev, Ukraine. E-mail: office@paton.kiev.ua
}

\begin{abstract}
The work is dedicated to increase of safety and service life of apparatuses of chemical production due to replacement of brazing process to welding in manufacture of the filter elements. Three methods of welding (argon arc, electron beam and laser) were compared applicable to joining of thin-wall tubular cone billets for the filter elements of stainless steel 08Kh18N10T steel. Defects, typical for indicated methods of welding, were investigated and procedures for their elimination were proposed. It is determined that laser welding has the largest productivity in combination with high weld formation stability that makes its application reasonable as industrial technological process in manufacture of thin-wall cone filter elements. 9 Ref., 5 Figures.
\end{abstract}

Ke y w ord s: stainless steel, thin-wall products, laser welding, productivity, edges, technological fixture, mechanical properties, corrosion resistance

Brazing is often used for joining thin-wall billets and requires application of expensive brazing filler materials [1] for producing critical joints at manufacture of corrosion-resistant metal structures in chemical, nuclear and other branches of industry. Replacement of brazing to welding allows reducing manufacturing cost of such joints as well as increasing their mechanical characteristics.

One of the peculiarities of welding of pipe fittings and filter elements of thin austenite stainless steel is a necessity of producing quality defect-free joints, which do not require further finish treatment. Also it is desirable to eliminate the welded product straightening. Obtained welded joints should to the maximum be close with the base metal on mechanical properties and corrosion resistance [2]. Another peculiarity of filter element welding can be necessity in consideration of looseness of abutting edges, caused by presence in them of the holes for end product filtering. All this requires thorough selection of welding method and technological mode. As a rule, indicated tasks are fulfilled with argon arc welding, more seldom laser or electron beam welding [3].

Aim of the present paper is rise of safety and service life of the filter elements of austenite stainless steel 08Kh18N10T by means of replacement of brazing process to welding one at their manufacture. For this a comparative analysis of three welding methods (argon arc, electron beam and laser) was carried out applicable to joining thin-wall tubular cone billets for filter elements; selection of a method providing high weld quality and the highest productivity; development of corresponding welding procedure; complex for testing the welded parts to validate adequacy of developed technology for further industrial implementation.

Cone tubular billets of filter elements of steel $08 \mathrm{Kh} 18 \mathrm{~N} 10 \mathrm{~T}$ [4] of $\delta=0.5$ and $0.6 \mathrm{~mm}$ thickness (Figure 1) were used as welded specimens in performance of experiments on argon arc, electron beam and laser welding. Modes and equipment were selected taking into account recommendations of works [5-7].

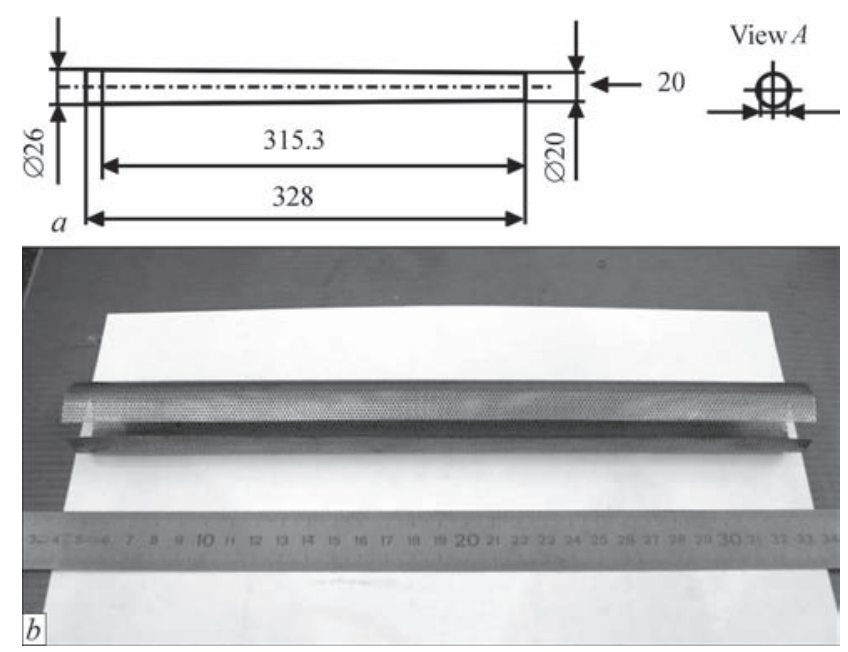

Figure 1. Sketch of tubular cone filter element of steel $08 \mathrm{Kh} 18 \mathrm{~N} 10 \mathrm{~T}(\delta=0.5$ and $0.6 \mathrm{~mm})(a)$ and view $(b)$ of billet being welded for its production

${ }^{*}$ The work is carried out in scope of NASU Program «Problems of Life and Safe Operation of Structures, Constructions and Machines» in 2013-2015. 
Argon arc welding. Filler wire Sv-08Kh18N10T (1.0 mm diameter) was used for producing sound welds taking into account presence of gaps between the edges being welded. Welding was carried out employing equipment of «Kemppi» Company (Finland), namely power supply «MasterTig MLS 3000» (welding current 5-300 A) and torch «TTC-250WS» (designed for up to 250 A current), and also automatic device was used for filler wire feed. The torch was moved relatively to part with the help of one-coordinate manipulator.

The results of carried investigations showed that a copper substrate with forming cavity should be used for formation of lower reinforcement bead and elimination of welded edges raising in argon arc welding of edges of mesh filter elements. Besides, it is necessary to increase heat sink by application copper pressure plates, which should press welded edges along the whole length at a distance not more that $3 \mathrm{~mm}$ on either side of the joint. Lack of penetration and burning through are the typical defects of argon arc welding of mesh filter elements. For their elimination welding should be carried out on the following modes, i.e. welding current $I=15 \mathrm{~A}$, arc voltage $U=20 \mathrm{~V}$; welding rate $v_{\mathrm{w}}=15 \mathrm{~m} / \mathrm{h}$, wire feed rate $v_{\text {wire }}=35 \mathrm{~m} / \mathrm{h}$, shielding gas consumption (argon) 10-15 1/h. Sound welds were formed as a result. A zone of mode stability in quality argon arc welding is sufficiently narrow, i.e. indicated mode parameters should be kept with high stability and accuracy.

Electron beam welding. The following equipment were used for experiment performance, namely vacuum chamber with one-coordinate manipulator for movement of an electron beam gun, vacuum aggregate for chamber pumping up to $133.3 \cdot 10^{-5} \mathrm{~Pa}$, power source V-250A and electron beam gun UL-119. Sound welds were received only under conditions of presence of solid firmly pressed edges. For this purpose the billets of mesh filter elements were made with previously performed solid edges, having a distance not less than $1 \mathrm{~mm}$ till the filter holes. It was determined in course of the investigation that the best welds are formed in welding with the following mode, namely beam current $I=10 \mathrm{~mA}$, voltage $U=21 \mathrm{kV}$, welding rate $v_{\mathrm{w}}=10-12 \mathrm{~m} / \mathrm{h}$, beam defocusing in a spot of around $1.5 \mathrm{~mm}$ diameter.

Laser welding. This process allows the gaps between the welded edges in the case of its performance by filler powder material feeding [8]. Granular powders of steel $08 \mathrm{Kh} 18 \mathrm{~N} 10 \mathrm{~T}$ or self-fluxing nickel alloys PG-10N-04 or PG-NCh3 [8] having granules up to $150 \mu \mathrm{m}$ diameter [9] were used as such. Welding was carried out on a copper substrate without forming cavities. Nd:YAG laser of DY044 model of up to $4.4 \mathrm{~kW}$ radiation power from «Rofin-Sinar» Company (Germany), one-coordinate manipulator, welding head and filler powder dosing unit were used in the experiments.

It was determined during the experiments that laser welding also can provoke appearance of lack of penetration and burning through. Selection of modes of filler powder feed in combination with specific values of power and rate allowed obtaining defect-free welded joints (Figure 2). The following area of technological process stability were determined at that, namely radiation power $P=0.5-0.6 \mathrm{~kW}$, welding rate $v_{\mathrm{w}}=140-160 \mathrm{~m} / \mathrm{h}$; defocusing value $\Delta F=-15-$ $-20 \mathrm{~mm}$; filler powder consumption $G_{\mathrm{p}}=0.2-0.3 \mathrm{~g} / \mathrm{s}$. Such sufficiently wide spread of mode parameters indicates significant stability of laser welding and allows predicting low percent of reject at process industrial application.

It is determined that productivity of argon arc welding of cone specimens of filter elements of 08Kh18N10T steel makes up to 20 filter elements per working shift ( 8 hours), when laser welding productivity is up to 40 filter elements per working shift. At that, in the first case percent of reject makes up to $20 \%$ and in the second case it is more than $2.5 \%$.

Comparison of considered three variants of welding of cone specimens of filter elements of steel $08 \mathrm{Kh} 18 \mathrm{~N} 10 \mathrm{~T}(\delta=0.5$ and $0.6 \mathrm{~mm})$ shows that laser welding has the highest productivity (10-15 times higher welding rate in comparison with competitive methods) in combination with high stability of weld formation. This is the method, which is reasonable
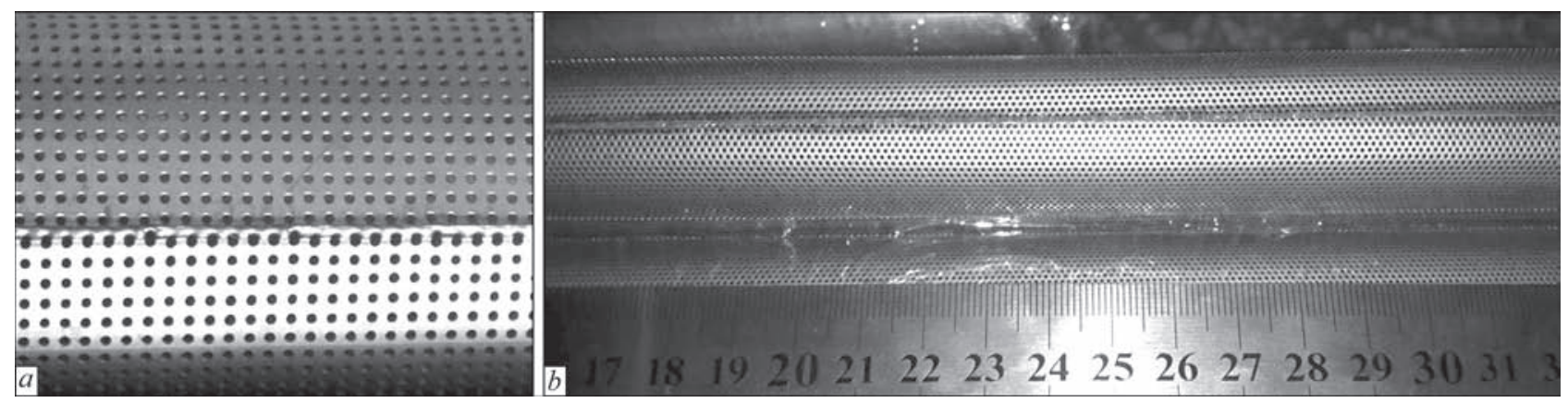

Figure 2. View of welded joint $(a)$ and specimen $(b)$ of filter element of stainless steel $08 \mathrm{Kh} 18 \mathrm{~N} 10 \mathrm{~T}(\delta=0.5 \mathrm{~mm})$, produced by laser welding with powder filler PG-10N-04 
for further development of industrial technology with next implementation.

Further development of the industrial technology of laser welding of cone filter elements for chemical industry was carried out on pilot specimens, which were produced in four steps:

- manufacture of perforated sheet of stainless steel $08 \mathrm{Kh} 18 \mathrm{~N} 10 \mathrm{~T}$ of $2000 \times 1000 \times \delta \mathrm{mm}(\delta=0.5-0.6 \mathrm{~mm})$ with filter holes of $0.8-1.0 \mathrm{~mm}$ diameter and step close to their diameter, using mechanical punching method or spark erosion;

- guillotine flat blanking of filter elements from perforated sheets of $2000 \times 1000 \times \delta \mathrm{mm}$;

- rolling of flat billets of filter elements for obtaining cone tubes of $\varnothing 26 \times \varnothing 20 \times 328 \mathrm{~mm}$;

- laser welding of edges of rolled billets for obtaining straight seam cone tubes with filter holes.

In flat blanking of the filter elements the filter holes are cut up from a perforated sheet. There is a problem of such edges tight mating without gap for further welding. The reference [6] indicates that a gap between the edges in laser welding should not exceed $10 \%$ of their thickness. Process scheme, shown in Figure 3, was used for this problem solving according to work [7] recommendations. Following the scheme the welded edges 1 are brought together with a gap close on size to their thickness, and tightly pressed to copper technological substrate 6 . During welding the gap is filled with filler powder material 2 and is melted using defocused laser radiation 4 . The next technological fixture was designed and manufactured for realization of proposed scheme: screw clamp for fixing cone tubular specimens; copper substrate inserted in the specimen; welding head with focusing system and dosing unit for feeding of filler materials in form of powder of 20-150 $\mu \mathrm{m}$ fraction. Prototype of developed at the PWI welding bench was used for welding of separate specimens for performance of mechanical and corrosion tests as well as pilot-commercial batch of filter elements for performance of service tests.

A range of specimens was welded using the selected technological modes with alternating and pulse laser radiation for determination of mechanical properties of produced joints. Static tension samples, type XXIV (three samples for each value) were cut out from produced specimens on GOST 6996-66. The tests were carried out using tensile testing machine MTS 318.25 at $20-25{ }^{\circ} \mathrm{C}$ temperature and loading rate $4 \mathrm{~mm} / \mathrm{min}$. Received results were used for determination of the average values of ultimate strength $\sigma_{t}$ (MPa) for application of continuous laser radiation as well as pulse radiation of low $(12 \mathrm{~Hz})$ and comparatively high $(200 \mathrm{~Hz})$ frequency. Welding heat inputs in all cases were the same. Figure 4 shows a diagram

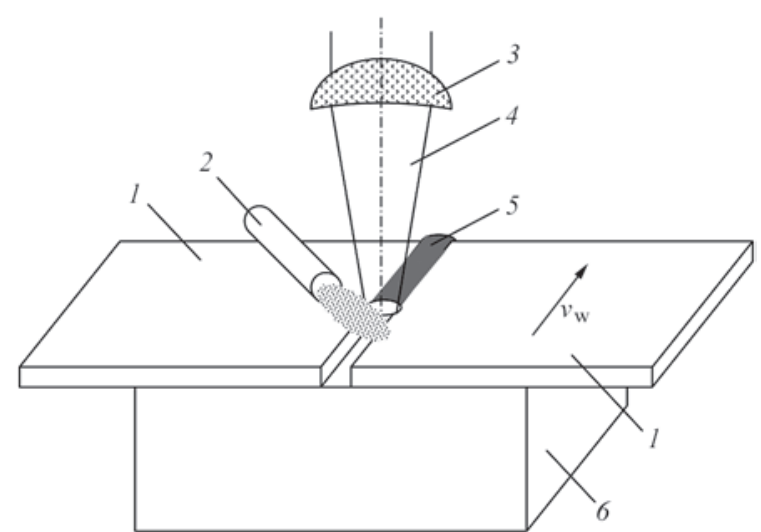

Figure 3. Technological scheme of laser welding process of edges of pilot specimens of cone filter elements with loose edges: 1 - welded edges; 2 - feeding of filler powder; 3 - focusing lens; 4 - laser radiation; 5 - weld; 6 - substrate (arrow shows direction of welded specimen movement)

with test results. As can be seen from the Figure, laser welding of loose edges with powder filler material in the case of application of continuous as well as pulse with low frequency radiation provides $90 \%$ level strength of the base metal. It can be explained by usage of defocused radiation, effect of which on weld grain refinement, and, respectively, rise of joint strength, is not so obvious as effect of focused one. Nevertheless, obtained index is acceptable for the problem being solved.

Determination of corrosion resistance of butt joints of steel $08 \mathrm{Kh} 18 \mathrm{~N} 10 \mathrm{~T}(\delta=0.5$ and $0.6 \mathrm{~mm})$ was carried out on a weight procedure. According to this procedure the templates close on width to weld width with HAZ were cut out from the welded specimens. The templates length made $5-10 \mathrm{~mm}$. Also, the templates of similar size were cut out from base metal (so called reference specimens). Prepared templates were weighed on analytical balance with up to $0.001 \mathrm{~g}$ accuracy after what they were immersed in a mixture of $\mathrm{HNO}_{3}+\mathrm{HCl}$ acids with 1:2 relationship. Within a given period (as a rule in 1-2 h) the specimens were taken out, thoroughly rinsed, dried and weighed one more time. Corrosion resistance was determined on a weight loss difference between the reference specimen of base metal and welded specimen.

Three specimens were done in each case and obtained data were averaged. Welding was carried out using continuous as well as pulse (with 12 and $200 \mathrm{~Hz}$ ) frequency radiation with filler powder of steel 08Kh18N10T and granulation $20-150 \mu \mathrm{m}$. The results were used for plotting the diagrams, shown in Figure 5. As can be seen from these diagrams, in all cases corrosion resistance of welded joints is satisfactory and makes from 90 to $98 \%$ of base metal resistance. Presence or absence of radiation pulse modulation makes small effect on corrosion resistance variation.

A pilot-commercial batch $(250 \mathrm{pcs})$ of cone filter elements was welded using developed commercial 


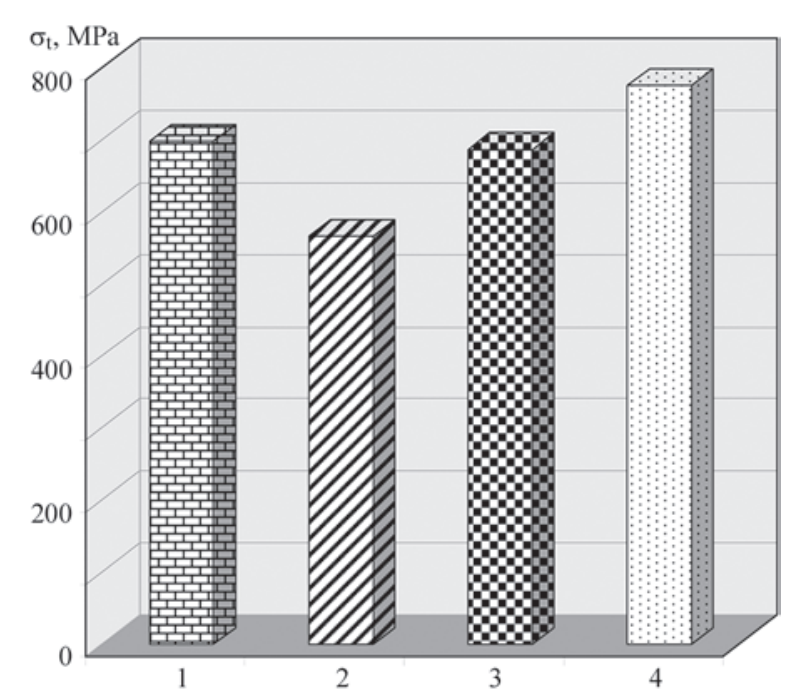

Figure 4. Comparison of strength of $08 \mathrm{Kh} 18 \mathrm{~N} 10 \mathrm{~T}$ steel welded joints $(\delta=0.5 \mathrm{~mm})$, produced by laser welding with filler powder of the same material and base metal strength: 1 - continuous radiation; 2 - pulse radiation $f=200 \mathrm{~Hz} ; 3$ - pulse radiation $f=$ $=12 \mathrm{~Hz} ; 4-$ base metal

technology of laser welding of thin-wall products with loose edges. The batch was delivered to relevant enterprise («Chernovitsky Khimzavod» ALC, Chernovtsy) for performance of service tests. The following was determined as a result of these investigations, namely there were no rejected products in the batch; all products correspond to structural dimensions and technical requirements; all products maintained service loads; based on data on life prediction the investigated batch of products is within the norms.

Carried work allows making the following conclusions:

- industrial technology was developed for laser welding of butt joints of perforated edges in tubular cone filter elements for chemical industry. It rises structure safety (in comparison with brazing), eliminates danger of embrittling structures in welds and HAZ, allows escaping application of expensive brazing filler materials, minimizes geometry dimensions of welded joints as well as approximates corrosion resistance and mechanical characteristics of produced welds to the base metal level;

- comparison was carried out for argon arc, electron beam and laser welding of billets of filter elements of austenite stainless steel $08 \mathrm{Kh} 18 \mathrm{~N} 10 \mathrm{~T}$. Typical defects for all considered methods of welding (burning through and lack of penetrations) and methods of their elimination were determined. Laser welding differs by the highest productivity (10-15 times higher welding rate) in combination with high stability of weld formation. This makes its reasonable for application as industrial technological process;

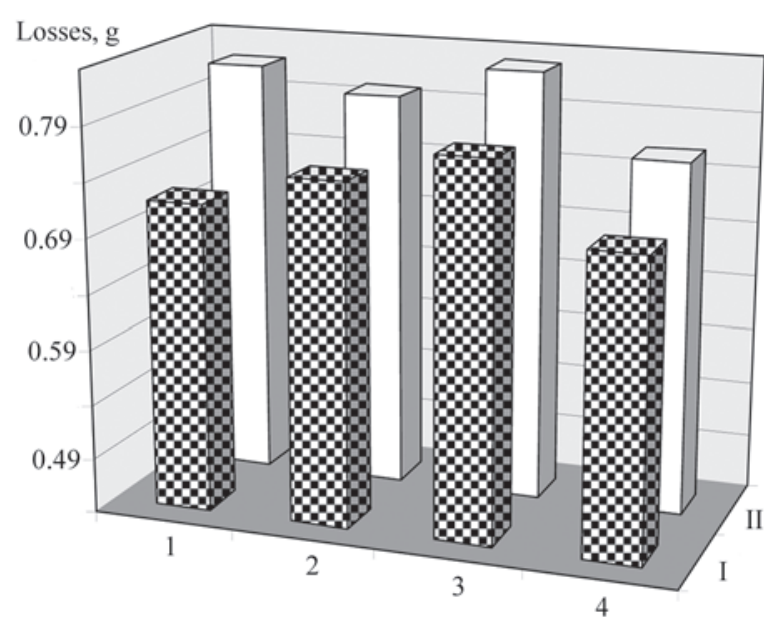

Figure 5. Values of mass loss by specimens of $08 \mathrm{Kh} 18 \mathrm{~N} 10 \mathrm{~T}$ steel welded joints at their etching in mixture of $\mathrm{HNO}_{3}+\mathrm{HCl}$ acids (description 1-4 the same as in Figure 4); I $-\delta=0.6 \mathrm{~mm}$; II -0.5

- experiments on laser welding with powder filler materials were carried out using developed technological fixture. They determined a range of optimum, from point of view of weld formation, process modes, i.e. radiation power Nd:YAG laser $0.5-0.6 \mathrm{~kW}$; welding rate $140-160 \mathrm{~m} / \mathrm{h}$; focus deepening $15-20 \mathrm{~mm}$; consumption of filler powder $0.2-0.3 \mathrm{~g} / \mathrm{s}$. In this range of modes formation of defect-free welds is stable that provides insignificant percent of rejection in industrial process application.

laser welding of loose edges using powder filler material as in the case of application of continuous and pulse radiation provide $90 \%$ strength of the base metal strength and corrosion resistance of welded joints from 90 to $98 \%$ of the base metal relative strength. Such indices are acceptable for problem being solved.

1. Lashko, N.F., Lashko, S.V. (1977) Brazing of metals. Moscow: Mashinostroenie.

2. Quintino, L. et al. (2006) MIG brazing of galvanized thin sheet joints for automotive industry. Materials and Manufacturing Processes, 21, 63-73.

3. (1974) Technology of fusion electric arc welding of metals and alloys. Ed. by B.E. Paton. Moscow: Mashinostroenie.

4. (2003) Steel and alloy grade guide. Ed. by A.S. Zubchenko. Moscow: Mashinostroenie.

5. Korchagin, P.V. (2006) Argon arc welding of 18-8 type steel parts with big difference of thicknesses: Syn. of Thesis for Cand. of Techn. Sci. Degree. Tolyatti.

6. Nazarenko, O.K. et al. (1987) Electron beam welding. Ed. by B.E. Paton. Kiev: Naukova Dumka.

7. Grigoryants, A.G., Shiganov, I.N., Misyurov, A.I. (2008) Technological processes of laser treatment. Moscow: MGTU.

8. Khaskin, V.Yu., Bernatsky, A.V. (2008) Welding of thin-wall steel products with loose edges made by laser surfacing. Svarshchik, 62(4), 14-15.

9. Borisov, Yu.S. et al. (1987) Thermal coatings from powder materials. Kiev: Naukova Dumka. 